ISSN 2414-987X
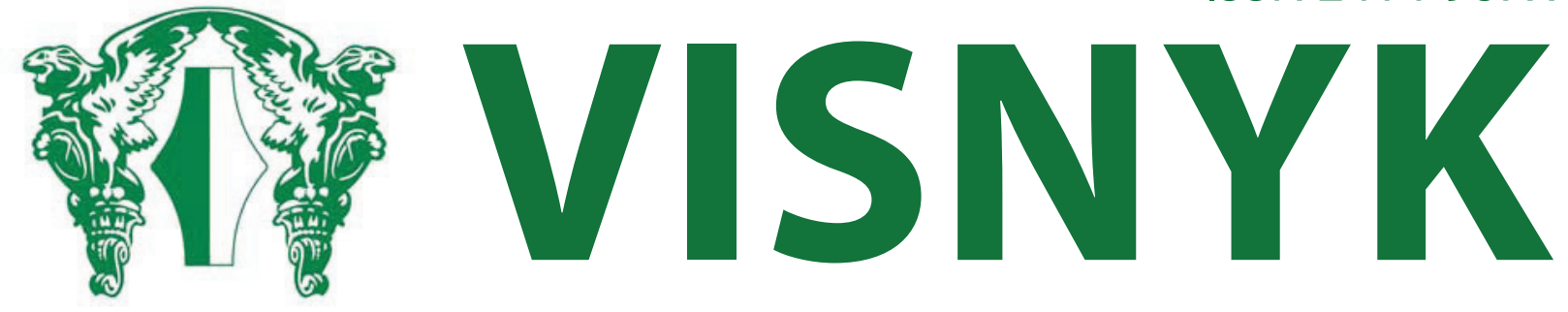

OF THE NATIONAL BANK OF UKRAINE

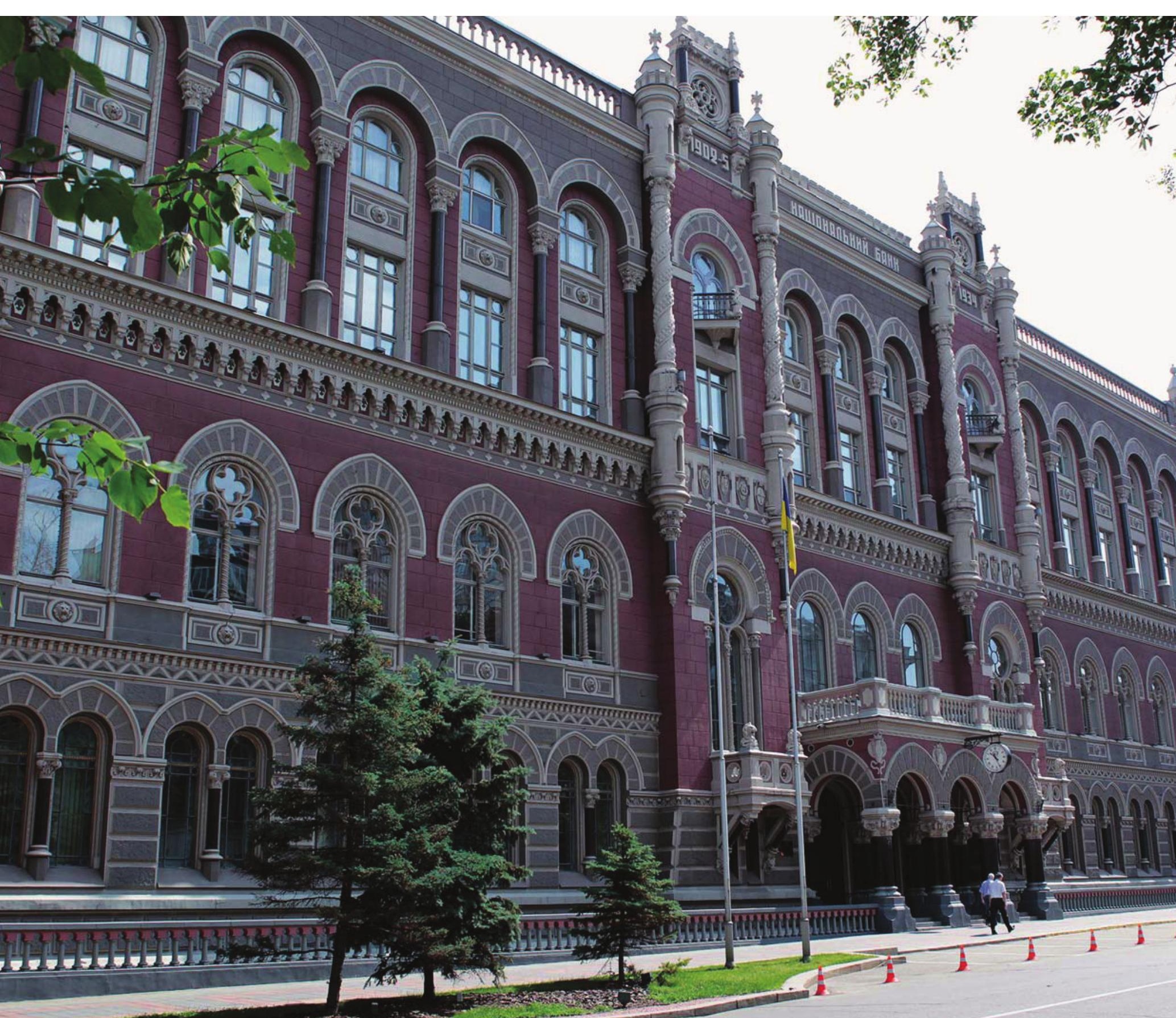

QUARTERLY RESEARCH

JOURNAL OF THE NATIONAL BANK OF UKRAINE

№ 233 September 2015 
Quarterly research Journal

of the National Bank of Ukraine

Published since March 1995

\section{Editorial Board}

\section{Dmytro Sologub}

Chairman of the Editorial

Board,

Deputy Governor,

the National Bank of Ukraine

\section{Vladyslav Rashkovan}

Deputy Governor, the National

Bank of Ukraine

\section{Vitaliy Vavryshchuk}

Director of Financial Stability

Department, the National Bank of Ukraine

\section{Yuriy Gorodnichenko}

Associate Professor, University of

California, Berkeley, PhD

\section{Oleksandr Petryk}

Alternative Executive Director, the

International Monetary Fund, PhD

\section{Sergiy Nikolaychuk}

Deputy Chairman,

Director of Monetary Policy

and Economic

Analysis Department, the National Bank

of Ukraine, $\mathrm{PhD}$

\section{Oleksiy Kryvtsov}

Director in the International Economic Analysis Department, Bank of Canada, PhD

\section{Tom Coupe}

Associate Professor, Senior

Economist, the Kyiv School of Economics, PhD

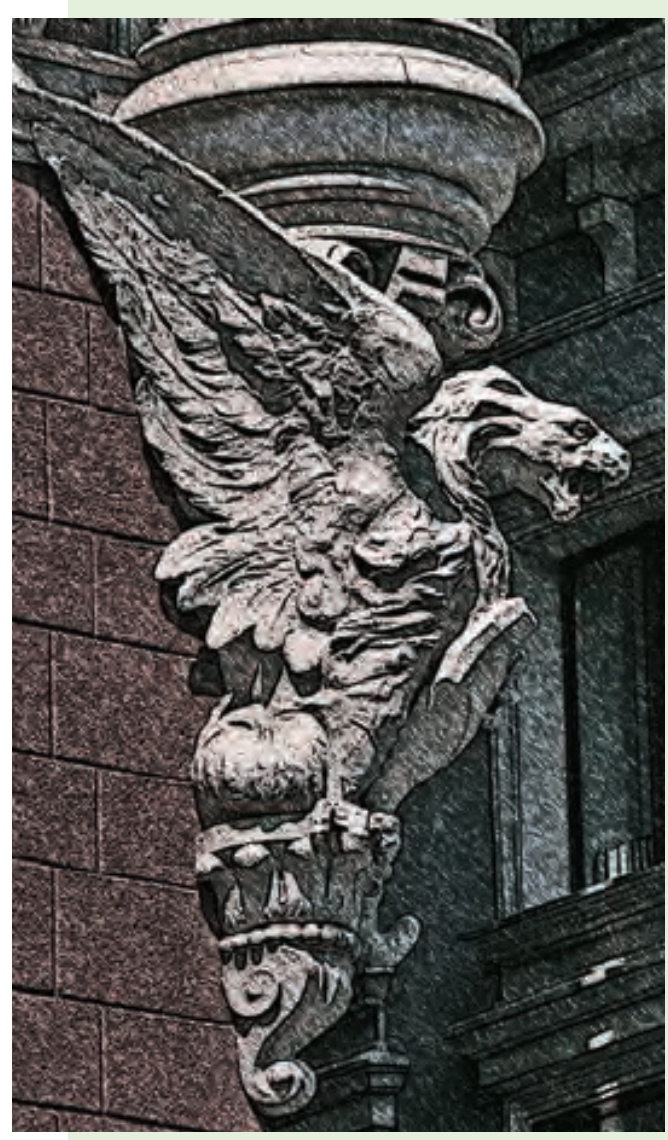

Founder and publisher:

National Bank of Ukraine

Editorial board ensures compliance with ethical standards of publishing

For reprinting materials

published herein the reference to the journal "Visnyk of the National Bank of Ukraine" is compulsory

The Editorial Board can publish materials being under discussion, not sharing the author's opinion

(c) National Bank of Ukraine 1995-2015

All rights reserved

https://doi.org/10.26531/vnbu2015.233

The author bears responsibility for the accuracy of the materials

Address: 9 Instytutska Street, Kyiv, 01601, Ukraine E-mail: journal@bank.gov.ua

Design and layout:

PJSC "INFOCON" Agency.

Address: 46 Khreschatyk st., Kyiv, 01001, Ukraine.

Tel.: +380 (44) 288-33-57.

www.infocon.ua 


\section{PREFACE OF THE CHAIRMAN OF THE EDITORIAL BOARD}

\section{Dear readers!}

The National Bank of Ukraine has started a long way of transformation to enhance and promote its institutional capabilities. This new trend affects all the Bank functions - the research is not the one for the exception. Taking most of the best practices, we have generated the new Vision for our research journal - the Visnyk of the National Bank of Ukraine. Here are the first results you can read.

We suppose the Journal in its new and updated format will be broadly available for all interested parties and would serve as a brainstorming and regular idea-mapping instrument on issues that correspond to the activities of the NBU.

We are open to sharing ideas and invite all professionals on banking and financial markets who set themselves ambitious goals to involve and collaborate.

In the search for effective cooperation, we promote such mutual values as the exceptional professionalism, trust, responsibility, pragmatism, and result-driven experience.

The agenda of the current issue of the Visnyk of the National Bank of Ukraine you are reading focuses on the issues of monetary policy development and implementation in the context of declared transition to inflation targeting. The presented papers broadly discuss the different aspects of this monetary policy regime.

Thus, the journal begins with the article Inflation Expectations in Ukraine: A Long Path to Anchoring? by Olivier Coibion and Yuriy Gorodnichenko. The authors investigate the factors of inflation expectations for different economic agents in Ukraine and compare with the other countries which mainly follow the inflation targeting regime. They conclude that the exchange rate is the primary signal for firms and households about the future price movements in the economy. On the way to inflation targeting the policy makers should pay a substantial attention to the foreign exchange market fluctuations to minimize the volatility in inflation expectations. 
In the following article, A Strategic Document on Monetary Policy for the Period of the Inflation Targeting Adoption in Ukraine, Volodymyr Lepushynskyi explains the strategic issues of successful implementation of the new regime - inflation targeting. Searching the international best practices in the inflation targeting the author argues the optimal format for the strategic document on the monetary policy for Ukraine that explains the targets setting, instruments selection, general decisionmaking, foreign exchange rate declaration, and communication on monetary policy decisions. Most of the preliminary findings presented in the article were put in the core of the Draft Monetary Policy Guidelines for 2016-2020 approved by the NBU Board in August.

Next David Vavra in his article Inflation Targeting Experience: Lessons for Ukraine aggregates the international practices in implementation and use of inflation targeting. The author investigates the last experience over past three decades and finds out that most central banks despite all the challenges and regardless their poor preparedness adopted inflation targeting regime soundly and, in general, achieved their goals. The author concludes that the success of the new monetary regime adoption and its credibility depends crucially on the speed of the regime elements' implementation and development.

The primary element of the inflation targeting regime infrastructure is the effective suite of the macroeconomic models used by the central bank for forecasting and monetary policy analysis. This is the core issue of the next article Using Macroeconomic Models for Monetary Policy in Ukraine, prepared by Sergiy Nikolaychuk and Yurii Sholomytskyi. The authors investigate the existing macroeconomic models used by the NBU and confirm their compliance with forgoing needs of the new monetary policy regime of inflation targeting. At the same time, basing on the international experience aggregation the authors claim the importance to work further on modeling toolkit enhancement, i.e. through development and implementation of dynamic stochastic general equilibrium model and strengthening the suite of econometric models for short-term forecasting.

We hope the new format of our Journal along with presented papers will facilitate our mutual scientific research, encourage discussions and stimulate new ideas. So once again, welcome everyone to collaborate and promote high quality and original research papers. 


\section{CONTENTS}

Olivier Coibion, Yuriy Gorodnichenko

Inflation Expectations in Ukraine: A Long Path to Anchoring?

Volodymyr Lepushynskyi

A Strategic Document on Monetary Policy for the Period

of the Inflation Targeting Adoption in Ukraine

\section{David Vavra}

Inflation Targeting Experience: Lessons for Ukraine

39

Sergiy Nikolaychuk, Yurii Sholomytskyi

Using Macroeconomic Models

for Monetary Policy in Ukraine 


\title{
INFLATION EXPECTATIONS IN UKRAINE: A LONG PATH TO ANCHORING?
}

\author{
Olivier Coibion \\ UT Austin and NBER
}

\author{
Yuriy Gorodnichenko \\ UC Berkeley and NBER
}

\begin{abstract}
We study survey data of inflation and exchange rate expectations in Ukraine. These data are available for households, firms and professional forecasters. We document some unique properties of these data as well as some limitations and discuss the longer run prospects for inflation expectations in Ukraine given the National Bank of Ukraine's desire to adopt an inflation target in the future.
\end{abstract}

JEL Codes: E3, E4, E5

Keywords: Expectations, Anchoring, Inflation Targeting

Gorodnichenko thanks NSF for financial support. We are grateful to the staff of the National Bank of Ukraine for sharing survey data. We also thank anonymous reviewers for the their comments on an earlier version of the paper.

\section{Introduction}

In April 2015, the head of the National Bank of Ukraine announced that the Ukrainian central bank would in the future adopt an inflation targeting regime, aiming to stabilize the inflation rate around 5\%. Inflation targeting regimes have long been viewed as being a successful way of stabilizing inflation, ever since New Zealand successfully brought down its inflation rate after adopting such a regime in 1990. By identifying a clear and visible target for the central bank, inflation targeting can help a central bank build credibility and anchor inflation expectations, thereby ultimately stabilizing both inflation and economic activity (Walsh 2011). How smoothly should we expect this process to go? How anchored are expectations likely to get? These are the questions that we consider in this paper.

Unlike most central banks, the National Bank of Ukraine has access to survey data on the inflation and exchange rate expectations of households, firms, and professional forecasters. ${ }^{1}$ This allows us to study, in much more detail than would be the case in almost any other country, the current expectations of different types of Ukrainian agents prior to the adoption of the inflation target. We review the current state of these surveys and discuss some of their limitations, in the hope that they may be addressed before any policy changes are enacted. This would enable policy makers to track expectations in a much more careful way during their planned policy regime change.

For example, the size and coverage of both the household and firm surveys are excellent, much larger in fact than comparable surveys in the U.S. and elsewhere. But the design of the questions about inflation and exchange rate expectations could be improved as they ask respondents to pick from preset list of bins. Since these bins are sometimes too large or evolve too slowly, much unnecessary noise can be introduced into the survey. In addition, the surveys do not ask about expectations of inflation at longer horizons (which are particularly useful when thinking about credibility), perceptions of recent inflation (which are useful when thinking about communication or inattention), or uncertainty around forecasts (which can also help assess credibility, communications strategies and general uncertainty).

\footnotetext{
${ }^{1}$ Most central banks have access to some survey measures of inflation expectations. However, very few banks have measures of inflation expectations for households, firms, and professional forecaster at the same time.
} 
Despite these limitations, the surveys also provide some unique features, such as household expectations of exchange rates or an extended time series of firms' expectations of both inflation and exchange rates. As in other countries, we find that both households and firms disagree much more about inflation than professional forecasters, and as in Mankiw, Reis and Wolfers (2003), this disagreement rises with the level of inflation. A similar result holds for exchange rates. Both household and firm expectations of exchange rates follow the exchange rate closely, as do firms' expectations of inflation, much more so than those of professionals. In these respects, the properties of Ukrainian agents' expectations mirror those found in other countries, even those with a long history of stable inflation such as the U.S. or New Zealand.

However, along several other metrics, Ukrainian expectations differ from what we observe in countries which have already been under inflation targeting regimes for an extended period, and these differences point toward some unique challenges potentially facing Ukrainian policymakers. One such challenge is the geographic/political divide of the country. Whereas expectations differ little by age, gender, education, or income, the one key predictor of individual expectations is region of origin: individuals from the West of Ukraine expect much lower inflation and a stronger hryvna than do individuals from the East and South. One possibility is that this reflects current economic disparities in the two regions, and that expectations will converge over time as political and economic conditions settle. Another possibility, however, is that, individuals in the two regions who receive the same news draw different inferences about the economic implications. This would imply that expectations might remain heterogeneous for a much longer period of time, thereby making policymakers' attempts at stabilization more difficult. Unfortunately, current data does not permit us to distinguish between these two possibilities.

Another unique element of the firm survey is that firms were asked whether they followed the announcements and actions of the National Bank of Ukraine. This allows us to measure the share of firms over time which explicitly tracked the communications of the central bank and compare their expectations to those of other firms. Consistent with what one might expect, the share of firms tracking the actions of the central bank rises sharply in times of crisis (particularly when the value of the hryvnia falls). However, we find no difference between the inflation expectations of firms who track the announcements and actions of the central bank and those who do not, either in terms of the mean of the forecast or in terms of the disagreement across agents. This suggests either that the communications of the central bank were of poor quality and did not lead agents to revise their expectations or that, more likely, there is a significant credibility gap that causes agents to fail their revise their forecasts in light of the information from the central bank. In contrast, Coibion et al. (2015) find that firms in New Zealand which are provided information about the central bank's inflation target revise their inflation forecasts by large amounts, consistent with the Reserve Bank of New Zealand (RBNZ) having a lot of credibility. We interpret this difference as indicating that the National Bank of Ukraine has a long road ahead in building the kind of credibility that the RBNZ now has.

A third unusual dimension of these surveys is that they track agents' expectations of exchange rates, including for households and firms. A surprising result is that, especially for households, there is a strong positive correlation between the evolution over time of their expectations of inflation and exchange rates. While some correlation might be expected from the pass-through of exchange rates into prices, the strength of the correlation is much too high to be explained by this channel. A more likely channel is the use of the exchange rate as a simple proxy by households of broader price movements in the economy, much as households in the U.S. do with gasoline prices (Coibion and Gorodnichenko 2015). Consistent with this conjecture, we find that there is no difference in the inflation or exchange rate expectations of firms which do not trade with other countries and those which do. This suggests that the exchange rate is widely used as this type of signal, otherwise firms which trade extensively would track exchange rates more and would then have different inflation expectations through the pass-through channel. One potential advantage of this signaling role of exchange rates for Ukrainian policy makers is that, unlike gasoline prices, the exchange rate is at least somewhat under their influence, so attempts to stabilize the exchange rate could have an unusually large positive externality through stable inflation expectations.

A broader lesson from the history of official inflation targeting countries like New Zealand and unofficial ones like the U.S., however, is that even after two decades of low and relatively stable inflation, household and firm inflation expectations remain difficult to anchor. In both countries, households display significant disagreement about both short run and long run inflation, and firms in New Zealand display at least as much disagreement as households. Mean forecasts of each have been persistently above actual levels of inflation over the last decade, as have been people's perceptions of inflation. This suggests that the road to anchoring expectations in Ukraine is likely to be a long one as well.

The paper is organized as follows. Section 2 describes the three surveys of expectations available for Ukraine and discusses their strengths and limitations. Section 3 studies the properties of inflation and exchange rate expectations in Ukraine. Section 4 assesses the prospects for anchoring expectations in Ukraine given the experiences in New Zealand, the U.S. and Poland. Section 5 concludes. 


\section{Data}

The National Bank of Ukraine has measures of inflation expectations for several types of agents: consumers (households), firms, and professional forecasters. In this section, we review the sources of this information and discuss the pros and cons of the available surveys.

\section{A. Consumers}

Every month, GfK Ukraine, a consultancy, surveys approximately 1,000 consumers about their demographics, current economic conditions, financial choices, shopping experience, political preferences and other aspects of their lives. The sample is nationally representative but it does not have a panel component.

Since 2000, this survey has had a module devoted to eliciting consumers' expectations of future inflation and the UAH/USD exchange rate, a key measure of the hryvnia's purchasing power for many households in Ukraine. Unfortunately, questions eliciting this information are not consistent over time. Between 2000 and 2014, the question about future inflation was qualitative ${ }^{2}$. Consumers could choose one of the following six options in response to "how will the prices of basic consumer products and services change in the next 1-2 months?": 1) prices will grow faster than now; 2) prices will grow at the same rate as now; 3) prices will grow slower than now; 4) prices will be at the current level; 5) prices will fall; or 6) do not know. In a similar spirit, possible responses to "how do you think the exchange rate of USD to UAH will change in 3 months?" were: 1) USD will get considerably cheaper; 2) USD will get somewhat cheaper; 3) USD/UAH exchange rate will not change; 4) USD will get somewhat more expensive; 5) USD will get considerably more expensive; or 6) do not know. This wording of questions is similar to the wording in surveys implemented in other countries (e.g., Poland). With additional assumptions, one can obtain quantitative predictions from these questions.

For this early part of the data, we construct an index of inflation and exchange rate expectations as follows

$$
\begin{aligned}
& E_{t}^{\text {Index }} \Pi_{t+1}=1 \times 1 \text { (Prices will growth faster) + } \\
& 0 \times 1 \text { (Prices will growth at the same rate as now) + } \\
& \text { (-1)x1 (Prices will grow slower than now) + } \\
& \text { (-2)x1 (Prices will be at the current level) + } \\
& \text { (-3)x1 (Prices will fall), } \\
& E_{t}^{\text {Index }} X_{t+1}=2 \times 1 \text { (USD will get considerably more expensive) + } \\
& 1 \times 1 \text { (USD will get somewhat more expensive) + } \\
& \text { Ox1 (UAH/USD exchange rate will not change) + } \\
& \text { (-1)x1 (USD will get somewhat cheaper) + } \\
& \text { (-2)x1 (USD will get considerably cheaper), }
\end{aligned}
$$

where 1 (statement) is an indicator function equal to one if the statement is true and zero otherwise. The indices are equal to zero if a consumer predicts no change in the rate of inflation or the level of the UAH/USD exchange rate. Positive values of the indices are consistent with inflationary/depreciation expectations. Because the time series of the indices are noisy, we use a 3-month moving average (centered) of the raw series for our analyses.

In July 2014, GfK introduced a new set of questions designed to yield quantitative measures of expected inflation and exchange rate. These questions also changed the horizon from 1-3 months in the previous measures to a one-year ahead horizon, which is comparable to equivalent surveys in other countries. Specifically, consumers are asked to pick from a set of inflation brackets running at five percent increments: inflation over the next twelve months will be a) less than zero ("prices will fall"), b) between 0 and 5 percent, c) between 5 and 10 percent, etc. Until inflation in Ukraine accelerated in 2015, the maximum bracket was

\footnotetext{
${ }^{2}$ For exchange rate expectations, we have access to data starting in 2006.
} 
Table 1. Consumers' expectations of inflation and exchange rate, $2015 Q 2$.

\begin{tabular}{|c|c|c|c|c|c|c|}
\hline & \multicolumn{3}{|c|}{ Inflation expectations } & \multicolumn{3}{|c|}{ Exchange rate expectations } \\
\hline & mean & st.dev. & \# of obs & mean & st.dev. & \# of obs \\
\hline & (1) & $(2)$ & (3) & (4) & (5) & (6) \\
\hline All & 21.1 & 16.3 & 1,972 & 26.3 & 5.2 & 1,758 \\
\hline \multicolumn{7}{|c|}{ Gender } \\
\hline Males & 21.3 & 16.5 & 916 & 26.5 & 5.2 & 844 \\
\hline Females & 21.1 & 16.2 & 1,056 & 26.1 & 5.2 & 914 \\
\hline \multicolumn{7}{|c|}{ Educational attainment } \\
\hline Less than secondary & 23.0 & 15.8 & 208 & 27.0 & 5.4 & 186 \\
\hline Secondary & 20.1 & 16.6 & 683 & 26.2 & 5.2 & 606 \\
\hline Some college & 19.8 & 16.7 & 396 & 25.7 & 5.3 & 359 \\
\hline College or more & 22.8 & 15.9 & 574 & 26.4 & 4.9 & 507 \\
\hline \multicolumn{7}{|c|}{ Type of settlement } \\
\hline Village & 17.3 & 15.5 & 638 & 25.3 & 5.2 & 574 \\
\hline $\begin{array}{l}\text { City, less than } 100 \mathrm{~K} \\
\text { people }\end{array}$ & 20.5 & 16.8 & 550 & 26.3 & 5.1 & 454 \\
\hline City, $101 \mathrm{~K}-500 \mathrm{~K}$ people & 24.2 & 16.6 & 333 & 27.3 & 5.6 & 309 \\
\hline $\begin{array}{l}\text { City, more than } 500 \mathrm{~K} \\
\text { people }\end{array}$ & 24.9 & 15.5 & 451 & 26.7 & 4.6 & 421 \\
\hline \multicolumn{7}{|c|}{ Age } \\
\hline $16-30$ & 19.9 & 16.4 & 542 & 26.2 & 5.1 & 514 \\
\hline $41-45$ & 21.1 & 15.5 & 542 & 26.5 & 5.1 & 487 \\
\hline $45-59$ & 22.4 & 16.6 & 469 & 26.6 & 5.2 & 413 \\
\hline $60+$ & 21.5 & 17.0 & 419 & 25.7 & 5.3 & 344 \\
\hline \multicolumn{7}{|c|}{ Region } \\
\hline Kyiv & 19.4 & 12.6 & 178 & 24.8 & 4.5 & 184 \\
\hline North & 22.1 & 17.6 & 341 & 25.6 & 5.0 & 258 \\
\hline West & 11.9 & 13.0 & 508 & 23.9 & 5.0 & 492 \\
\hline Center & 23.8 & 15.1 & 443 & 27.8 & 5.0 & 405 \\
\hline South & 25.8 & 17.6 & 335 & 28.2 & 4.5 & 289 \\
\hline East & 28.2 & 15.2 & 167 & 27.8 & 4.7 & 130 \\
\hline
\end{tabular}

Notes: The table reports one-year-ahead expectations in the survey of consumer expectations. Kyiv includes only the city of Kyiv. North includes Zhytomyrska, Kyivska, Sumska, Chernigivska oblasts. West includes Volynska, Zakarpatska, Ivano-Frankivska, Lvivska, Rovenska, Ternopilska, Chernovytska oblasts. Center includes Vinnystska, Dnipropetrivska, Kirovogradska, Poltavska, Khmelnytska, Cherkaska oblasts. South includes Zaporizka, Mykolaivska, Odeska, Khersonska oblasts. East includes Kharkivska oblast. 
"inflation will be more than 30\%". In 2015, additional brackets (also with 5 percent increments) were introduced with the maximum bracket being "inflation will be more than 50\%". The question about the expected exchange rate had a similar structure although brackets were more detailed, running in increments of 0.5 UAH in 2014 and early 2015 and increments of $1 \mathrm{UAH}$ after March 2015.

Table 1 provides descriptive statistics for the second quarter of 2015. On average, consumers predicted high inflation (21.1\%) but they also strongly disagreed about the magnitude (standard deviation of $16.3 \%$ ). Likewise, consumers expected a strong dollar (26.3 UAH/USD) and exhibited strong unanimity in this prediction (standard deviation of 5.2 UAH). There is little visible difference across men and women as well as across people with different educational attainment, income or age.

The one striking form of heterogeneity in beliefs is across regions. People living in West Ukraine expected inflation to be only $12 \%$ on average and expected a stronger hryvna than the rest of the population. In contrast, those living in the South and the East expected a much higher rate of inflation than the rest of population ( $26 \%$ and $28 \%$ respectively) and a weaker hryvna. These regional differences in beliefs could stem from the different economic conditions there at the time, due in particular to the political and military turbulence in the South and East. In this case, one might expect these regional differences in beliefs to fade over time when the political situation stabilizes. Less optimistically, these differences could reflect deeper divides which lead individuals to react differently to the same economic news. This form of heterogeneity in beliefs would likely be much more long lived than one based only on current economic conditions. Further, it could pose a real quandary for monetary policy makers, since news which might be interpreted as stabilizing by one group could be interpreted as destabilizing by another. Unfortunately, the available data do not permit us at this stage to differentiate between these hypotheses, but trying to do so should likely be a priority for future work.

\section{B. Firms}

The survey of firms' expectations-conducted by regional offices of the NBU-is quarterly with a sample size of approximately 1,000 firms covering different sectors, sizes, and regions. Survey forms and responses are distributed and collected via phone, email, fax, or mail. Survey forms are filled out by general managers, chief accountants, or chief financial officers. The selection of firms into the survey is based on a stratified random sampling. The sampling frame is based on the registry of businesses as well as more informal sources such as "yellow-pages". The survey has a panel component (we do not have access to micro-level data).

The survey collects one-year expectations for inflation since 2006 and for the exchange rate since 2010. Similar to recent waves of the consumer survey, the questions are structured in such a way that managers of firms can pick a bracket for future inflation (in 5 percent increments) or the exchange rate (in $2 \mathrm{UAH}$ increments for recent waves). Also similar to the survey of consumers, recent surveys of firms augmented the list of brackets to accommodate higher inflation and exchange rate depreciation expectations. For example, the early part of the survey had a top bracket of "inflation will be more than $25 \%$ ", while more recently it has had a top bracket of "inflation will be more than $45 \%$."

Table 2 provides descriptive statistics for the most recent wave of the survey (2015Q2). Relative to consumers, firms expect higher inflation ( $27 \%$ vs. $21 \%$ ) and about the same level of the UAH/USD exchange rate (25.4 UAH/USD vs 26 UAH/USD). ${ }^{3}$ Similar to households, firms strongly disagree in their predictions about future inflation (standard deviation of $10.9 \%$.) and the exchange rate (standard deviation of 3.3 UAH) but the level of disagreement is lower than the level of disagreement for consumers. These expectations are broadly similar across industries, firm sizes, or exposure to international trade. In contrast to results for households, there is no evidence that firms in different regions of the country have different inflation or exchange rate expectations. Interestingly firms that follow the actions of the NBU have similar expectations to firms that do not follow. These patterns suggest that firms pay significant attention to inflation statistics and track the exchange rate closely.

Because this firm survey has a large cross-section, represents the entire distribution of Ukrainian firms, and is quantitative in nature, it represents an unusual source of data for a central bank. For example, no such comparable data exists in the U.S., U.K., Euro-Zone, Canada, or Japan. While these countries have other surveys of firms available, these are generally either qualitative in nature or limited to very large firms. Only Sweden, to the best of our knowledge, has a similarly long-running, quantitative and representative survey of firms' inflation expectations.

\footnotetext{
${ }^{3}$ In part, this difference is observed because of the different timing of the survey. The survey of consumers is pooled across three months of 2015Q2, while the survey of
} firms is conducted in the middle of the quarter. 
Table 2. Firms' expectations of inflation and exchange rate, 2015Q2

\begin{tabular}{|c|c|c|c|c|c|c|}
\hline & \multicolumn{3}{|c|}{ Inflation expectations } & \multicolumn{3}{|c|}{ Exchange rate expectations } \\
\hline & mean & st.dev. & \# of obs & mean & st.dev. & \# of obs \\
\hline & (1) & (2) & (3) & (4) & (5) & (6) \\
\hline All & 27.1 & 10.9 & 841 & 25.4 & 3.3 & 837 \\
\hline \multicolumn{7}{|c|}{ Industry } \\
\hline $\begin{array}{l}\text { Agriculture, forestry, } \\
\text { fishing }\end{array}$ & 25.6 & 10.7 & 112 & 25.4 & 3.2 & 112 \\
\hline Mining & 29.8 & 9.0 & 51 & 25.3 & 2.5 & 51 \\
\hline Manufacturing & 25.4 & 9.9 & 160 & 25.2 & 3.2 & 160 \\
\hline Utilities & 27.5 & 10.1 & 40 & 25.3 & 3.5 & 40 \\
\hline Construction & 28.9 & 11.6 & 36 & 25.3 & 3.6 & 33 \\
\hline Trade & 26.7 & 11.4 & 172 & 25.7 & 3.4 & 169 \\
\hline $\begin{array}{l}\text { Transport and } \\
\text { communication }\end{array}$ & 28.3 & 11.7 & 97 & 25.1 & 3.3 & 97 \\
\hline Other & 28.0 & 11.0 & 173 & 25.5 & 3.6 & 175 \\
\hline \multicolumn{7}{|c|}{ Size } \\
\hline $\begin{array}{l}\text { Small (less than or equal } \\
\text { to } 50 \text { employees) }\end{array}$ & 28.2 & 11.1 & 326 & 25.5 & 3.5 & 321 \\
\hline $\begin{array}{l}\text { Medium (51-250 em- } \\
\text { ployees) }\end{array}$ & 25.9 & 10.5 & 289 & 25.4 & 3.3 & 288 \\
\hline $\begin{array}{l}\text { Large (more than } 250 \\
\text { employees) }\end{array}$ & 27.1 & 10.8 & 226 & 25.2 & 3.1 & 228 \\
\hline \multicolumn{7}{|c|}{ International trade } \\
\hline Export only & 27.0 & 11.4 & 77 & 25.3 & 3.4 & 76 \\
\hline Import only & 26.3 & 11.1 & 68 & 25.2 & 3.0 & 68 \\
\hline Export and import & 26.3 & 10.5 & 206 & 25.6 & 3.4 & 207 \\
\hline No international trade & 27.6 & 10.9 & 490 & 25.3 & 3.4 & 486 \\
\hline $\begin{array}{l}\text { Firms following the } \\
\text { NBU's actions }\end{array}$ & 27.8 & 11.0 & 188 & 25.4 & 3.4 & 188 \\
\hline \multicolumn{7}{|c|}{ Regions } \\
\hline Kyiv & 26.3 & 11.2 & 145 & 25.2 & 3.6 & 144 \\
\hline North & 26.0 & 11.5 & 68 & 25.1 & 3.5 & 67 \\
\hline West & 27.7 & 10.0 & 154 & 25.3 & 2.8 & 154 \\
\hline Center & 26.7 & 10.7 & 265 & 25.3 & 3.2 & 264 \\
\hline South & 26.9 & 10.7 & 133 & 25.5 & 3.4 & 132 \\
\hline East & 27.7 & 10.6 & 64 & 25.8 & 3.5 & 64 \\
\hline
\end{tabular}

Notes: The table reports one-year-ahead expectations in the survey of firms expectations. Kyiv includes the city of Kyiv and Kyivska oblast. North includes Zhytomyrska, Sumska, Chernigivska oblasts. West includes Volynska, Zakarpatska, Ivano-Frankivska, Lvivska, Rovenska, Ternopilska, Chernovytska oblasts. Center includes Vinnystska, Dnipropetrivska, Kirovogradska, Poltavska, Khmelnytska, Cherkaska oblasts. South includes Zaporizka, Mykolaivska, Odeska, Khersonska oblasts. East includes Kharkivska oblast. 


\section{Figure 1. Dynamics of inflation and UAH/USD exchange rate, 2006-2015}

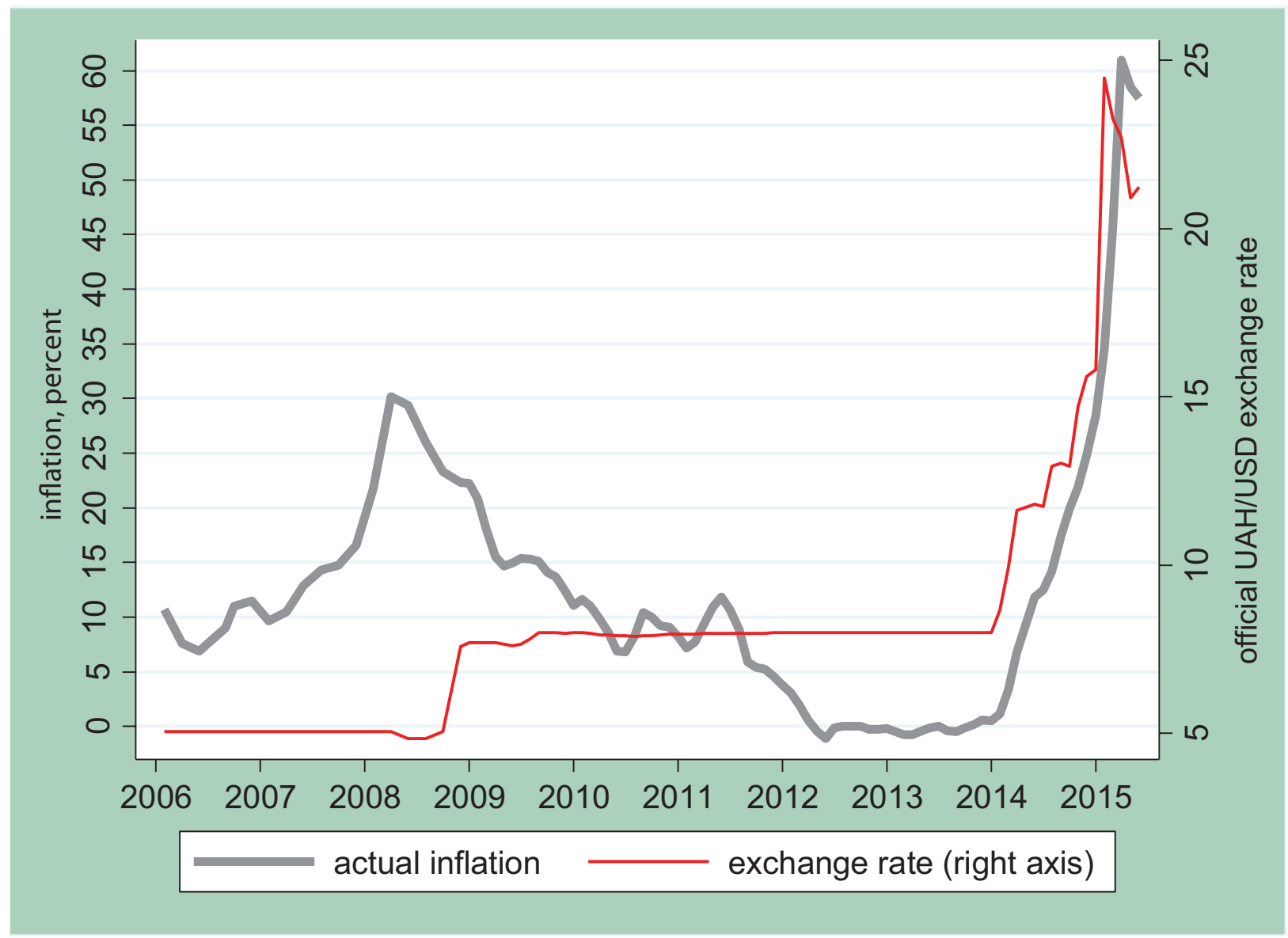

Source: National Bank of Ukraine, State Statistics Service of Ukraine.

\section{Professional forecasters}

In July 2014, the NBU started to survey financial analysts in major financial firms about their expectations of inflation and the exchange rate. The size of the sample is smaller: at most 17 respondents. However, this size is similar to comparable surveys of professional forecasters in other countries. For example, the number of responses in the Survey of Professional Forecasters (SPF) run by the Federal Reserve Bank of Philadelphia varies between 9 and 53 respondents with the mean equal to 34. In contrast to other surveys, the respondents are asked to report numeric forecasts rather than pick a bracket. In addition, the survey collects 3 -year-ahead predictions for inflation and the exchange rate.

\section{International perspective on the surveys}

The surveys in Ukraine have a number of advantages over foreign analogues. First, the surveys have large sample sizes relative to similar surveys in other countries. For example, the Michigan Survey of Consumers (MSC) in the U.S. surveys 500 people in a given month while the GFK survey in Ukraine has approximately 1,000 respondents. Second, the survey of firms collects more information about firms' expectations and demographics than counterparts in other countries. For example, the Livingston survey in the U.S. provides only limited information about the type of forecaster (e.g., non-financial vs. financial firm). Third, recent waves of consumer and firm surveys have quantitative information, while comparable surveys in other countries often can provide only qualitative information. For example, the Conference Board Survey in the U.S. asks firms to report if prices are going to increase, decrease, or stay the same.

However, the design of the surveys could still be improved along several dimensions. First, expectation questions are offered only in brackets. While some brackets are detailed (there are over 20 brackets for the exchange rate question), others are too coarse (brackets for inflation have $5 \%$ increments). As a result, some information is lost relative to the case when respondents can 


\section{Figure 2. Effects of using brackets: raw mean vs. fitted mean}

\section{Panel A: Inflation expectations}
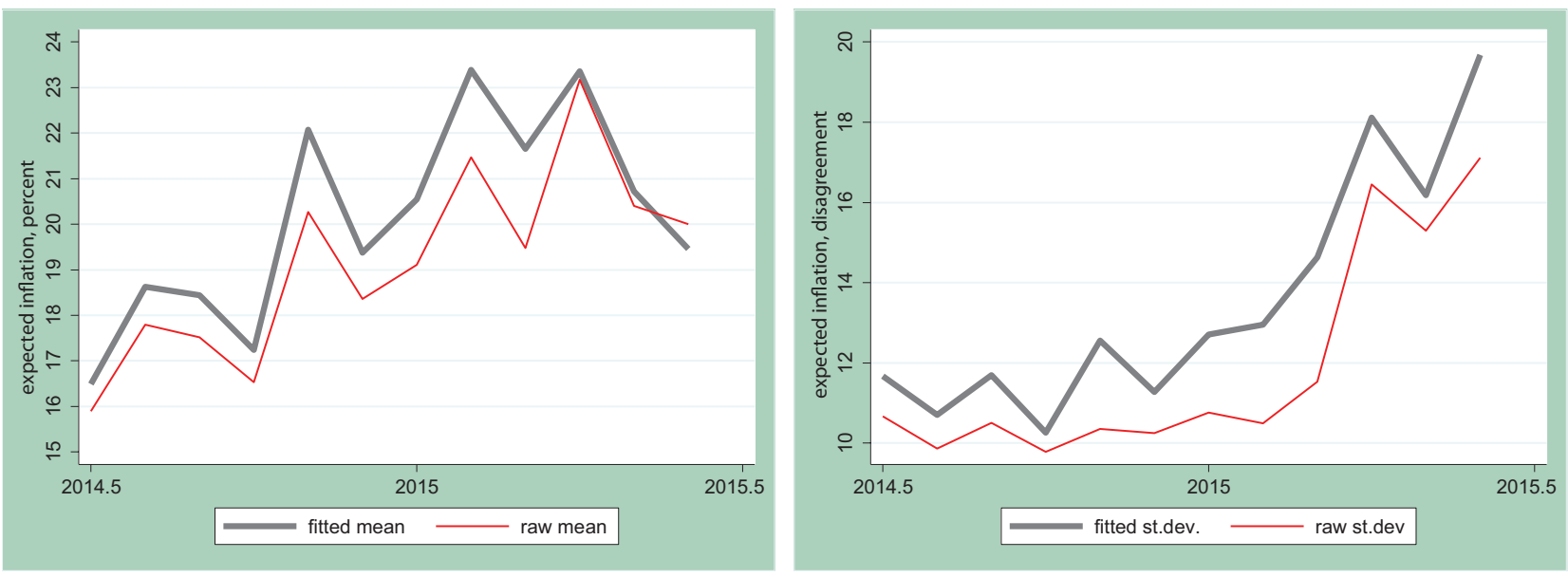

Panel B: Exchange rate expectations
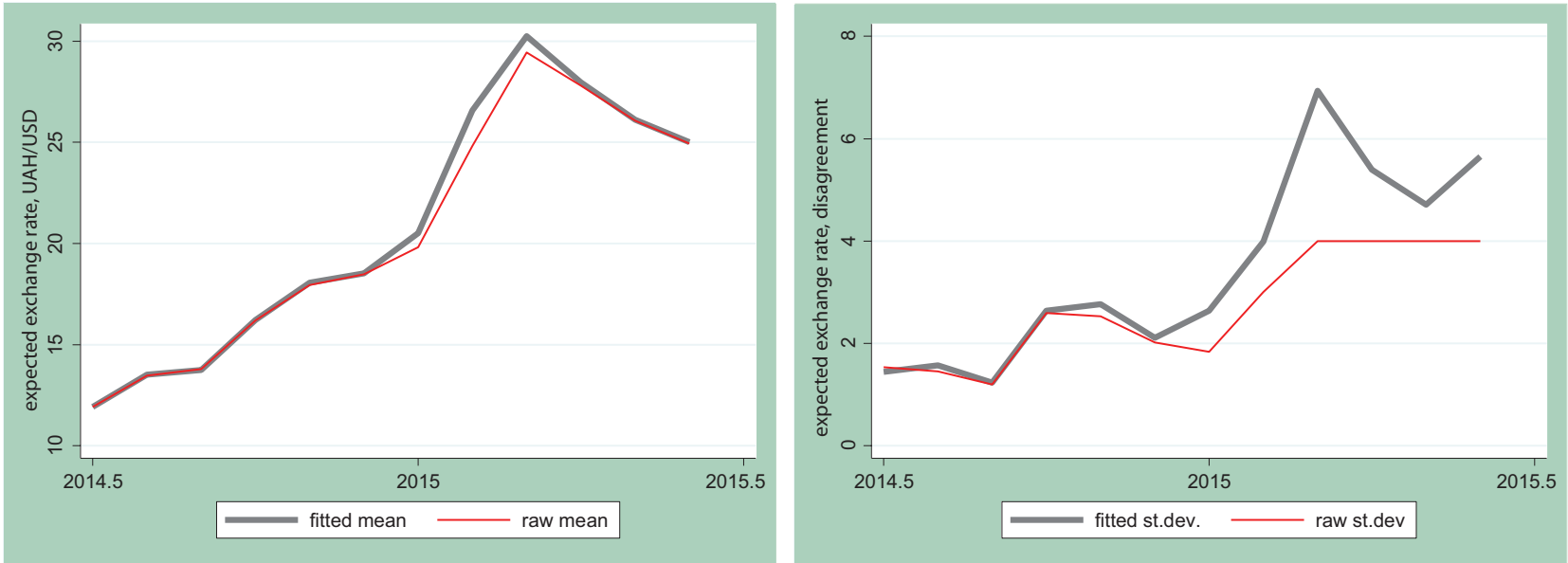

Notes: the raw means are calculated as $\sum_{b=l}^{B} f_{b}$ midpoint $_{b}$ where $B$ is the number of brackets, $f_{b}$ is the share of firms picking bracket $b$, midpoint $_{b}$ is the midpoint of bracket $b$. For top brackets, the midpoints are set to the lowest value of the bracket plus a half of the average increment in other brackets. For bottom brackets, the midpoints are set to the largest values in the bracket value minus a half of the average increment in other brackets. The raw standard deviation is calculated as

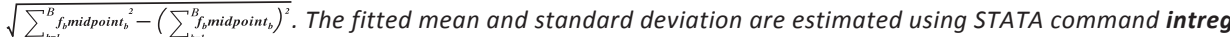
(interval regression) which fits a normal distribution to match across brackets. See Cameron and Trivedi (2010) for more details on intreg and interval regression.

report a numeric value for their expectations. Because the brackets are granular (especially for inflation), the survey may fail to fully capture changes in the distribution of beliefs. In addition, in times of rapidly changing economic conditions, brackets may easily get outdated, yielding lumps in the top/bottom brackets. Finally, changes in the sizes of brackets could make the data not directly comparable over time if the introduction of new brackets changes respondents' perceptions about the possible ranges of outcomes.

Some of these concerns can be addressed by fitting a normal distribution to the distribution across brackets (a type of censored regression, see Cameron and Trivedi, 2010). Figure 2 shows that fitting a censored regression to estimate the mean and standard deviation on the distribution of responses across brackets tends to yield higher inflation expectations and more disagreement about these expectations. At the same time, the difference between the raw and fitted (regressionbased) mean and standard deviation is smaller for the exchange rate because the question on exchange rate expectations 


\section{Figure 3. Inflation and exchange rate expectations of firms and households}

\section{Panel A: Firms}
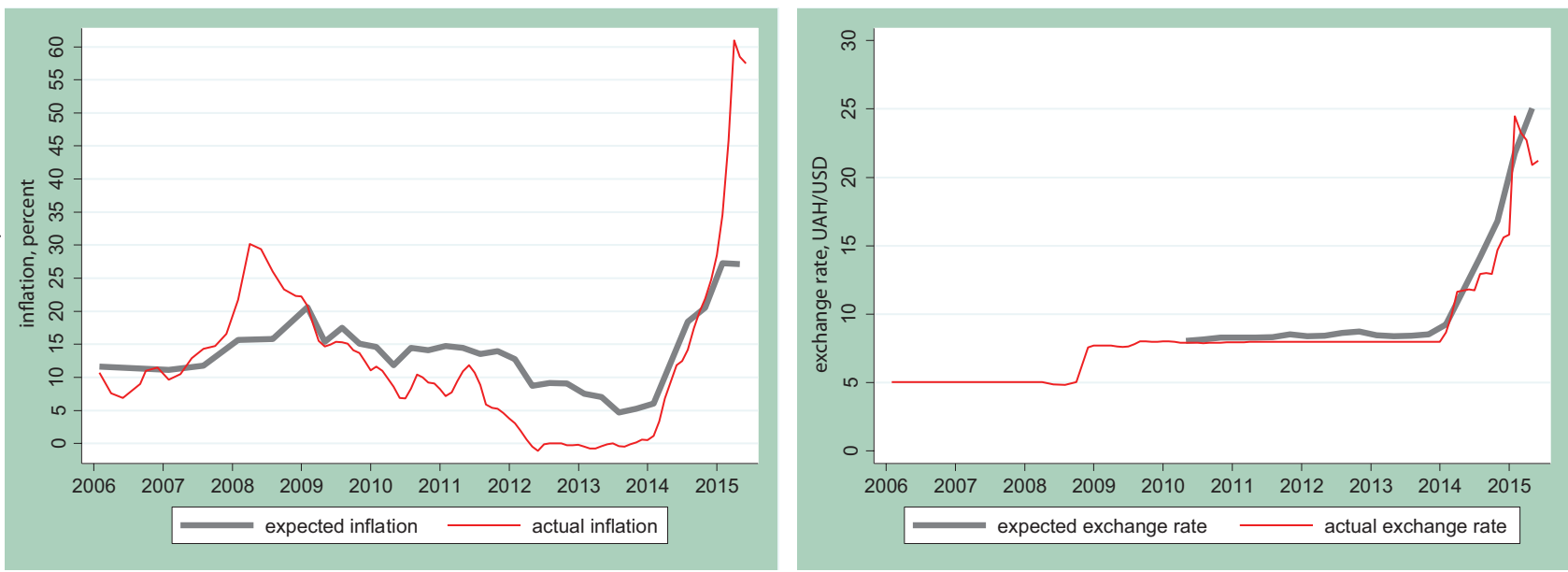

\section{Panel B: Consumers}
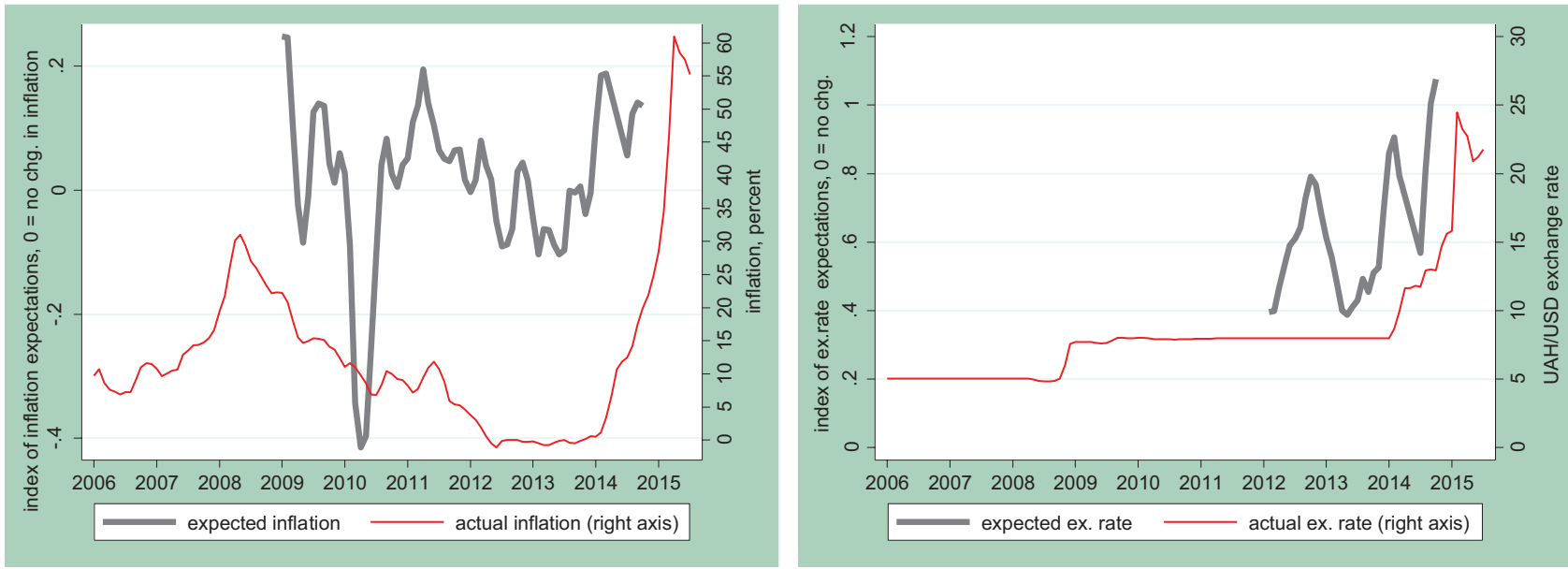

Notes: The figures report forecasts and actual values of inflation (left figures) and exchange rates (right figures). In Panel B, the indices of inflation and exchange rate expectations are calculated using equations (1) and (2) respectively

has more and finer brackets. ${ }^{4}$ In any case, allowing consumers to provide "continuous" responses would be likely to provide more information at little additional cost.

Second, the surveys do not ask respondents to report probability distributions. As a result, the central bank cannot establish ex ante uncertainty in forecasts and, thus, it is harder to assess whether expectations are anchored. ${ }^{5}$ Recent developments in survey design (e.g., Manski 2004) suggest simple procedures to elicit the subjective uncertainty (probability distribution) of expectations. For example, in addition to asking for point one-year-ahead predictions for inflation, the Survey of Consumer Expectations (SCE) run by the Federal Reserve Bank of New York asks consumers to assign probabilities to several bins of possible inflation realizations. Given that the current surveys of households and firms already provide bins to respondents in asking about their expectations of inflation and exchange rates, it would be simple to allow respondents to assign probabilities to these bins rather than just picking one.

\footnotetext{
${ }^{4}$ In the rest of the paper, we use raw moments.

${ }^{5}$ If expectations are well anchored, forecast uncertainty should be minimal as agents should assign low probabilities to extreme variations in inflation or other relevant macroeconomic aggregates, especially at longer horizons.
} 
Third, the surveys do not ask agents to report their perceptions of inflation (nowcasts or backcasts). While workhorse models in macroeconomics routinely assume full-information rational expectation (FIRE) so that agents are aware of past and current inflation, survey evidence for other countries (e.g., Coibion et al. 2015, Coibion and Gorodnichenko 2012, 2015) suggests that perceived inflation may deviate considerably from actual inflation. Because individuals' perceptions of past inflation are a very strong predictor of their expectations of future inflation, understanding the dynamics of inflation expectations will ultimately be difficult without also gathering information on consumers' and firms' nowcasts and backcasts of inflation.

Fourth, the success of inflation targeting and related policy regimes is often measured by how sensitive long-term inflation forecasts are to macroeconomic shocks. Intuitively, if the central bank is credible at delivering, for instance, 5 percent inflation, then current economic conditions should have little bearing on inflation 5-10 years into the future. Currently, only the survey of professional forecasters collects information about 3-year-ahead inflation expectations. ${ }^{6}$

Finally, the surveys do not have a usable panel structure so that it is difficult to assess how agents revise their beliefs about current and future inflation. This is an important limitation because, without a panel component, one cannot establish why agents have high or low inflation expectations. These expectations may be consistent with e.g. strong ex ante priors (which may be hardly affected by policy), lack of information (which may be addressed by enhanced communication policies), or responses to agent-specific or aggregate shocks (which may be influenced by standard macroeconomic tools of a central bank). To distinguish between these alternative explanations, one should observe the evolution of agents' beliefs. For example, the MSC interviews about a third of respondents 6 months after the first interview and thus creates a rotating panel. The SCE follows consumers monthly up to a year.

\section{Properties of expectations}

Figure 3 shows the dynamics of the actual inflation rate and the UAH/USD exchange rate versus the expectations of firms (mean forecast) and consumers (mean value of the index). The expectations are highly correlated with the actual series. For example, the correlation between inflation expectations of firms and actual inflation is 0.86 . For the exchange rate, the correlation is even higher: 0.95. While these magnitudes may appear striking, they are similar to what one can observe for other countries. For example, the correlation between actual inflation and consumer expectations over 1998-2015 (a stable period of inflation) in New Zealand is about 0.77 , while the correlation in the U.S. is 0.47 over 1998-2015 (a stable period of inflation in the U.S.) and 0.9 over 1978-2015 (this period includes high and volatile inflation in the later 1970s and early 1980s as well as the Volcker disinflation).

The indices of expectations for Ukrainian households are less strongly correlated 0.34 and 0.54 for inflation and exchange rate respectively). The reduced magnitudes of the correlations likely reflect noise in the indices rather than a genuine unresponsiveness of consumer expectations to fluctuations in inflation and the exchange rate. Indeed, when we compare the dynamics of mean oneyear-ahead expectations across agents in Figure 4 (over the period for which we have a direct quantitative measure of household forecasts rather than an index), we find that they track each other closely. An acceleration of inflation in late 2104 and early 2015 translated into increased inflation expectations and the pattern is similar for exchange rate expectations. As we discuss below, this similarity of expectations across different types of agents in times of high inflation is observed in other countries as well but one may predict that expectations may diverge as inflation in Ukraine subsides.

The available time series are too short to do formal tests of rationality. Indeed, Croushore (2010) documents that departures of survey expectations from rational expectations over short periods of time can be frequent even when they appear rational over longer periods. However, one can note two observations. First, firms' expectations of inflation-the longest time series of expectations available to us - have an average error of approximately zero. Second, the expectations were lagging actual inflation and exchange rate dynamics in late 2014 - early 2015, the time of large movements in these variables, which is similar to how expectations behave in similar situations in other countries, as emphasized in Coibion and Gorodnichenko (2012).

Firms' and consumers' disagreement about the future course of inflation and exchange rate is strongly positively correlated with the actual series. ${ }^{7}$ For example, between mid-2013 when inflation expectations were at the lowest level and mid-2015 when they peaked, the standard deviation of firms' forecasts more than doubled. The positive correlation between disagreement among agents in their inflation expectations and the level of inflation has also been documented in the U.S. by Mankiw, Reis and Wolfers (2003) for households and professional forecasters. While disagreement is not equivalent to uncertainty, elevated and rising disagreement is consistent with poorly anchored inflation expectations.

\footnotetext{
${ }^{6}$ Recently, the NBU added a question about expected 3-year-ahead inflation to the firm survey. Unfortunately, this question is asked only once a year and the horizon is short relative to the 5 -to-10 year standard.

${ }^{7}$ Some variation in our measure of disagreement is due to the fact that the survey questions elicit inflation expectations in brackets which are revised over time in terms of coverage of possible inflation values as well as the size of brackets.
} 
Figure 4. Inflation and exchange rate expectations across agents: mean prediction and disagreement
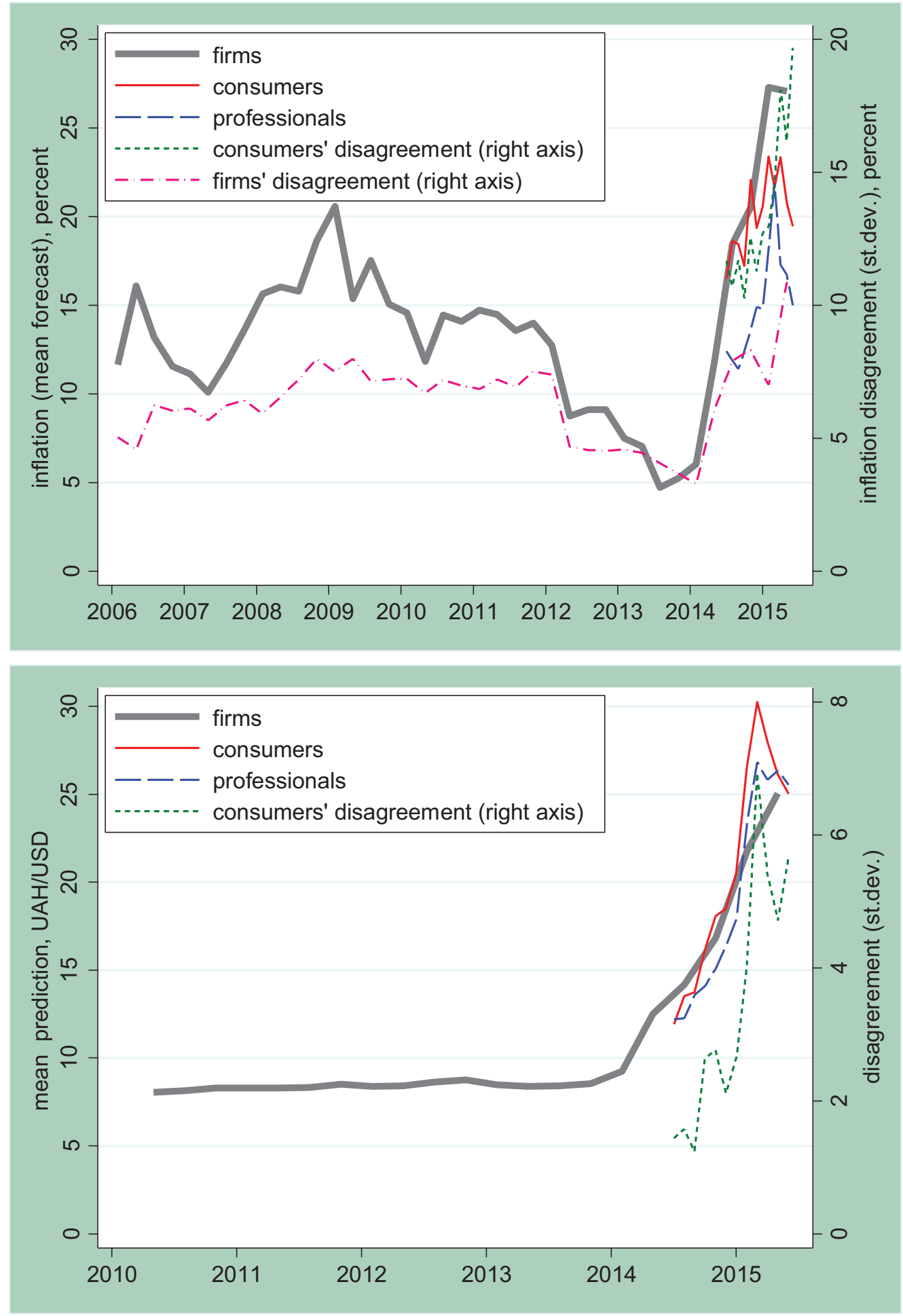

Notes: The figures present mean forecasts and disagreement for firms, consumers and professionals (as available) for inflation (top figure) and exchange rates (bottom figure). The mean and standard deviation for households are used with STATA's intreg to account for intervals rather than continuous variables. 
Figure 5. Inflation and exchange rate expectations

Panel A: Consumers

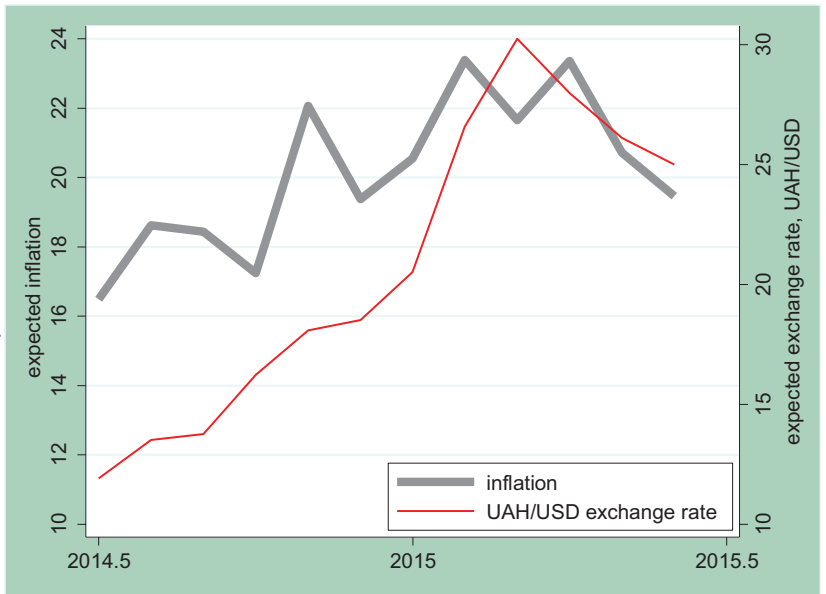

Panel C: Professional forecasters

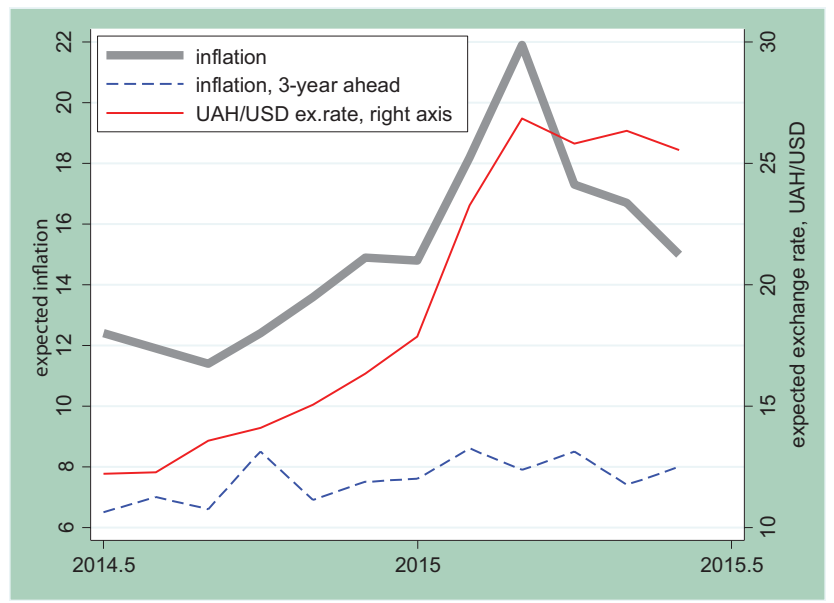

Panel B: Firms

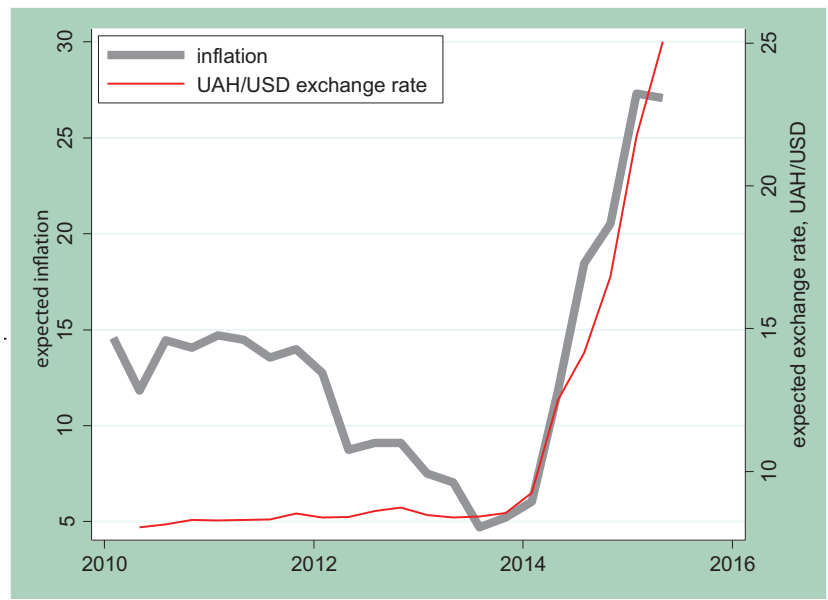

Notes: Each figure plots the mean forecast for inflation and exchange rates for each type of agent, as described in the text.

Figure 5 shows that inflation and exchange rate expectations are tightly connected. The massive depreciation of the hryvnia in 2015 led to a sharp rise in the inflation expectations across all types of agents. Obviously, some of this tight relationship can be accounted by the pass-through from exchange rate expectations. However, there could be other channels. For instance, in countries with chronically high inflation, economic agents could routinely use exchange rates as a sufficient statistic summarizing the stance of monetary and fiscal policies as well as other macroeconomic conditions to infer the rate of inflation. As a result, inflation expectations could be sensitive to exchange rate fluctuations above and beyond what is justified by pass-through. Coibion and Gorodnichenko (2015) document a similar mechanism in the U.S. where American households use gasoline prices to infer the aggregate inflation rate and their expectations exhibit a disproportionately strong sensitivity to movements in commodity prices (e.g., the price of gasoline and food).

To assess this conjecture, we plot in Panel A of Figure 6 the mean inflation expectations and disagreement about inflation of firms which did not engage in any trade with other countries, along with the expectations of all firms. If the pass-through explanation was the correct one, one would expect firms which engage in trade with other countries to devote more time and resources to forecasting the exchange rate than others. As a result, they would tend to form different exchange rate forecasts which, through the pass-through channel would lead to different inflation forecasts. But as documented in Panel A of Figure 6 , there is no visible difference in the inflation forecasts of firms which trade and those which do not, either in terms of their mean forecasts or in terms of their disagreement. This suggests that the exchange rate is treated as an informative signal about the economy and inflation by all firms in the economy. 
While households and firms both display strong correlations between their inflation and exchange rate forecasts, the 3-year ahead inflation predicted by professional forecasters has been much less sensitive to recent exchange rate volatility. This pattern is certainly an encouraging sign for Ukrainian monetary policymakers, although the level of their expected inflation has been higher than the 5-percent inflation target (with acceptable deviations within one percentage point) declared by the NBU (NBU 2015). This difference may reflect several factors. First, the NBU plans to gradually disinflate toward the target and during this stage the bands around the target may be wider. Perhaps the $8 \%$ inflation rate predicted by professional forecasters will be in the upper part of the admissible range for inflation. Second, the central bank may be not credible in the eyes of professional forecasters. Unfortunately, the available data again does not permit us to differentiate these two explanations. One would need additional information about uncertainty in inflation forecasts as well as expectations of inflation at longer horizons.

Another unique property of the firm survey is that firms were asked to report if they follow the actions and announcements of the NBU. Panel B of Figure 6 shows that the share of firms following the NBU commoves strongly with crises and the level of inflation. For example, just before the start of the Global Financial Crisis in 2008, approximately 10 percent of firms followed the NBU. In the heat of the crisis, the share jumped to 25 percent. The share fell again close to 10 percent by the end of 2012 and it started to climb up again as the Ukrainian economy slid into recession in 2013 and, as inflation peaked in 2015, the share jumped to over 25 percent. Strikingly, the level of expectations or disagreement is very similar across "non-followers" and

\section{Figure 6. Inflation expectations of subsamples of firms.}

Panel A: Firms with no international trade (neither import nor export)
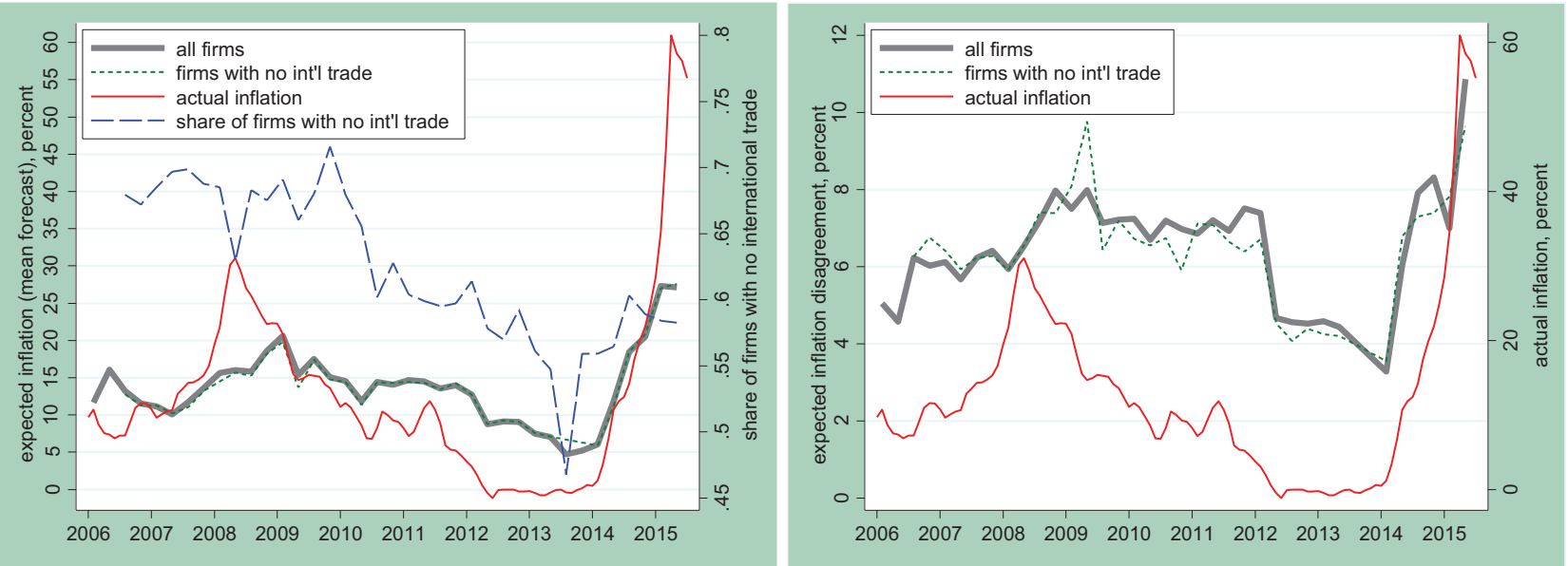

Panel B: Firms that follow the National Bank of Ukraine
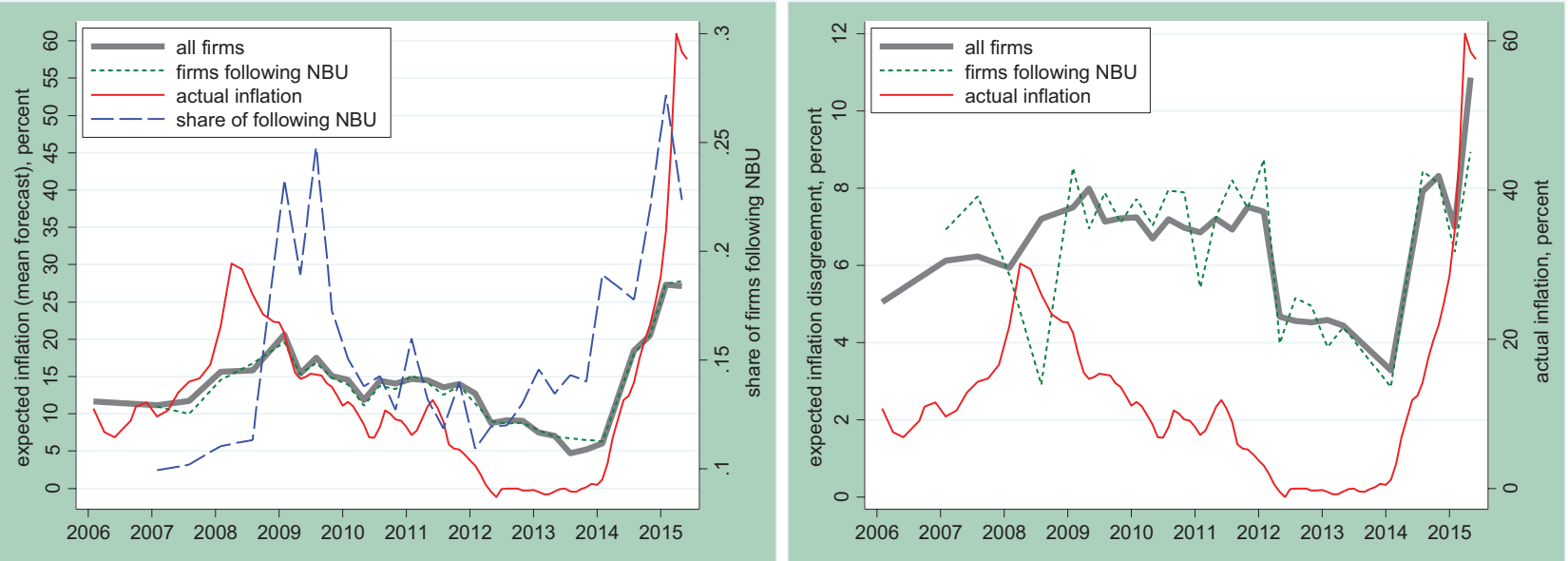

Notes: Panel A plots mean expected inflation (left panel) and disagreement (right panel) for firms which did not trade with other countries, as well as all firms in the survey of firms. In addition, the time-varying share of firms with no international trade is plotted. Panel B plots an equivalent figure, but for firms who reported following announcements and actions of the National Bank of Ukraine. 
Figure 7. Time series of inflation forecasts in the U.S.A.

Panel A. Comparison of expectations across agents
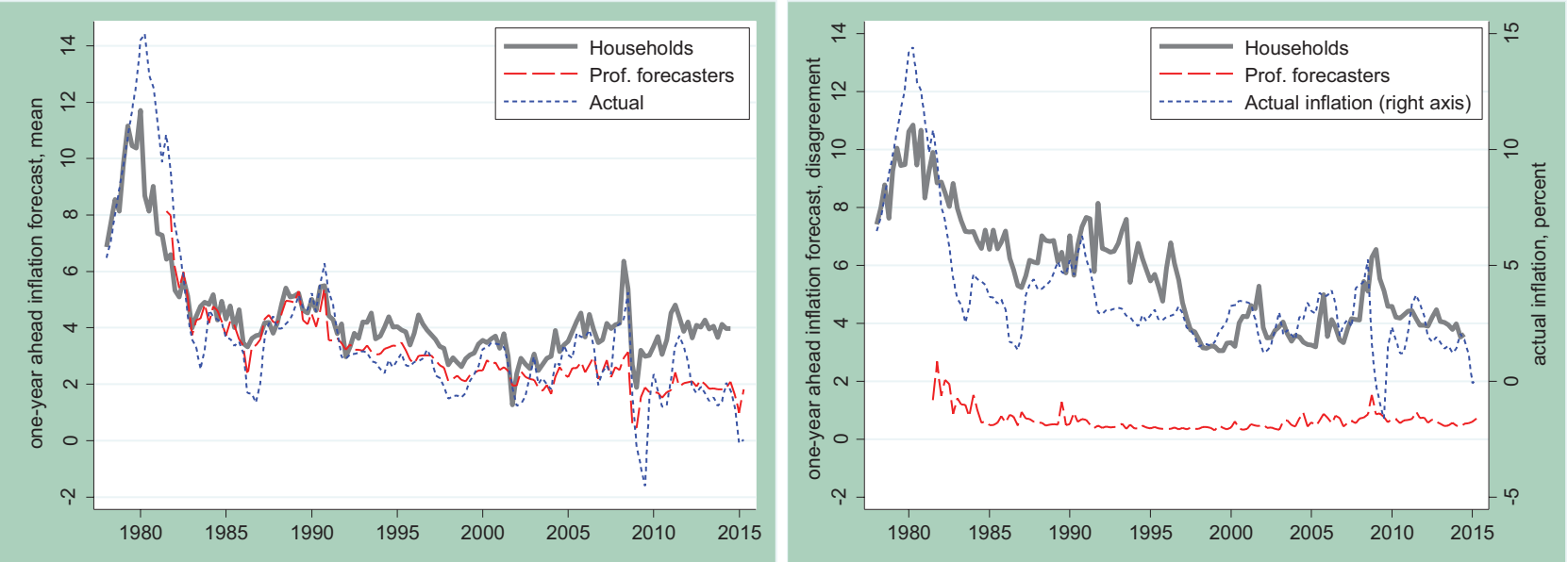

Panel B: Households
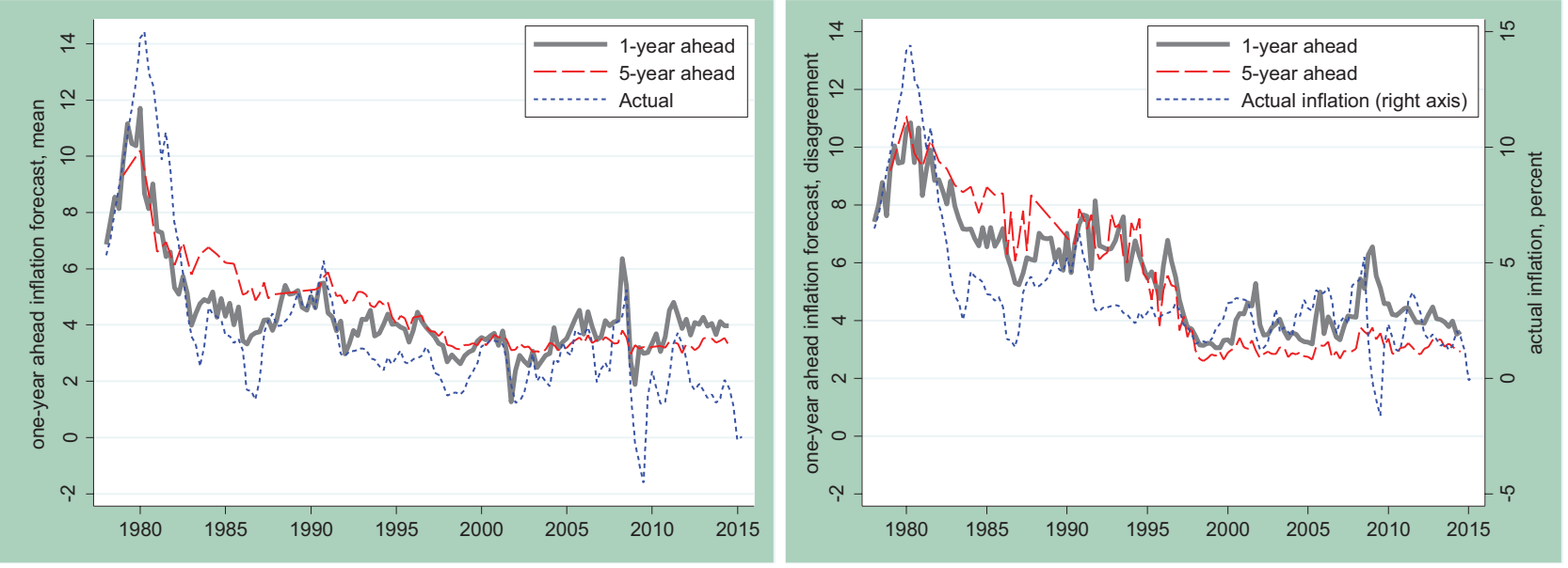

Panel C: Professional forecasters
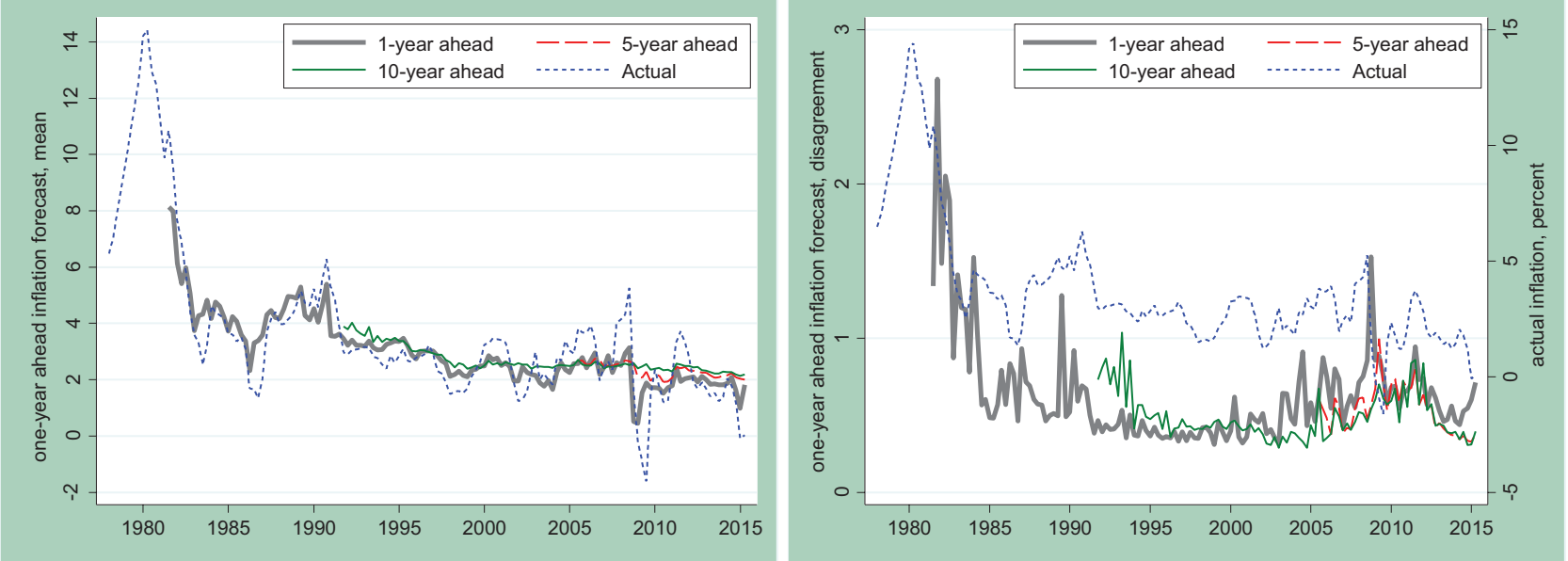
"followers". One possible interpretation of this pattern is that it reflects poor communications on the part of the NBU: their announcements fail to provide enough information to affect agents' expectations. Another interpretation is that this reflects a credibility gap: while agents want to know what the central bank is saying, they are skeptical about its ability to affect inflation over short horizons, so their expectations are unchanged relative to those of other agents.

The absence of a difference in beliefs for agents who receive news from the NBU is in sharp contrast to other evidence from inflation targeting countries where central bank credibility is high. For example, in New Zealand, when firm managers are presented with information about the central bank's inflation target, this leads to large revisions in their inflation forecasts, especially if they were initially uncertain about future inflation (Coibion, Gorodnichenko and Kumar, 2015). This is indicative of the work that lies ahead for the NBU in building its credibility, a task that is likely to take years.

\section{Future dynamics of expectations}

Because Ukraine's macroeconomic history is rather short, we will use international experience to predict the future behavior of inflation expectations. Specifically, we will focus on the U.S.A., New Zealand, and Poland, countries that went through significant disinflations and adopted some form of inflation targeting. The longest, high-quality series of inflation expectations are available for the U.S. New Zealand, the pioneer of inflation targeting, is interesting because it is a small open economy dependent on commodity prices-which is similar to Ukraine-and with a long history of low and stable inflation, an outcome of its inflation targeting regime. Finally, we analyze Poland because in many ways, the Ukrainian authorities treat Poland-also a transition economy-as a role model. Apart from the Polish economy showing enviable economic development and modernization, the Polish central bank successfully implemented inflation targeting and brought inflation down from over 30 percent per year to 2-3 percent per year.

Panel A of Figure 7 shows the dynamics of one-year-ahead inflation expectations and actual inflation since the late 1970s for the U.S. Note that in the early part of the sample, expectations of households and professional forecasters ${ }^{8}$ tracked each other closely but a significant divergence began in the early 2000. As discussed in Coibion and Gorodnichenko (2015), this divergence was driven by rising prices of gasoline and other goods readily visible to households. In other words, households assign a weight to gasoline prices, food prices, and house prices that is higher than what is assigned by statistical agencies and, consequently, professional forecasters. This pattern suggests that even after the Volcker disinflation of the early 1980 s and the de facto inflation targeting regime in place since the 1990s, consumers in the U.S. still do not have completely anchored expectations. In contrast, expectations of professional forecasters ${ }^{9}$ are stabilized at the 2-percent inflation target declared by the Federal Reserve System. There are several other manifestations of the divide in anchoring of inflation expectations.

First, disagreement about future inflation is much higher for households than for professional forecasters: the standard deviations of beliefs in the cross-section of households and professional forecasters are about 4 percentage points and 0.5 percentage points respectively. The disagreement of households declines little with the forecasting horizon, while it falls in the case of professional forecasters (see Panels B and C of Figure 7). However, the Volcker disinflation shrank the disagreement of households from 10 percentage points in 1980 to 4 percentage points in 2000s and 2010s.

Second, while the 5-year-ahead inflation expectations of households are less than their 1-year-ahead inflation expectations on average, the mean 5-year-ahead forecast is still well above the official target and it tends to co-move with the short-term inflation forecast (Panel B of Figure 7). On the other hand, the 5- and 10-year ahead inflation predictions of professional forecaster are nearly fixed at the official inflation target (Panel $\mathrm{C}$ of Figure 7).

We observe similar patterns in New Zealand. In the 1970s and 1980s, New Zealand experienced high and volatile inflation but after adopting inflation targeting in 1990, the Reserve Bank of New Zealand was able to reduce and stabilize inflation at 2 percent (Panel A of Figure 8). Unfortunately, we do not have expectations series going back to the pre-adoption period. However, in contrast to the U.S. data, we have information about both households' and firms' expectations of future inflation as well as their perceptions of past inflation. Panel B of Figure 8 shows that between 1999 and 2015 inflation expectations as well as perceptions of inflation were stable over time. On the other hand, the average level of inflation expectations was close to 4 percent, considerably above the official target of two percent. At the same time, expectations of professional forecasters (not shown) have remained very close to two percent and exhibit little sensitivity to cyclical fluctuations. Note that firms' expectations and perceptions - taken from Coibion et al. (2015) - are even higher than expectations of households.

\footnotetext{
${ }^{8}$ Unfortunately, there is no survey of firms' inflation expectations in the U.S.

${ }^{9}$ Expectations of financial markets are similar to expectations of professional forecasters in the U.S.
} 


\section{Figure 8. Inflation and inflation expectations in New Zealand}

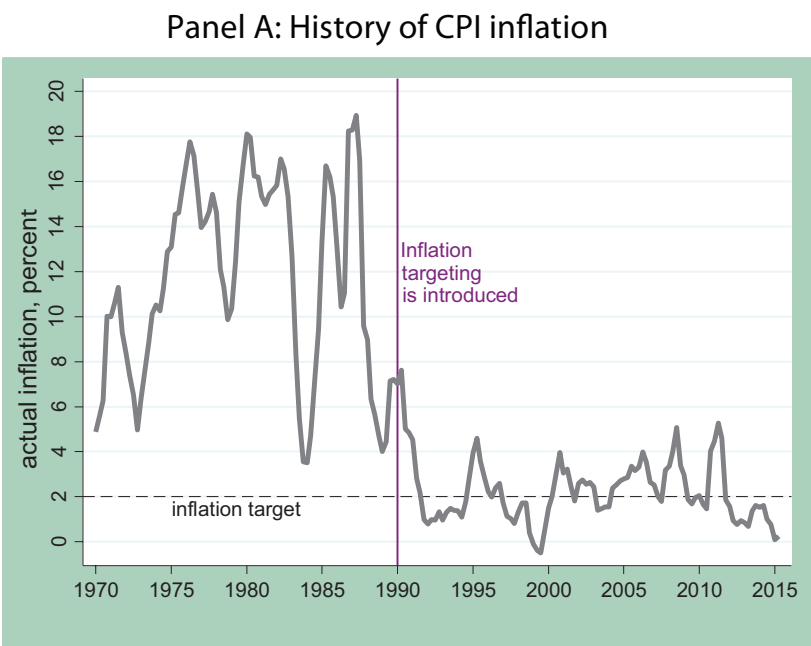

Panel C: Disagreement in forecast/backcast

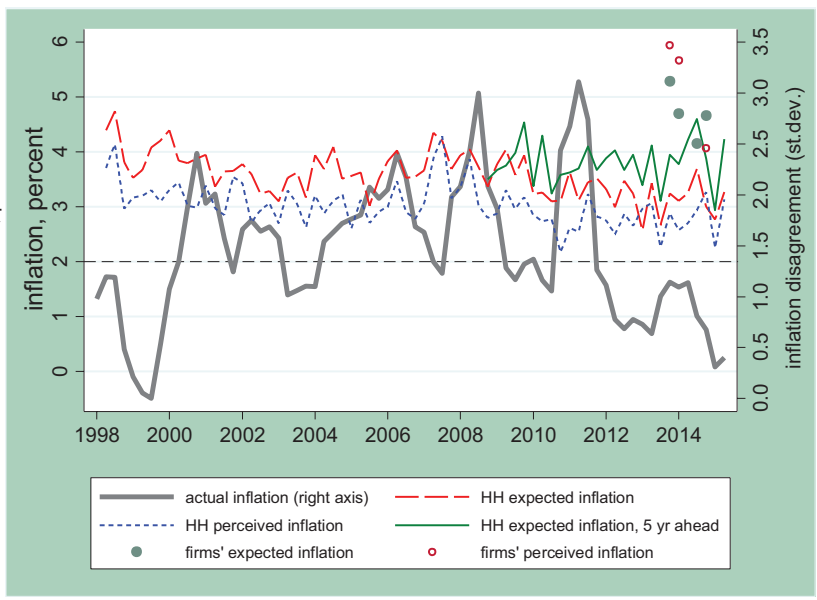

Panel B: Mean forecast/backcast of inflation

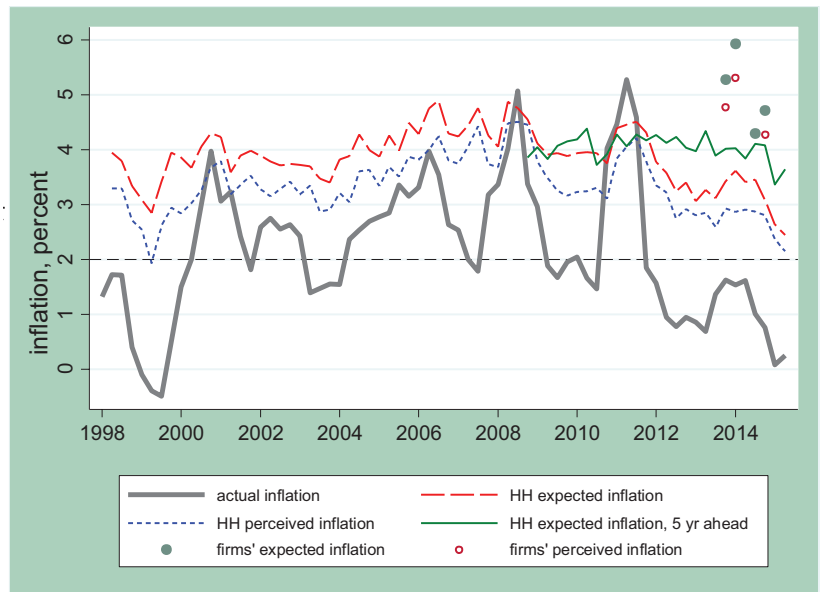

Notes: The middle figure plots forecasts of inflation by households (" $\mathrm{HH}$ ") in New Zealand at the 1-year horizon or the 5-year horizon, as well as their backcasts ("perceived") of inflation over last twelve months. The bottom panel plots equivalent time series for disagreement.

Similar to the U.S., there is little disagreement across professional forecasters about future inflation (the standard deviation of the cross-sectional distribution is 0.2 percentage points; see Coibion et al., 2015) but households and firms have a much higher level of disagreement: the standard deviation of the cross-sectional distribution is close to 4-5 percentage points, which is similar to the level observed in the U.S. now. Results are similar when we examine long-term (5-year-ahead) expectations for inflation. Strikingly, the level of disagreement about past inflation is similar, indicating that informational frictions are likely to play an important role in the incentives and costs to collect and process information. It appears as if there is a limit to how far central banks can go in anchoring the expectations of firms and households.

Finally, we find that, similar to the U.S., inflation expectations in Poland tracked actual inflation closely as the level of inflation converged toward the official target. However, the stunning degree to which inflation expectations track actual inflation reflects the limitations of the survey design in Poland. Specifically, the survey asks respondents to report their inflation in a format similar to the one GfK survey in Ukraine used to have before July 2014. As a result, the point predictions of inflation are based on additional assumptions: the agency implementing the survey fits a distribution of beliefs to match the observed distribution of survey responses so that the central tendency of inflation expectations is largely imputed. Because many people pick "prices will grow at the same rate as now", the implied mean of inflation expectations is very close to actual inflation. Not surprisingly, households' expectations are well below the official target in recent quarters, while professional forecasters predict that inflation will be close to the target.

The history of these three countries allows us to draw several conclusions. First, the level of expectations follows actual inflation. It is therefore unlikely that the NBU will be able to anchor expectations before it disinflates and stabilizes inflation. 
Figure 9. Inflation and inflation expectations in Poland.

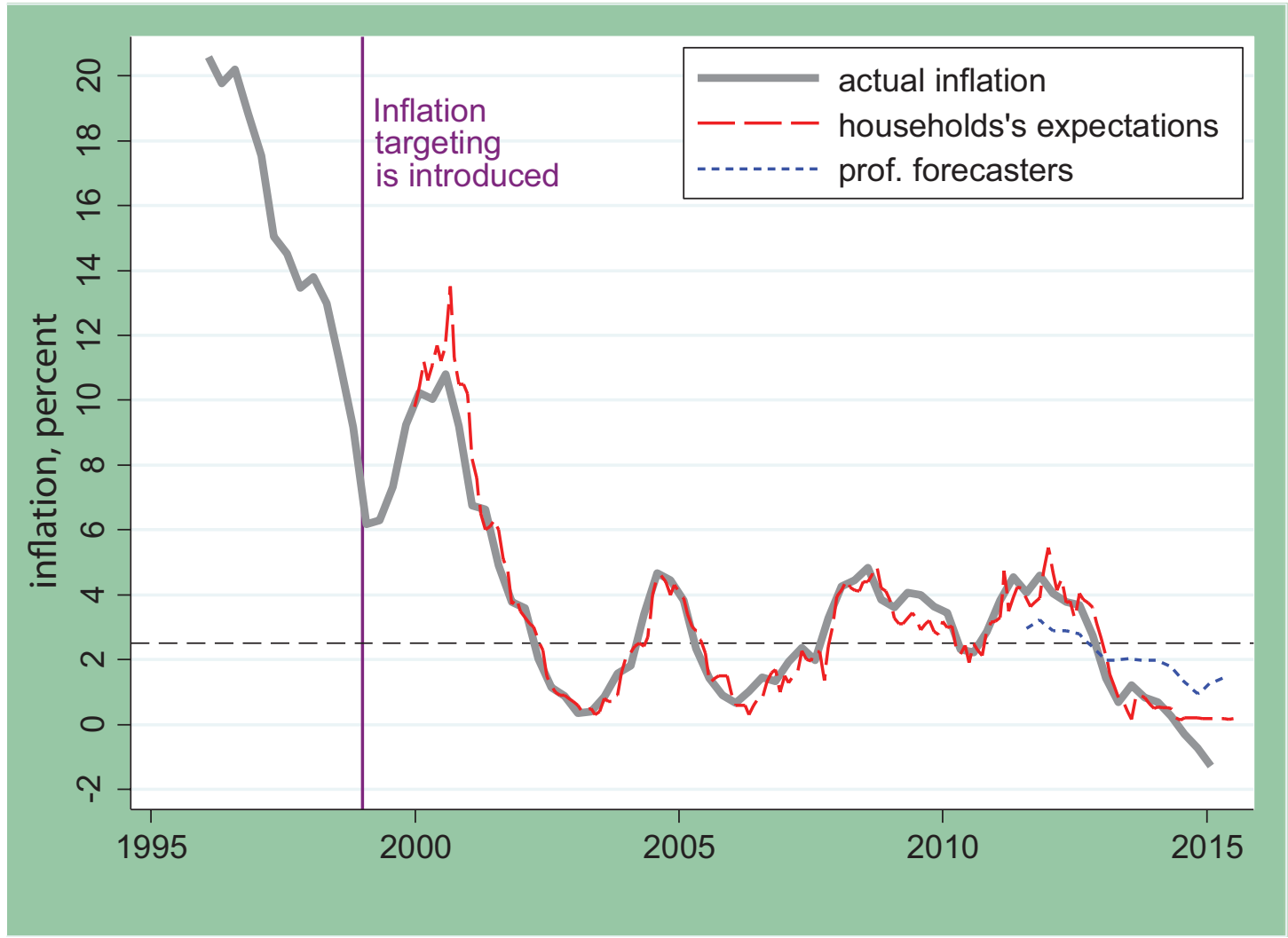

Source: National Bank of Poland.

In other words, the NBU will have to earn credibility by delivering on its promises. Because disinflation is often associated with tight monetary policy, an economic contraction may be inevitable.

Second, while the NBU should be able to anchor the inflation expectations of professional forecasters, financial markets and the like, it may be unable to anchor inflation expectations of households and firms. The experience of the U.S. and New Zealand suggests that, even decades into inflation targeting regimes and with very credible central banks, household and firm expectations do not appear anchored in the way that professionals' are. One explanation is that as inflation falls and stabilizes, many economic agents have reduced incentives to track inflation and other macroeconomic variables. A similar outcome in Ukraine is likely if disinflation is successful.

Third, inflation expectations of firms and households are often sensitive to movements in inflation "proxies", such as gasoline prices in the U.S. Given the history of inflation in Ukraine, economic agents there put a disproportionately large weight on changes in the UAH/USD exchange rate to infer the rate of inflation. Because the exchange rate, unlike gasoline prices, is partly under the influence of the central bank, it may be possible to achieve a more rapid anchoring of expectations by using monetary policy tools to manage this proxy variable. Of course, directly stabilizing the exchange rate would contradict the inflation targeting regime, and the past experience of Ukraine clearly suggests that by fixing the exchange rate the NBU had to accept high and volatile inflation. Thus, policymakers should aim to find a balance between using the exchange rate to manage expectations and to hit the inflation target.

In summary, one may anticipate that a successful disinflation by the NBU will bring down inflation expectations in the future, albeit with some delay. Likewise, the disagreement in expectations-which may be interpreted as a measure of uncertainty about inflation-will decline. It is likely that households/firms' expectations may diverge from those of professional forecasters. One may also predict that long-term inflation expectations of professionals will stabilize at the official inflation target of 5 percent. 


\section{Concluding remarks}

As the National Bank of Ukraine prepares its future conversion to an inflation targeting regime, it must come to terms with many profound challenges, including a high rate of inflation, economic weakness and political instability. But one advantage it will have over previous countries which have gone through this experience is a pre-existing set of surveys that measure the inflation expectations of different agents in the economy. This will enable the NBU to track in realtime the success of its communications strategy and the extent to which the regime change is affecting the economic expectations of Ukrainians. While the surveys are not completely ideal in their current forms, it would take only small changes and additions to bring them to the frontier of this type of survey, and such changes could reap many benefits to policymakers. For example, they could provide measures of long-run inflation expectations for households and firms, measure the uncertainty in these agents' forecasts, and track these agents' perceptions of recent inflation dynamics. Each of these would be enormously useful for a central bank in the midst of a disinflationary effort.

But even without these changes, the surveys have already proven informative. For example, they have revealed striking differences and similarities in the inflation and exchange rate expectations of Ukrainian households and firms. They have also revealed a surprisingly strong correlation between expectations of exchange rate changes and expectations of inflation over time, supporting the notion that Ukrainians use the exchange rate as a key signal of overall price movements in the economy. This suggests that even under an inflation targeting regime, policymakers may want to try to limit fluctuations in the hryvna to avoid excess volatility in the inflation expectations of households and firms in Ukraine.

Unfortunately, the lesson from other inflation targeting countries is that the battle to anchor expectations is a long one, even when inflation rates have been brought down and held down for many years. Twenty-five years after adopting inflating targeting in New Zealand, households and firms there still forecast inflation well above the target, as do households in the U.S. This process may be even more challenging for Ukraine that has a history of recent hyperinflation. Thus, Ukrainian policymakers will likely need to be patient and not expect immediate results, at least when it comes to inflation expectations.

\section{References}

- Cameron A.C., Trivedi P.K. (2010). Microeconometrics Using Stata. Rev. ed. College Station, TX: Stata Press.

- Coibion O., Gorodnichenko Y. (2012). What Can Survey Forecasts Tell Us about Informational Rigidities? Journal of Political Economy, Vol. 120, No. 1, pp. 116-159.

- Coibion O., Gorodnichenko Y. (2015). Information Rigidity and the Expectations Formation Process: A Simple Framework and New Facts. American Economic Review, Vol. 105, No. 8, pp. 2644-2678.

- Coibion O., Gorodnichenko Y. (2015). Is The Phillips Curve Alive and Well After All? Inflation Expectations and the Missing Disinflation. American Economic Journal: Macroeconomics, Vol. 7, No. 1, pp. 197-232.

https://doi.org/10.1257/mac.20130306

- Coibion O., Gorodnichenko Y., Kumar S. (2015). How Do Firms Form Their Expectations? New Survey Evidence, Working Paper, No. 21092, NBER.

- Croushore D. (2010). An Evaluation of Inflation Forecasts from Surveys Using Real-Time Data. B.E. Journal of Macroeconomics, Vol. 10, No. 1, pp. 1-30. https://doi.org/10.2202/1935-1690.1677

- Mankiw N.G., Reis R., Wolfers J. (2003). Disagreement about Inflation Expectations. NBER Macroeconomics Annual, Cambridge, MIT Press, Vol. 18, pp. 209-248. https://doi.org/10.1086/ma.18.3585256

- Manski C.F. (2004). Measuring Expectations. Econometrica, Vol. 72, No. 5, pp. 1329-1376.

https://doi.org/10.1111/j.1468-0262.2004.00537.x

- National Bank of Ukraine (2015). When will price stability achieved in Ukraine? Available at:

https://bank.gov.ua/control/en/publish/article?art_id=17505335\&cat_id=17505318

- Walsh C.E. (2010). The Future of Inflation Targeting. Economic Record, Vol. 87, Special Issue, pp. 23-36. 


\title{
A STRATEGIC DOCUMENT ON MONETARY POLICY FOR THE PERIOD OF THE INFLATION TARGETING ADOPTION IN UKRAINE
}

\section{Volodymyr Lepushynskyi}

National Bank of Ukraine

\begin{abstract}
The article explains why the Main Guidelines of Monetary Policy need to be adopted in a new format: A monetary policy strategy for 2016-2020. This document must combine the program component (goals, objectives and ways of achieving them) and communication component (explanations in understandable format). Based on international experience of inflation targeting central banks in devising strategic documents on monetary policy, the article offers a format of this document for Ukraine and the key provisions it should include. In particular, it explains the approaches to setting the document's goals, use of the instruments necessary to achieve these goals, decision making procedures, declarations and application of an exchange rate regime, and also communication of monetary decision-making.
\end{abstract}

JEL Code: E520

Keywords: monetary policy strategy, inflation targeting, floating exchange rate

\section{Introduction}

Almost a decade and a half ago, the National Bank of Ukraine has first announced the intention to adopt an inflation targeting regime (NBU Council, 2001). After that, a statement of this intention was repeated in the National Bank's numerous program documents. It continued to be mentioned but was no longer exciting any hopes in economists who take interest in monetary policy.

Let's make it clear from the outset: successfulness of an economy and stability of its monetary unit are determined not by a monetary regime but the country's ability to compete in the global economy. And that requires, first of all, structural reforms.

Ukraine hardly has anything to brag about in this respect. Under these conditions, no modern monetary regime could help regular crises, which befell the Ukrainian economy. Consequently, Ukraine's monetary policy was aimed at offsetting the consequences of these crises. Setting invariable inflation targets and commitments to achieve these targets was, therefore, doomed to fail.

Today, situation is completely different. Implementation of reforms in Ukraine is the matter of national survival. The slogan "Ukraine is doomed to reforms" has become widely popular. It gives chance to a successful implementation of the necessary changes in monetary policy, in particular, evolution of monetary regime in Ukraine into inflation targeting framework. 
Ukraine took the obligation to continue efforts towards future adoption of inflation targeting under Extended Fund Facility program with IMF. This year National Bank of Ukraine made a substantial progress in building policy making procedures, development of analytical and forecasting potential and redesigning monetary policy implementation framework. Now these elements are quite close to inflation targeting central banks.

However, there are still other important elements left: announcement of clear numerical targets for inflation and the National Bank's institutional commitment to achieve these targets. These objectives may be attained by the NBU Board's adoption of a strategic document on monetary policy, the Main Guidelines of Monetary Policy for 2016-2020.

The article offers analysis of other inflation targeting central banks' experience in developing strategic documents on monetary policy and provides recommendations based on this analysis as regards the relevant elements for a similar strategic document for the National Bank of Ukraine.

\section{Strategic documents on monetary policy}

\subsection{International experience}

Most central banks in developing countries which successfully use inflation targeting regime outlined the process of transition to a new regime in a special document: medium-term monetary policy strategy.

Depending on country, these documents have unique features in terms of the scope, content and period for which they were adopted. The documents have different degree of specification: from outlining general goals of monetary policy (Monetary Strategy document of the Czech National Bank) to detailed description of operational objectives (General framework of inflation targeting regime and monetary and exchange rate policy of the Central Bank of Turkey, 2006). Strategic documents on monetary policy approved by central banks of Albania, Georgia, Poland, Serbia have their own particularities as well.

Nevertheless, strategic documents on monetary policy from various countries have common features. First of all, they are program and communication documents simultaneously, because they set out:

- clear and, most importantly, invariable numerical inflation targets. It means not an inflation forecast but target, thus envisaging that monetary policy would be actively aimed at reaching this target;

- target setting procedure and possible reasons for divergence from targets;

- terms and conditions of transition to inflation targeting;

- ways of achieving the central bank's objectives, in particular, determining the main instrument of monetary policy and operations for supporting this instrument;

- motivation to implement inflation targeting, i.e. explanation of why this particular regime is acceptable for the country at a particular stage of its development. Also (which is the most important point in communication aspect), how the implementation of this regime would benefit the ordinary citizen;

- central bank's accountability mechanism, i.e. how the public could learn about the monetary policy measures and success in achieving its goals.

The main reason for publication of this document that is the promulgation and fulfillment of the central bank's commitments is to gain the public credibility, which is critically important for stabilization of inflation expectations.

\subsection{State of affairs in Ukraine}

According to the Law of Ukraine On the National Bank of Ukraine, the Main Guidelines of Monetary Policy (hereinafter referred to as the Main Guidelines) set out the National Bank's performance indicators for the medium-term perspective for the purpose of achieving the National Bank's goals. In other words, there are no de-jure obstacles to turning this document into a monetary policy strategy. 
However, the Main Guidelines for past periods have been significantly different from the aforementioned strategic documents on monetary policy of other central banks. Among the key differences were:

- absence of invariable medium-term goals, principles and objectives of monetary policy. As a rule, the Main Guidelines included a section setting out medium-term goals and objectives. Nevertheless, every year the NBU Board usually approved a revised version of the Main Guidelines for the following year with, most importantly, changed goals. In other words, the central bank had no vision of monetary policy for the medium-term perspective;

- the Main Guidelines were not a clearly program document. It was simultaneously an analytical (an overview of monetary policy within the context of macroeconomic conditions in past years), forecast (a macroeconomic forecast for the following years) and program (setting goals for the following year and, more vaguely, for a medium-term period) document. In fact, this document was, to a large extent, a reiteration of other documents, particularly the NBU Council's evaluation of the monetary policy implementation results, and its forecast section mirrored the Government's relevant forecast. As a result of its multi-functionality, the document's program and especially communicative functions were diluted, because it focused on either the lore of ages long gone by' or second-string information;

- absence of differentiation between targets and forecasts. Before this year's amendment, the Law of Ukraine On the National Bank of Ukraine contained a provision stipulating that the Main Guidelines shall be developed on the basis of indicators calculated by the Cabinet of Ministers. As a result, the Main Guidelines set out a forecast the achievement of which the NBU had to facilitate. If the forecast was changed, the Main Guidelines were amended accordingly as well. However, general practice of central banks shows that the forecast and target of monetary policy have very different functions. The target is a constant, and the policy is aimed at achieving it. If forecasted inflation differs from the target level, a central bank must take the required monetary policy actions.

Moreover, forecast is not a central bank's obligation, and therefore, cannot serve as the anchor for expectations. Harmonization of the Main Guidelines with the best practices of drafting documents of this kind and to the needs of inflation targeting adoption is quite in line with the requirements of law regarding this document's medium-term orientation.

Action required:

- adopting the Main Guidelines as the Monetary Policy Strategy for the Medium-Term Perspective. Timespecific perspective of this document should be harmonized with the period for which Ukraine's other national strategic documents were adopted, first of all, "Ukraine-2020" Sustained Development Strategy approved by a Decree of the President of Ukraine. Considering the foregoing, the revised and updated Main Guidelines should also be adopted for the period of 2016-2020;

- the Main Guidelines should become a program and communication document, which means that its content must be compact. The Main Guidelines' section pertaining to evaluation of the monetary policy implementation results must become a separate document to be approved by the NBU Board, whereas macroeconomic forecasts are already being published in a separate document: NBU Inflation Report (where the NBU should analyze how forecasts are correlated with declared targets);

- setting numerical targets, emphasizing their invariability and aiming monetary policy at achieving them. If the target could not be achieved in a short-term run, this should not be a reason for revising it; on the contrary, the NBU has to clearly explain how the changes in its instruments would bring actual inflation indicators back to the target level. Clarity of commitments and transparency of fulfillment actions must become the pillars of the NBU credibility.

The above actions are quite real to realize, especially considering the legislative amendments concerning development of the National Bank of Ukraine's institutional capability. Detailed overview of the monetary policy's aspects which we propose to highlight in the revised Main Guidelines is provided below. 


\section{Motivating the implementation of inflation targeting regime}

As international experience proves, the presence of "Motivation" section is an important feature of medium-term monetary policy documents. This section describes the desired state a central bank intends to achieve and the benefits it would bring to the economy in general and for every ordinary citizen in particular. This section also outlines the reasons why a central bank has chosen particularly the inflation targeting rather than other alternative regimes to achieve the desired state.

It's not a secret that for decades, Ukrainian economy has been suffering from volatile and unpredictable inflation that undermined the hryvnia's credibility. While in the early 1990s, high inflation was an inevitable consequence of transformational processes, afterwards it became the result of an unreasoned macroeconomic policy, which had a substantial populist component. Thus, during some periods, inflation was declining to low levels and even deflation became. But what's important is that inflation fluctuated significantly during quite short periods of time. In view of the above, high inflation expectations persisted in the society, finding their reflection in:

- high interest rates on hryvnia deposits and, therefore, hryvnia loans;

- inclination toward dollarization of both savings (foreign currency is one of the means of protecting them against depreciation) and loans (because the costs of foreign-currency resources are lower);

- volatile conditions of running a business and deteriorating business environment.

Therefore, having reached the desired target of low and stable inflation, the NBU can ensure that:

- inflation would no longer be a significant reason to worry about for households and businesses;

- credibility of the hryvnia would grow, helping expand the sphere of its use and driving dedollarization;

- individual savings and income would be protected against depreciation;

- low nominal interest rates would stimulate investments and economic growth;

- private individuals and businesses would adequately assess foreign exchange risks and would be ready to potentially substantial fluctuations of the exchange rate.

Why only the inflation targeting regime could help achieve this environment? And why a chance for successful implementation of inflation targeting is in the nearest future, if it wasn't done in the past almost 15 years? The answer is quite simple: Ukraine simply has no other alternative.

There are three main monetary regime types in the world: exchange rate pegging, monetary targeting (monetary aggregates targeting) and inflation targeting. There are regimes that do not fall under this classification, but mostly, they are either eclectic (setting many targets which, as a rule, a central bank cannot successfully achieve) or transitional between the aforementioned regimes.

One of the key advantages of inflation targeting is that it envisages clear framework of transparent policymaking aimed at price stability in medium term perspective while allowing some degree of freedom to react on external and domestic shocks in short run. Results of empirical studies demonstrated that (Roger, 2010; Jahan, 2012):

- inflation expectations are under more efficient control and more stable in countries which are practicing inflation targeting;

- countries that adopted inflation targeting especially emerging market economies have made substantial progress in disinflation for last 20 years and are more protected from external shocks and crisis (GDP loss and inflation acceleration are smaller).

Regimes alternative to inflation targeting have substantial drawbacks that make them unsuitable for Ukraine. 
The exchange rate pegging regime is not suitable for Ukraine for many reasons. The most obvious one is that in order to maintain the national currency pegged to, say, the US dollar, the NBU has to have large international reserves. But unfortunately, this precondition is nonexistent in our country. Otherwise, this regime is doomed to fail.

One should also not forget that the exchange rate pegging regime led to accumulation of substantial macroeconomic imbalances in the past. It didn't create conditions for but led to them. The reckless macroeconomic policy resulted in the country living "beyond its means", which was vividly reflected in the critical figures of BoP current account deficit (9\% of GDP in 2013). The exchange rate pegging helped defer for some time the hryvnia's inevitable devaluation, but only by "eating away" the nation's international reserves and postponing the inevitable correction of exchange rate.

In addition, longstanding exchange rate pegging created wrong impression of businesses and households regarding foreign exchange risks. Under this impression, they incautiously assumed foreign-currency liabilities. The consequences of those actions continue to cause social tensions till present day, despite the de-facto prohibition on providing individual financing in foreign currency lasting for many years.

Therefore, maintenance of the exchange rate pegging regime creates risks for Ukraine to go through all the consequences of past crises it went through before.

Ukrainian economy is small and open, which means that it doesn't set the rules of the game on the global scale but only follows them. For an economy like that, flexible exchange rate must play the role of "buffer" against outside shocks. What does that mean for the ordinary citizen and why would he need these exchange rate fluctuations which only cause him headache?

The answer is simple: sustaining of the employment, because if the demand or prices for Ukrainian goods on foreign markets decline, the hryvnia must depreciate to keep the prices for Ukrainian goods competitive and help businesses retain their sales markets and, consequently, their employees keep the job.

To be sure, adverse consequences such as declining capacity of the ordinary citizen to buy imported goods or to travel abroad are present, but these consequences are much "softer" comparing to the growing unemployment on the nationwide scale.

The reverse situation is also possible: as a result of a positive external shock when the growing foreign demand or export prices threaten "overheating" of the economy, a stronger hryvnia becomes a "safety device" preventing accelerating inflation.

Overall, in the countries with floating exchange rate the volatility of this indicator is higher (Klein and Shambaugh, 2009). Nevertheless, nominal volatility of exchange rate helps stabilize real economic growth. That's what they mean by saying that exchange rate serves as a buffer against external shocks (see: Section 2). According to the study by Edwards and Yeyati, in countries employing tighter monetary regimes, trade condition shocks are amplified. All other conditions equal, economies with flexible exchange rates are growing at a higher rate comparing to countries with a fixed exchange rate (Edwards and Yeyati, 2004).

Edwards notes that fluctuations of a floating exchange rate are diminishing if inflation targeting is also used. The reason for that is that "inflation targeting is a transparent and predictable monetary regime serving to absorb unforeseen shocks or "news" (Edwards, 2006).

Does floating exchange rate mean that it is going to lower without alternative? Definitely not. All depends on the success of structural reforms which would determine the economy's competitiveness and on the external environment. Exchange rate fluctuations would only protect the national economy against sharp changes in global market conditions. For example, recalling Poland's experience, the exchange rate of the Polish zloty to euro is presently at approximately the same level as when inflation targeting was introduced there almost 15 years ago, although during this period, the exchange rate's fluctuations were, at times, over $30 \%$.

There is an erroneous opinion that the central bank using this regime cannot intervene in the foreign exchange market. However, according to the IMF's definition, the use of this regime involves "interventions (direct or indirect) on the foreign exchange market aimed at moderating the rate of change and preventing undue fluctuations in the exchange rate" (IMF, 2014). The main 
criterion of this regime is that official intervention policy should not be aimed at establishing a certain level (or band) for the exchange rate.

In other words, the National Bank may smooth exchange rate fluctuations but should not intervene to counter a currency appreciation or depreciation trend.

Using a floating exchange rate also complies with one of the National Bank's most important objectives for the next several years: restoration of international reserves. Considering the unstable economic situation and volatile market expectations, an adequate level of international reserves would ensure stability of financial system and protect the economy from potential shocks.

The National Bank must replenish its international reserves without hampering the efforts of achieving price stability while at the same time maintaining a floating exchange rate. The objectives of interventions on the foreign exchange market and inflation targets may conflict with each other. For example, in an attempt to accumulate reserves a central bank may lower the exchange rate, thus sacrificing price stability. Therefore, priorities must be set to prevent the conflict of objectives; in particular, price stability must have the unquestionable priority when implementing monetary policy.

At the same time, accumulation of international reserves should not result in fixing the exchange rate. To avoid it, a prudent intervention strategy should be devised: the National Bank should not counter sustained hryvnia appreciation or depreciation trends caused by fundamental factors.

The potential for the exchange rate to fluctuate toward either appreciation or depreciation serves as an important factor preventing business entities from taking excessive foreign exchange risks.

However, it worth mentioning even when the switch to floating exchange rate has come into effect, public attention would focus, to a large degree, on the exchange rate which would still remain for a while a de-facto "anchor" for expectations. Only afterwards, when a central bank was able to bring inflation to a low and stable level public attention would shift from the exchange rate to inflation rate. Considering such a significance of the exchange rate, strategic documents on monetary policy devote a separate section to the coverage of abovementioned goals of the central bank's currency exchange policy. The National Bank's strategic document should have this section as well.

Another type of monetary regime is monetary targeting. This is a regime which is currently used de-jure in Ukraine. The stand-by agreement with the International Monetary Fund (IMF) sets the quantitative criterion of efficiency for the net domestic asset growth and an indicative target for monetary base.

This is the IMF's standard practice of setting "safeguards" preventing central banks from conducting a too expansive policy incompatible with the programs`stabilization objectives.

However, efficient application of monetary targeting to control inflationary processes requires close correlation between money supply and prices. The absence of this correlation in the short- and medium-term perspective led to the abolition of monetary targeting in all developed countries which employed it and the majority of developing countries where this correlation is much weaker (IMF, 2014a).

It is worth noting that for countries de-facto using or switching to inflation targeting regime, the money supply growth criteria set out in IMF programs may not apply; instead, the Monetary Policy Consultation Clause applies. What it actually offers is a quarterly or half-year evaluation of inflation deviations from target levels by IMF experts in the form of formal consultations with authorities to bring the relevant indicators into accordance with target trajectory. Ukraine can also count on the switch to this format of cooperation with the IMF, if it could prove its determination to implement inflation targeting. The IMF says that the Monetary Policy Consultation Clause could be implemented either with the launch of a new program or in the event of modification of existing IMF programs (IMF, 2014a).

The absence of the commitment to follow preset target values of monetary indicators gives monetary policy a greater flexibility. It allows a central bank to focus on inflation targets. Nevertheless, quantitative monetary indicators remain an important component of the central bank's analysis which supplements conventional economic analysis. In particular, loan and monetary aggregate data contain important information regarding pricing and financial stability risks (Bernard et all, 2015). 


\section{Stages of transition to inflation targeting in Ukraine}

Can the National Bank switch to inflation targeting in the nearest future, say, in 2016? To begin with, we have to define for ourselves what inflation targeting is. During more than decade of discussions about the necessary preconditions for implementation of inflation targeting in Ukraine, they have already turned into a mantra. One could even get an impression that for this transition to take place, Ukrainian economy first has to catch up with the UK or Canada.

Definition of inflation targeting in the IMF's De Facto Classification of Exchange Rate Regimes and Monetary Policy Frameworks is worth recalling: "This [regime] involves the public announcement of medium-term numerical targets for inflation with an institutional commitment by the monetary authority to achieve these targets. Additional key features include increased communication with the public and the markets about the plans and objectives of monetary policymakers and increased accountability of the central bank for attaining its inflation objectives. Monetary policy decisions are guided by the deviation of forecasts of future inflation from the announced target, with the inflation forecast acting (implicitly or explicitly) as the intermediate target of monetary policy" (IMF, 2008).

In other words, it mentions, first of all, the central bank's operational procedures: announcement of a target, commitment to this target, substantiation and communication of monetary policymaking decisions.

In fact, the majority of developing countries began transition to inflation targeting during a crisis or post-crisis period when other monetary regimes were impossible to apply. These periods saw the absence of both macroeconomic stability and a sophisticated financial system usually mentioned as preconditions for an effective application of this regime (Schaechter and Zelmer, 2000). At the same time, it did not interfere the overwhelming majority of these countries with subsequently stabilizing inflation at a low level. The example of the Czech Republic, which switched to inflation targeting in a crisis period when exchange rate pegging was impossible to maintain is worth recalling.

Transition to an inflation targeting regime may begin before all required preconditions are in place, if there is a clear commitment to achieve a complete implementation of this regime (IMF, 2014b). Moreover, as international experience proves, the transition to inflation targeting per se often becomes a catalyst of institutional changes in the country, particularly improvement of fiscal discipline or development of financial markets (Batini et al., 2005).

A similar situation is currently observed in Ukraine: given the absence of effective alternatives to inflation targeting, there are actually no obstacles to organizing of the National Bank's procedures in accordance with the inflation targeting regime's standards. Many of them have already been de-facto implemented, first of all:

- a decision-making system based on macroeconomic forecasts: regular monthly meetings of the Monetary Policy Committee presently transformed into regular meetings of the National Bank's Board on monetary issues (after amendment of the Law of Ukraine On the National Bank of Ukraine);

- analytical potential of supporting medium-term monetary policymaking decisions, first of all, inflation forecasting tools (Nikolaychuk and Sholomytskyi, in print);

- operating approaches to implementation of monetary policy, in particular, increasing the effect of interest rates on the National Bank's operations on short-term interest rates on interbank financing market;

- the National Bank's communications with the market, increasing accountability for its monetary policymaking decisions.

However, there are still other important elements left: announcement of clear numerical targets for inflation and the National Bank's institutional commitment to achieve these targets. These objectives may be attained by the NBU Board's adoption of a strategic document on monetary policy, the Main Guidelines of Monetary Policy for 2016-2020.

In that case, evolution of monetary regime in Ukraine may take the following form (Figure 1): 
Figure 1. Possible evolution of monetary regime in Ukraine

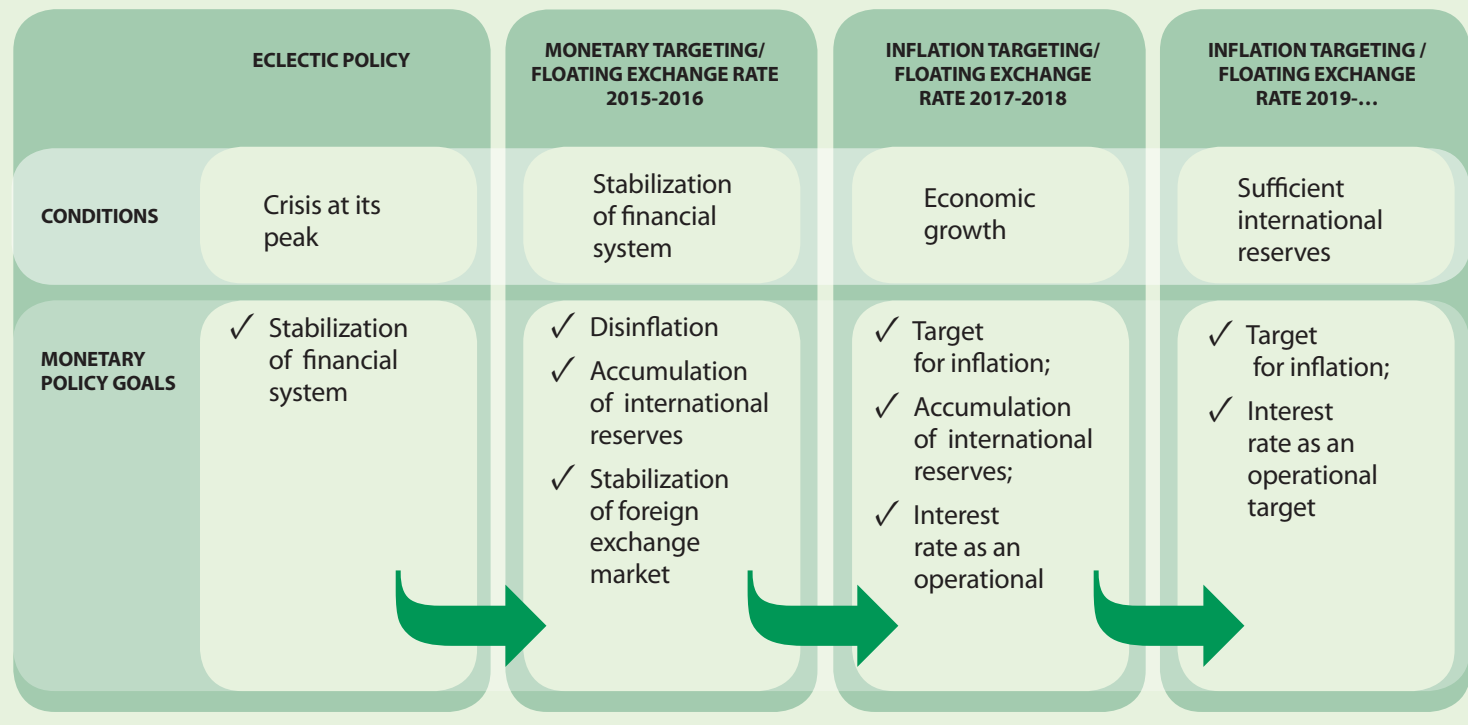

1. Eclectic monetary policy: a past stage. During a macroeconomic, banking and currency crisis, monetary policy was aimed at attaining a wide range of objectives associated with maintaining the country's viability and avoiding collapse of financial system.

2. Breakaway from eclecticity in monetary policy, which became possible after adverse effects of crisis were mitigated and banking system was "cleaned up". Monetary targeting is the current stage. According to its obligations under the IMF's Stand-By Program, the National Bank has to attain numerical targets for money supply. That is a de-jure monetary policy regime, although as mentioned earlier, a large number of the National Bank's procedures are presently conformable to a "lite" inflation targeting regime, i.e. without announcing short-term numerical targets for inflation.

3. Inflation targeting. Switching to this regime requires announcement of numerical targets for inflation and appropriate modification of IMF's Stand-By Program criteria. This regime should be announced when actual inflation rate in Ukraine declines to a moderate level (say, around 10\%). What makes this regime different from the "classical" inflation targeting is the existence of a target for international reserves accumulation.

4. "Classic" inflation targeting. Switching to this regime would, to a certain degree, be symbolic, because it won't require announcements or procedure changes. Inflation has to reach a medium-term target level, and monetary policy must be aimed at attaining this objective. By that time, international reserves should grow to a sufficient level, which means that reserve accumulation target would no longer be on agenda.

\section{Inflation targets}

The announcement of clear (numerical) targets for inflation and the mechanism of achieving them must be one of the key elements of a strategic document on monetary policy.

\subsection{Setting targets}

When devising a strategic document, a number of questions which usually cause broad discussion have to be answered:

\section{Who is responsible for setting inflation targets?}

In the case of Ukraine, the answer is obvious: Council of the National Bank. Some countries using inflation targeting regime cannot independently adopt inflation targets (because this is a parliament's, government's, or joint government's and central bank's responsibility). Considering the foregoing, setting a target for inflation requires coordination with the government or other public institutions. In particular, it requires execution of a joint Memorandum between the government and central bank on joint recognition of inflation targets. In Ukraine, the body responsible for adoption of the Main Guidelines is a separate supervisory body operating within the National Bank's organization. Therefore, setting inflation targets is fully within the National Bank's competence. 


\section{What indicator should be used as an inflation target?}

As of today, all countries employing inflation targeting use the Consumer Price Index (CPI) as the target price indicator, although in the beginning of the new monetary regime's implementation process, some of them (e.g. Czech Republic, South Korea) used core inflation as the target indicator.

The main reasons for using the CPI (and not another price indicator, e.g. GDP deflator that has more solid theoretical base) are operational: calculations are done monthly and with the minimum time lag, no need for statistical revisions of past period data.The key advantages of using the total CPI vs core CPI include:

- easy to perceive and monitor by the public;

- full coverage of the consumer basket without excluding some of its components (which could be extremely important for particular consumer groups);

- comparability with other countries.

The key drawback of the total CPI lies in its high volatility caused by the effect of non-monetary factors, which complicates the achievement of inflation targets. Nevertheless, this drawback can be largely offset if the central bank provides a clear explanation of possible reasons hampering achieving of desired targets.

\section{What kind of target should it be: a point or a band?}

An inflation target may be set as a point or a band, the so-called "comfort zone". Comfort zones are seldom used by central banks to set inflation targets. In particular, the former member of the Board of Governors of the Federal Reserve System Frederic Mishkin criticized, in his speech ironically titled Comfort Zones, Shmumfort Zones, the practice of setting inflation targets in this form. He concludes that it makes interpretation of a target difficult. For example, if a target band is set at 1-2\%, it means that a central bank is equally tolerant toward inflation which has the rate of $1.1 \%$ or $1.9 \%$. It complicates both formulation of monetary policy (due to the absence of a clear target which should be oriented at when making decisions) and communications with the public (Mishkin, 2008).

Considering the foregoing, setting comfort zones for inflation targets is considered inadvisable for anchoring expectations, because the central bank does not publish a single figure to which expectations could be "tied". The aforementioned drawbacks would amplify if we take into account that for developing economies the comfort zone must be wider than 1-2\%.

Considering all these drawbacks, setting targets as points (with an interval of possible divergences) is the most popular approach today for countries with inflation targeting: it is used in 17 out of 27 countries. Another five countries use point targets only (Hammond, 2012), because a clearly set numerical target brings maximum advantage to effective communications with the public and to management of inflation expectations.

The point-based approach to setting a medium-term target for inflation is recommended for the National Bank of Ukraine. Point targets with an interval of possible divergences are proposed to determine and achieve disinflation trajectory. Setting target as a point would anchor inflation expectations of the public, which is one of the important elements of macroeconomic stability. At the same time, an interval of possible divergences for targets set for specific years would give the National Bank certain flexibility in managing inflation which could become volatile due to short-term and insignificant shocks that do not require response from monetary policy.

What level of inflation should be associated with price stability in the medium-term perspective? What should disinflation trend look like in order to achieve it?

Medium-term targets for inflation in developing countries are usually several percentage points higher than inflation targets in developed countries (Hammond, 2012). It can be explained by:

1. Higher degree of uncertainty / shocks caused by structural adjustments;

2. Greater errors in inflation measurements;

3. Substantial changes in relative prices due to higher labor productivity growth rates in the tradable sector (the Balassa-Samuelson effect). 
The following estimates of optimal inflation rates in the medium-term perspective are available for Ukraine:

- Petryk and Nikolaychuk (2007): 4\% (based on an analysis of changes in relative prices and keeping inflation of tradable goods at the level of developed countries);

- $\operatorname{IMF}(2014): 3 \%-5 \%$;

- Gorodnichenko (2014): 3\% - 5\% (by extrapolating an optimal inflation model for the U.S. based on maximizing the usefulness function in the condition of zero lower limit of interest rates, taking into account the greater (2-3 times) magnitude of macroeconomic shocks in Ukraine).

The Main Guidelines of Monetary Policy for 2015 have already set the medium-term target for the CPI growth rate at $5 \% \pm$ $1 \mathrm{pp}$. This target was set on the basis of the aforementioned studies and must be enchrined in a strategic document on monetary policy. At the same time, it should be communicated as a point target without a divergence interval, defining the level which the National Bank intends to achieve in the medium-term perspective.

At the same time, specific targets for the coming years that outline a gradual disinflation process required to attain a medium-term target for inflation should be set as a point with a gradually-narrowing interval. A wide interval is necessary at the initial stages, in particular, to increase flexibility of monetary policy when responding to short-term shocks whose impact could be substantial in the initial phases of post-crisis recovery.

Considering the macroeconomic forecast for the coming years, expected growth of administratively-regulated prices and tariffs, and the need to better stimulate the economy for post-crisis recovery, the downward dynamics of inflation targets (in terms of the total CPI growth rate) in the coming years must be low-inclined (Figure 2):

- December 2016: $12 \pm 3 \%$ year-on-year;

- December 2017: $8 \pm 2 \%$ year-on-year;

- December 2018: $6 \pm 2 \%$ year-on-year;

- December 2019 and beyond: $5 \pm 1 \%$ year-on-year.

Figure 2. Possible trajectory of medium-term targets for inflation in Ukraine

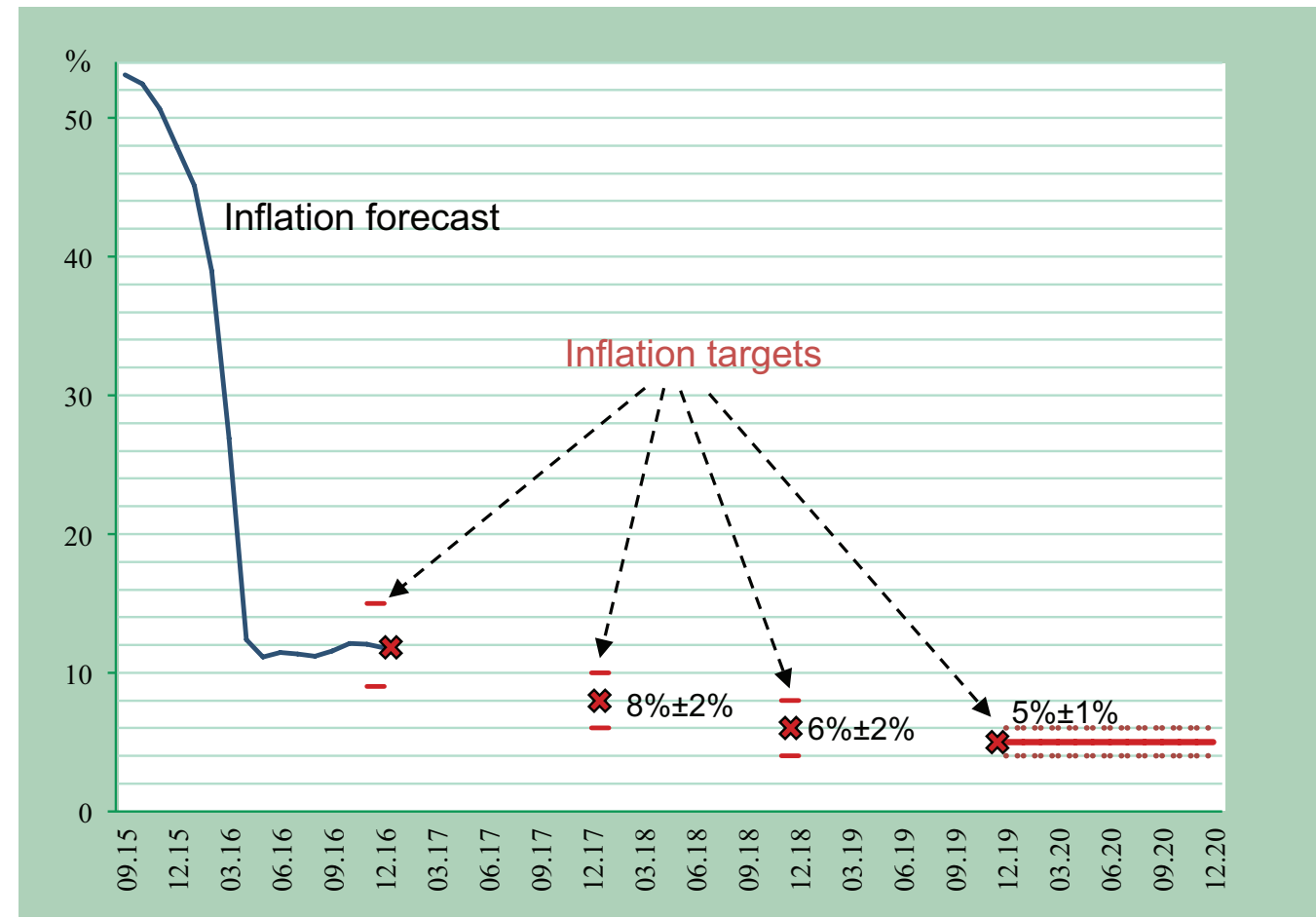




\section{Possible reasons preventing attainment of inflation targets}

Since the strategic document on monetary policy envisages invariability of inflation targets, it should identify the reasons allowing for divergence of actual inflation from inflation targets.

In a short-term period, inflation may diverge from preannounced targets due to impact of external and internal shocks which are beyond monetary policy's control, such as, in particular, changing prices for raw materials and other highly-volatile components of the Consumer Price Index, divergence of administratively-regulated prices from preannounced levels, etc.

Under these circumstances, bringing inflation to a target level in the shortest possible time could be very costly from the viewpoint of economic growth. The aforementioned shocks are inflationary, but they simultaneously cause consumer demand to shrink, which slows down inflation (with a certain lag). Therefore, a tighter monetary policy in response to these shocks would be counterproductive, considering that monetary policymaking decisions must take into account, first of all, inflation forecast.

Therefore, monetary policy must focus on preventing realization of secondary effects from these shocks, i.e. their effect on inflation expectations, thus achieving the medium-term targets for price stability. The period of time during which inflation must be brought into accordance with the medium-term target should be clearly defined in every event like that and communicated to the public.

\subsection{Achieving inflation targets}

The inflation targeting practice envisages a quite clear procedure of making monetary policymaking decisions aimed at achieving inflation targets. Its definition in strategic documents on monetary policy has different scope and specification, but nevertheless, it includes, as a rule:

- monetary policy key interest rate (hereinafter referred to as the key interest rate) as the main instrument of monetary policy;

- pegging the pricing of the main liquidity regulation instrument to the key interest rate - provision or withdrawal thereof depending on the structural position of banking system's liquidity (deficit or surplus). This instrument must have the greatest effect on the interbank credit market interest rates which then would influence interest rates on other banking operations;

- regular procedure of making and communicating decisions on the key interest rate;

- monetary policy secondary instruments supporting the main instrument.

The foregoing is important from the viewpoint of expectations formation on monetary market: by announcing its key interest rate, a central bank sets a benchmark for the market value of monetary resources.

Considering the above, the National Bank's strategic document on monetary policy should include the following in the "achieving inflation targets" section:

- setting out the key interest rate: interest rate on main liquidity regulation instruments, i.e. instruments, which have the greatest influence on the market. This rate must be synchronized with the discount rate which de-jure serves as the benchmark value of money. The National Bank must clearly declare which of its operations are main operations, and set a fixed interest rate for them. In that case, the market's attention will be focused on the change of interest rates on these operations and the response to these changes will be quick. Bearing in mind that banking system presently experiences structural surplus of liquidity, these operations should involve floatation of deposit certificates (for 7 or 14 days). In case of structural liquidity deficit refinancing tenders of the NBU could be treated as the main policy instrument and interest rate on this instrument could be treated as the key rate;

- declaring that decisions on the key interest rate will be based on macroeconomic forecast, first of all in order to bring inflation forecast to a target value. Monetary policymaking decisions also require a comprehensive analysis of macroeconomic, monetary and financial indicators which helps identify price stability risks; 
- regular (according to a preannounced schedule) meetings of the National Bank's Monetary Policy Board with publication of Board decisions made at these meetings;

- setting a bandwidth for overnight rates (on the National Bank's overnight loans and deposit certificates) as a mechanism of supporting the key interest rate. This bandwidth would limit interest rate fluctuations on the interbank market around the key interest rate;

- description of other supporting operations intended, first of all, to increase the main instrument's effectiveness. Unlike the main instrument, these operations would not influence the market value of resources but serve to amplify its effect.

The National Bank is already actively using many of these elements. In particular, change of the National Bank's interest rates already influences the dynamics of interest rates on the interbank market. However, interest rates on the main liquidity regulation operations (which are interest rates on deposit certificates) need to be converged to the discount rate which dejure serves as the benchmark value of money.

\section{Monetary policy communications}

There is a famous saying that money likes silence. But speaking about the central bank's activity, it's worth adding that the silence should not be anguishing. Thus, the central bank is an independent institution. But all business entities are dependent on the central bank, because to a substantial degree, their wellbeing depends on it.

There is a broad consensus among the scholars that besides ensuring the central bank's public accountability, transparency of monetary policy may boost its effectiveness (Blinder, 1998; Woodford, 2003).

That's why the communications section is an essential component of strategic documents on monetary policy.

It is extremely important that the society understands that the central bank's activity is adequate to its priority objective maintaining inflation at a low, stable level. As the former Chief Economist of the European Central Bank O. Issing said: "Openness and clarity are equally important for transparency of monetary policy" (Issing, 1999).

In other words, the openness (you can see what you want, we have nothing to hide) is as important as competently built communications. The society needs to have enough information to assess reasonability of decisions made in monetary sphere.

Under the exchange rate pegging regime, communications do not play such a decisive role, because expectations are influenced only by the invariability of the exchange rate today and tomorrow. On the contrary, under inflation targeting regime, communication attains the exceptional importance, because the public needs to understand how a monetary policymaking decision made today would facilitate, via the chains of macroeconomic variables called transmission mechanism, price stability in the medium-term perspective. For that, it is the only way to stabilize inflation expectations, which is what inflation targeting is needed for at the end of the day.

Many communication elements, typical for inflation targeting regime, have already been implemented at the National Bank of Ukraine. In particular, in March 2015 it published the first Inflation Report which serves as the key instrument in central banks' communications under inflation targeting regime. Quarterly publications of this document help convey to the public, in a simplified (adapted) format, the array of data which the central bank uses to make decisions, in particular: on-the-day macroeconomic forecast with the focus on inflation, price stability risks and, in the end, National Bank's measures taken to offset these risks.

An important element of the central bank's communications under inflation targeting regime is a proper substantiation and communication of its monetary policymaking decisions. In doing so, it is important to build the so-called "routine cycle" of making decisions with regard to key instruments. After all, the central bank is not a news agency and the purpose of its communications is not to broadcast sensations and "canards" but, on the contrary, constant (routine) explanation, in easy-tounderstand form supported by facts, of how its measures would help achieve inflation targets. 
Advantages of building a routine cycle:

- Predictability of central bank's actions, for barring extraordinary events, all decisions are made right according to the schedule. Unlike the practice of making spontaneous decisions, it allows to place an emphasis on the consistent policy aimed at achieving medium-term targets;

- Facilitating equal access to information, because a decision becomes known to all market participants at the same time and the only source of information is the central bank;

- Tying market expectations regarding the change of monetary instruments to a particular regular event (press conference, press release, etc.), thus improving effectiveness of these instruments;

- Increasing transparency and accountability and expanding dialogue with markets. Regular explanations by the central bank of its monetary policymaking decisions help better perceive and understand these decisions by financial market participants.

In order to build this routine cycle, the National Bank has launched monthly meetings of the Monetary Policy Committee (the Committee) held according to a preannounced schedule. After every meeting, the Committee used to publish a press release explaining decisions it made with regard to monetary policy instruments.

Presently, in view of the enactment of legislative changes enhancing the National Bank's institutional capability which reformed, in particular, working principles of the National Bank's Board, the approaches to the adoption and communication of monetary policymaking decisions have somewhat changed as well. The Committee meetings remain an important platform for discussion of monetary policymaking decisions, thus improving their justifiability. At the same time, decisions will now be de-jure and de-facto adopted at the regular meetings of the National Bank's Board for Monetary issues.

To build a full-fledged routine cycle, changes in monetary instruments have to be announced not only on a predetermined day but at the same time. That's the area where the National Bank is currently improving the relevant processes.

In particular, taking into account the operating practice of leading central banks, the National Bank's routine cycle may look as follows (Figure 3):

Phase 1: One week before the National Bank's Board makes a decision. Preparation by the National Bank's departments concerned of a macroeconomic forecast, expanded analysis of economic conditions, monetary indicators and financial stability, and development on this basis of a staff proposal regarding monetary policy for the National Bank's Board.

Phase 2: The day before the National Bank's Board makes a decision. The Committee holds a meeting which plays an important role in getting a full "macroeconomic picture". The meeting is attended by the Bank's staff (directors of Departments for Monetary Policy and Economic Analysis, Open Market Operations, Financial Stability, Statistics and Reporting) and members of the National Bank's Board. At these meetings, the Bank's staff makes presentations of macroeconomic forecast, development of financial markets and financial stability, reports analysis results, shares experience and opinions with the National Bank's Board members who make the decision.

Phase 3: Day when the National Bank's Board makes a decision. Presentation of a staff proposal to the National Bank's Board.

Phase 4: Decision Monetary policy is made by the National Bank's Board.

Phase 5: Communication of a National Bank's Board's decision (at a specifically-determined time on a decision adoption day). 
Figure 3. Possible scheme of organizing a "routine cycle" of adopting and communicating monetary policymaking decisions at the National Bank.

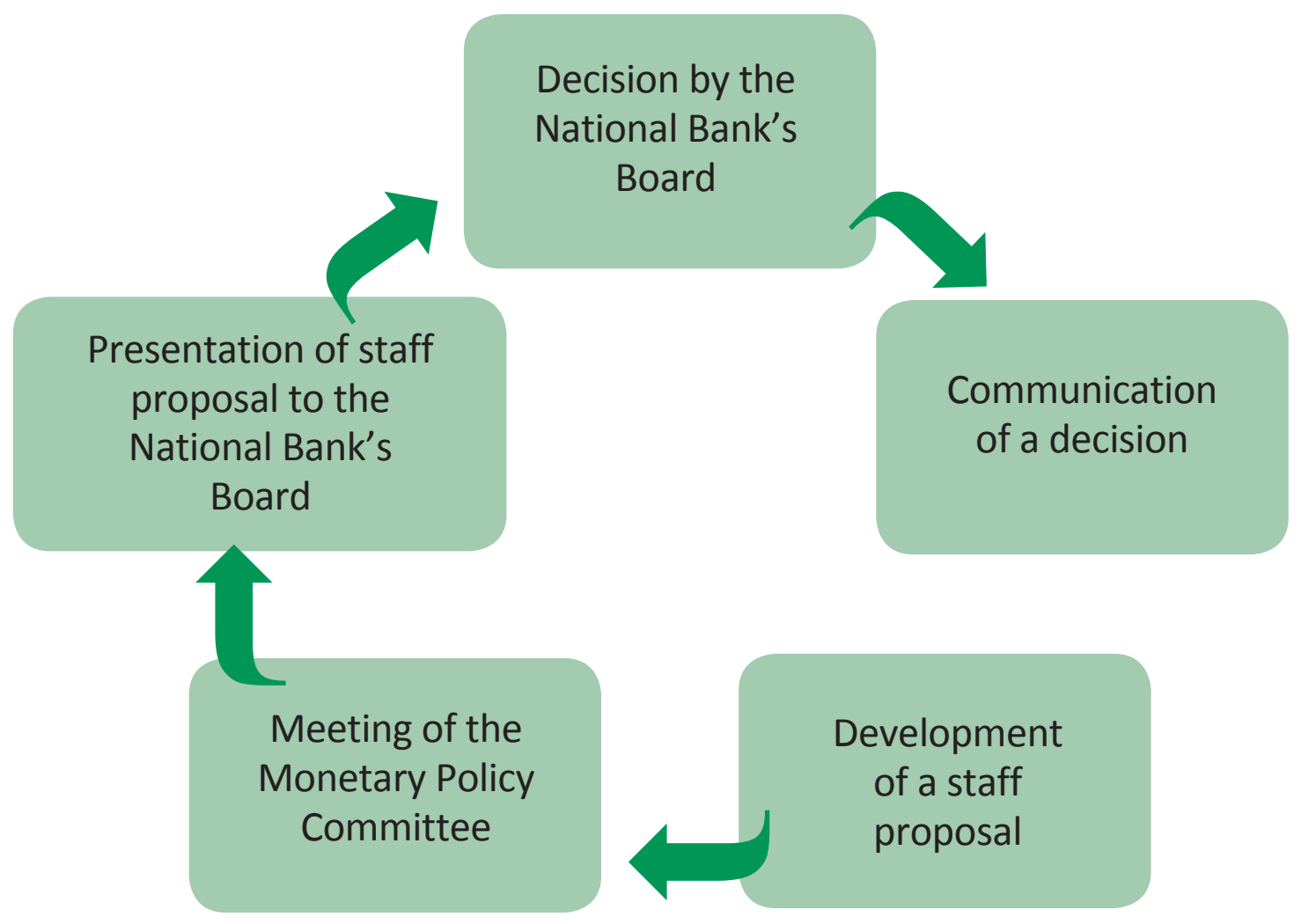

\section{Concluding remarks and recommendations}

Today, the adoption by the National Bank's Council of the Main Guidelines of Monetary Policy in a new format, format of the National Bank's monetary policy strategy for 2016-2020 remains a contemporary objective. This document must have program component (setting monetary policy goals and ways of achieving them) and communication component (conveying goals and objectives to the public in an easy-to-understand form).

Taking into account international experience, this document must include:

1. Explanation of advantages of a chosen monetary strategy;

2. Clear commitment to adopt inflation targeting by the particular deadline;

3. Medium-term price stability target (5\% for CPI year-on-year change) and clear trajectory of achieving it. These targets must be invariable in order to gain public trust;

4. Definition of:

- instruments and procedures for achieving inflation targets;

- goals of foreign exchange policy under floating exchange rate regime;

5. Description of monetary policy goals and decisions communication strategy.

Declaration by the National Bank of clear goals for monetary policy, mechanisms of achieving them and fulfillment of its commitments will help increase public credibility and stabilize inflation expectations, thus setting a necessary precondition for price stability. 


\section{References}

- Bank of Albania (2008). Monetary Policy Document for the 2009-2011 period.

- Batini N., Kuttner K., Laxton D. (2005). Does Inflation Targeting Work in Emerging Markets? Chapter 4 of the September 2005 World Economic Outlook, International Monetary Fund.

- Blinder A. (1998). Central Banking in Theory and Practice, MIT Press, Cambridge MA.

- Central Bank of Turkey (2006). General framework of inflation targeting regime and monetary and exchange rate policy for 2006.

- Council of the National Bank of Ukraine (2001). Main guidelines of monetary policy for year 2001, elaborated and approved by the Council of the National Bank of Ukraine.

- Czech National Bank, CNB Monetary Strategy document. Available at:

https://www.cnb.cz/en/monetary_policy/strategic_documents/c_dms.html

- Edwards S. (2006). The relationship between exchange rates and inflation targeting revisted. Working paper, No. 12163, NBER.

- Edwards S., Yeyati L. (2004). Flexible exchange rates as shock absorbers. European Economic Review, No. 49, pp. $2079-2105$.

- Gorodnichenko Y. (2014). Inflation target for Ukraine, VoxUkraine Blog. Available at: http://voxukraine.blogspot.com/2014/05/IT.html

- Hammond G. (2012). State of the art of inflation targeting - 2012, Bank of England, CCBS Handbook, No. 29.

- IMF (2014 a). Conditionality in Evolving Monetary Policy Regimes, IMF Policy Papers.

- IMF (2014 b). First IMF Central Bank Forum for Developing Markets: The Road to Inflation Targeting and Transitional Monetary Arrangements, Press Release, No. 14-435.

- IMF (2014 c). Annual Report on Exchange Arrangements and Exchange Restrictions 2014.

- IMF (2014 d). De Facto Classification of Exchange Rate Regimes and Monetary Policy Frameworks.

- IMF (2014 e). Ukraine: Request for a Stand-By Arrangement-Staff Report; Supplement; Staff Statement; Press Release; and Statement by the Executive Director for Ukraine. Country Report, No. 14/106, IMF. Available at: http://www.imf.org/external/pubs/ft/scr/2014/cr14106.pdf

- Issing O. (1999). The Eurosystem: Transparent and Accountable, or Willem in Euroland. Journal of Common Market Studies, Vol. 37, No. 3, pp. 503-519. https://doi.org/10.1111/1468-5965.00175

- Jahan S. (2012). Inflation Targeting: Holding the Line. Finance \& Development, IMF, Washington, DC.

- Klein M.W, Shambaugh J.C. (2009). Exchange Rate Regimes in the Modern Era, The MIT Press.

- Laurens B., Eckhold K., King D., Maehle N., Naseer A., Durré A. (2015). The Journey to Inflation Targeting: Easier Said than Done. The Case for Transitional Arrangements along the Road. Working Paper, No. 15-136, IMF.

- Mishkin F.S. (2008). Comfort Zones, Shmumfort Zones: A Speech at the Sandridge Lecture of the Virginia Association of Economists and the H. Parker Willis Lecture of Washington and Lee University, Lexington, Virginia.

- National Bank of Georgia. Monetary Policy Strategy of the National Bank of Georgia. Available at:

https://www.nbg.gov.ge/index.php?m=628\&lng=eng

- National Bank of Poland (1998). Medium-Term Strategy of Monetary Policy (1999-2003).

- National Bank of Serbia (2006). Memorandum National Bank of Serbia on the Principles of the New Monetary Policy Framework Aiming at Low Inflation Objectives. Available at:

https://www.nbs.rs/internet/english/30/Memorandum_new_monetary_policy_framework_200609.pdf

- Nikolaichuk S., Sholomytskyi Y. (2015). Using Macroeconomic Models for Monetary Policy in Ukraine. Visnyk of the National Bank of Ukraine, No. 233, pp. 54-64. https://doi.org/10.26531/vnbu2015.233.054

- Petryk O., Nikolaichuk S. (2007). Vyznachennia optymalnoho rivnia infliatsii dlia Ukrainy, Visnyk of the National Bank of Ukraine, No. 6, pp. 10-22.

- Roger S. (2010). Inflation Targeting Turns 20. Finance \& Development, Vol. 47, No. 1, IMF, Washington D.C.

- Schaechter A., Stone M., Zelmer M. (2000). Adopting Inflation Targeting: Practical Issues for Emerging Market Countries, Occasional Paper, No. 202, IMF.

- Woodford M. (2003). Interest and Prices: Foundations of a Theory of Monetary Policy. Princeton University Press, Princeton. 


\title{
INFLATION TARGETING EXPERIENCE: LESSONS FOR UKRAINE
}

\author{
David Vavra' \\ OG Research, Ltd.
}

\begin{abstract}
In the past three decades, many advanced market and emerging market economies have modernized their monetary policy frameworks. We research the experience of these economies for lessons relevant to the monetary policy in Ukraine, which has recently embarked on a similar modernization program. Most countries we study have adopted some form of inflation targeting, given unfavorable experiences with previous regimes based on money and exchange rate, however with the exchange rate continuing to play an important role. Most of the pillars of effective IT monetary policy developed over time through determined efforts led by central banks, and the initial conditions did not matter for success. Countries have experienced numerous challenges with regards to communication, credibility, policy transmission, and fiscal dominance. Overcoming these challenges gave rise to new practices, which now form the state-of-the art monetary policy, irrespective of whether it is called an IT regime. A general lesson for Ukraine (as well as other future modernizers and IT adopters) is that determination and speed in building the pillars of IT policy is paramount for success and credibility of the new framework.
\end{abstract}

JEL Codes: E58, E52

Keywords: inflation targeting, monetary policy, inflation targets

\section{Introduction}

In the past three decades, many advanced market ( $A M)$ and emerging market (EM) economies have modernized their monetary policy frameworks. Their experience during the modernization process offers valuable lessons for countries that are considering improving their own policy frameworks, such as recently Ukraine. In this study, we aim to consolidate the experience of previous transitions of monetary policy regimes by studying and summarizing the steps undergone, the challenges faced and the measures undertaken to overcome these challenges.

Such evidence, we hope, will provide useful inspiration for the Ukrainian authorities. The monetary policy in Ukraine is right now at a critical juncture of choosing a new nominal anchor for the future after floating the currency under pressure in 2014. The National Bank of Ukraine (NBU) has in the past two decades tried to achieve or contribute to a number of objective, including low inflation, stable and predictable exchange rate, sound financial and banking system, and sustainably growing economy.

There have always been good reasons for aiming at these various objectives. For instance, a stable value of the currency in a highly dollarized economy is an important anchor for public's expectations, guiding their production, saving and investment decisions. Volatile inflation hurts socially most vulnerable parts of the society, in addition to obscuring the real value of transactions, increasing uncertainty and inhibiting the investments by increasing risk premiums.

Unfortunately, the NBU has struggled in attaining any of these objectives. Inflation has fluctuated from minus 1 to more than 30 percent (excluding 2014, 2015 episodes) and growth rates varied from minus 15 to more than 12 percent. The exchange rate moved on several occasions, in the long-term changing its value more dramatically than many of the floating currencies during the same long-term period. The financial and banking system all but collapsed during in the aftermath of the global financial crisis. In the period up to the crisis, the dollarization of the economy was increasing continues to be significant.

${ }^{1}$ I thank Botir Khan and Bi Ran for helpful comments and discussions. 
It turns out that many of the countries included in this survey have shared a similar experience and were likewise struggling to find a way forward. Their experience could therefore usefully be considered by the monetary authority in Ukraine, when making the strategic choices for the forthcoming period.

We find that most countries, which have transitioned previously, have adopted some form of inflation targeting (IT), given unfavorable experiences with previous regimes. Before the start of the process, they targeted both money and exchange rate. Policy transparency and accountability were absent and almost nothing was known of transmission mechanisms. These countries have chosen inflation as the nominal anchor and the pace of transition depended on the timing as well as market conditions. Most of the pillars of effective monetary policy were developed over time and the initial conditions did not matter for success. Countries have experienced numerous challenges with regards to communication, credibility, policy transmission, and fiscal dominance.

The rest of the paper is organized as follows. The next section discusses the beginning of the modernization process, while the next sections concentrate on the process management, including the conditions that make the modern monetary framework effective, challenges during transition and the ways to tackle such challenges. Finally, we summarize the performance of IT countries and conclude.

\section{Why did these countries decide to change their frameworks?}

In general, the transition to more effective monetary policy frameworks was motivated by unfavorable experiences with nominal anchors in terms of the exchange rate and money, as well as a desire to lower the rate of inflation and to anchor inflation expectations through a simple observable target variable.

The initial frameworks would typically share some of the following features:

- Intermediate targets in terms of money and/or exchange rates. Typically the authorities would follow both the exchange rate and money targeting, which was certainly the case in most EMEs, but also in many developed economies (especially those in the EMS). Only some, especially developed economies such as US and Canada, would work only with monetary anchors.

- Operational framework based on base money or free reserves, occasionally interest rates. The EMEs would usually set volume based operation targets (with some exceptions, such as Israel), while the experience of the developed economies was more diverse and some used interest rate as operational targets (e.g. Canada and US).

- Unclear separation of monetary and fiscal policies. The concept of monetary policy autonomy was not clearly established de facto and often not even de jure. While some developed economies (US, Germany, Canada) had very independent central banks, elsewhere autonomy came more gradually. For instance, in Great Britain the de facto and de jure policy independence was only established in the second half of 1990s (Freedman and Laxton, 2009). Similar situation also existed in Columbia where the first inflation targets were announced in early 1990s by the Minister of Finance and no autonomy in the design and execution of monetary policy existed (Hamann et al., 2014). In many EMEs monetary policy often worked under the shadow of fiscal policy and political pressure to keep interest rates low to help contain rising public debt (and often also to finance politically important projects). This was also de facto the case in many transition EMEs, in which de jure central bank independence existed early on thanks to newly adopted central bank laws modeled on best practices (Batini and Laxton, 2006).

- Little policy transparency and accountability. Communication policy could loosely be characterized as keeping "the press out of the bank and the bank out of the press" (Blinder et al., 2008). In many cases this reflected the lack of autonomy or authority to conduct monetary policy by the central banks. In others, the opacity was given by the choice of monetary intermediate and operational targets, whose changes were difficult to communicate transparently, and also perhaps from a belief that surprise policy moves are more effective. Regular explanations of policy actions in inflation and monetary policy reports and press briefings would be unusual. ${ }^{2}$

${ }^{2}$ The term "Inflation Report" was coined by the Bank of England in mid 1990s as a compromise reflecting the fact that the Bank did not have the authority over monetary policy at the time 
- Little knowledge about monetary policy transmission mechanism and workings of the real economy. Only large developed economy central banks would have macroeconomic models with worked out transmission channels (often backward-looking) and invest in the macroeconomic analysis as a tool for policy guidance (Freedman and Laxton, 2009). Given the emphasis on monetary intermediate targets, monetary theories of inflation would play an important role in policy setting. Most analytical activities in EMEs would consist of liquidity forecasting and financial programming as a basis for setting the intermediate and operational targets (Capek et al., 2003).

In developed countries the main motivation for a change was the drive to reduce inflation (Canada, US) in the environment, in which money targets have lost their anchoring power and some countries lost the ability to keep fixed exchange rates under market pressure (UK) (Freedman and Laxton, 2009).

In EMEs the problems with previous regimes often stemmed from a pursuit of a number of different intermediate, as well as operational, targets (Otker-Robe and Vavra, 2005). The inconsistencies among these targets became exacerbated by rapid capital flow movements, as the international financial markets became more integrated and these countries had liberalized their capital accounts. The problems were especially acute in smaller EMEs, in which the pressure to sterilize capital flows put money supply out of control, putting pressure on the exchange rate and exacerbating internal imbalances (Columbia, Czech Republic, Hungary, Serbia).

In several EMEs the link between money and inflation was falling apart or monetary targeting (often under IMF tutelage) was considered to have contributed to unnecessarily deep recessions (Philippines). In others, the stability of monetary relationship provided an anchor, which companied the transition to a more effective policy framework for some time (Columbia, Indonesia).

In most cases (both EM and AEs) the transitions were orderly and gradual, while in a few others disorderly and under market pressure. In some cases they were planned arising from a conscious decision to transit to a different monetary anchor, elsewhere they just evolved from the previous regimes. For instance, in Israel, Columbia and Chile inflation targets were put in place initially to support crawling ER bands. In Romania and Hungary, they arose against the need to achieve inflation convergence of the EU integration criteria. In Canada, the transition to inflation reflected the need to anchor inflation expectations in face of specific shocks (Freedman and Otker-Robe, 2009).

Some countries started the process following a currency or general economic crisis (Czech Republic, Brazil, Indonesia, Thailand, and Uruguay). In other cases the process was better planned and individual steps were taken in a planned sequence (Poland, Israel, Chile). In some, we see both the crisis and plan elements together, with the crisis acting as a catalyst of a planned process (Turkey).

Some elements evolved independently, others were more sequenced. For instance, the intention to steer (a loose form of targeting) market interest rates, rather than set volume based operational targets derived from intermediate money targets, emerged very early in many of these countries, irrespective of the regime. On the other hand, changing the communication practices and increasing policy transparency took place in tandem with adopting inflation targeting regimes and strengthening the analytical frameworks.

In summary of the country experiences, it appears that the nature of the trigger did not matter for success. However, it affected the sequencing and speed of implementation of elements of more effective monetary policy. In particular, the crisis trigger transitions often forced accelerated development of inflation as an alternative anchor with all the supporting elements, although the sequencing would not always be as optimal and planned as in the economies transiting more gradually for other reasons than a crisis.

\section{What new frameworks did the countries choose, given their specific circumstances?}

Ultimately, most countries strengthening their policy frameworks ended up with some form of Inflation Targeting, however very few would qualify for what we label a "full-fledged" inflation targeting. Indeed, especially among the EMEs, the exchange rate has retained a "special status" until these days. In practically all countries it has remained an important instrument/ operational variable. In many it has not yet lost its role in anchoring expectations, although it ceased being an official intermediate target many years ago (Georgia, Serbia, Armenia, Russia). The latter is especially true for highly dollarized economies (Roger et al., 2009; Stone, 2003).

The exchange rate consideration played an important role in the choice of the intermediate target and nominal anchor. The choice of the countries without an exchange rate anchor, i.e. mostly advanced economies, was more deliberate and less constrained than those with an exchange rate anchor (most EMEs). Initially, these advanced economies chose inflation as the 
new anchor, considering it a better conduit to achieving price stability (New Zealand) and disinflation objectives (Canada) than monetary targets. Other advanced economy central banks (e.g. the FED and ECB) embraced the principles of inflation targeting following good experience of the early adopters.

For the countries, which had started off with an exchange rate anchor the choice of the intermediate target reflected closely the ability to deal with a fear to float and the speed of embracing exchange rate flexibility (Israel, Poland, Hungary). Ex rate targets often accompanied the transition process for many years and monetary variables to some extent too (ECB, Armenia, Uruguay).

During the transition process, the exchange rate (and to a lesser extent monetary targets) were being transformed from intermediate targets and anchors to important transmission variables and instruments. The process reflected a growing emphasis on reducing inflation as compared to other goals (e.g., competitiveness), as the long-term priorities for monetary policy shifted, but also the comfort the authorities would feel in understanding the analytics of an inflation-interest rate framework. Flexible exchange rates helped absorb the impact of the inflows and let the authorities set interest rates at levels consistent with inflation targets. Reduced implicit exchange rate guarantees also helped limit incentives for speculative inflows. This process was faster in countries, which exited from a fixed exchange rate arrangement abruptly and under stress (Czech Republic, UK).

The countries experiencing an exchange rate or balance of payments crisis would typically all choose inflation as the alternative target soon after the crisis, following monetary targets in the meantime. This is especially true of the transition EMEs, but also several developed economies would adopt inflation targeting soon after the collapse of their fixed exchange rate arrangement, e.g. UK or Spain. A direct focus on inflation seemed the only viable alternative to quickly establish credibility in these countries (Turkey, Czech Republic).

\section{How did they start the process and put conditions and the principles for and effective IT in place?}

In many cases the process of putting in place the elements of an effective IT policy framework evolved over long periods, sometimes lasting close to a decade. This is especially true for EMEs transiting to more modern policy frameworks in 1990s (Poland, Czech Republic, Brazil). The countries transiting in 2000s in general took less time to implement some of these elements, which may reflect both the fact that the state-of-the art was better known (than in 1990s) as well as the benefits of learning from the previous experience of the first wave countries. This is certainly the case of Serbia, Georgia and Moldova, which were able to put in place these elements very quickly, sometimes in a matter of months or only a few years.

Most theoretical literature studying conditions facilitating a transition towards more effective monetary policy frameworks examines the issue from the perspective of countries transiting to some form of inflation targeting (Carare et al. 2002, 2003, Batini et al., 2005). There are a number of different versions of conditions conducive to a smooth transition to modern monetary policy frameworks, and more specifically to IT. According to one classification (Batini et al., 2005) these are:

- institutional independence (full legal autonomy, lack of fiscal dominance, operational CB independence, fiscal balance,...);

- financial system health (capitalization of banks, stock and bond market development, FX mismatches, ...);

- well-developed technical infrastructure (data availability, systematic forecast process, models for conditional forecasts);

- economic structure (ER pass-through, dollarization, trade openness, sensitivity to commodity prices,...).

Other classifications tend to emphasize less the "exogenous processes", such as the financial system health and the economic structure, and sometimes bring in the initial macroeconomic balance as an additional consideration (Carare et al., 2002). In summary, the empirical literature finds overwhelmingly that no country transiting to Inflation Targeting had all elements considered useful for a smooth transition fully in place prior to IT adoption (Batini et al., 2005). Predictably industrial country ITers fared better in "fullfilling the conditions" at the start of their transition than emerging markets ITers (with Canada probably only one satisfying most of the conditions or coming close to it).

In particular, the future ITers had shared the following features at the beginning of their transitions:

- little or no forecasting capability and no forecasting model; EMs often had bad data;

- most scored poorly on financial and banking system health, but had a relatively favorable capital and open foreign currency positions; 
- most enjoyed some institutional independence in the form of lack of fiscal dominance and instrument independence, however legal independence was often circumscribed;

- many countries also kept a dual anchor (e.g. Hungary, Poland, Island). This is partly true also of the ECB, which (although not an ITer) pursues the principles of modern monetary policy and officially has followed both inflation as well as monetary aggregates;

- countries also scored poorly in terms of legal independence of the central bank and in having ineffective policy transmission dominated by the exchange rate channel.

As for the conditions that seemed to have been in place at the outset of the transition in a majority of countries and which the literature generally assumes as the critical set of conditions, which is good to have before the process of strengthening monetary policy framework can begin:

- inflation target, relatively generously defined (price stability mandate);

- central bank's control over its own balance sheet (while some other forms of fiscal dominance may have been present);

- instrument independence and certain effectiveness of its implementation;

- a functioning of spot FX market, and some financial system capacity to manage FX risk.

The IT country cases show that conditions make the transition easier, but are not a show stopper. More generally, many of these conditions are in fact characteristics of a well-functioning effective monetary policy regime. The process of putting them in place is therefore tantamount to making the new policy regime more effective and credible.

In general, it appears that not having all the desirable arrangements in place at the outset of the transition process is not an impediment to the performance of the regime. Literature shows that "Preconditions" do not make much difference in explaining the improvement in macroeconomic performance in terms of inflation, output growth and their variability under IT (Freedman and Otker-Robe, 2010). It appears that it was more the resolve and speed of implementing the conditions rather than their initial level, which mattered for the performance of the regimes. Indeed, in many countries adopting an inflation targeting regime, it appears the causality ran from the adoption of an IT regime to the satisfaction of the supporting conditions rather than the other way round.

The literature also finds that the improvements in the conditions achieved by the transiting countries (notably in technical infrastructure) significantly outpaced the speed of similar developments in non-transiting countries (Batini and Laxton, 2006). This lends credence to the assertion that the resolve to transit has a positive effect on the speed of the adjustment (Freedman and Otker-Robe, 2010).

\section{How did they manage the transition/modernization process?}

Sequencing of the steps in building the elements of effective monetary policy was an important factor in the durability of the transition and the macroeconomic performance. Although establishing each element of effective monetary policy took often many years, in general the sequencing looked as follows:

- Basic elements of policy and instrument independence exist and the central bank has a control of its balance sheet. Although the fiscal position may be unsustainable and other forms of fiscal pressure exist, the central bank has enough autonomy to decide which instruments to use and authority to promote the financial market development.

- Some elements of interest rate targeting appear together with allowing for some exchange rate flexibility. Many countries understood quite early in the transition the benefits of interest-rate based policy and the necessity to allow for some exchange rate flexibility. The latter would often be triggered by operational practicalities, but soon would become a necessity given the desire to implement policy through changes in interest rates.

- Efforts to stimulate the development of financial markets (domestic debt market, FX spot and forward markets, sometimes FRA market) begin, sometimes in steps with financial account liberalization. Allowing for some exchange rate volatility would soon trigger the process of building FX markets and become a spur to FX risk management capacities. The second most important institutional element in this phase was the regular issuance of fungible government debt, without which the local currency yield curve could not develop, thus undermining the role of the interest rate transmission channel. The development of the FX derivative and FRA 
markets would also take place in some countries at this stage, putting pressure on the central bank to become more transparent about its policy course. ${ }^{3}$

- Exchange rate flexibility is gradually increased. Market pressure sometimes forces a fast exit, often in connection with liberalizing the capital flows. The forces of the impossible trinity and increased capital account liberalization gradually increase the need for more exchange rate flexibility. In the countries following simultaneously inflation and exchange rate targets, the conflicts between the two would require relaxing the exchange rate target. However, ideally the liberalization of the capital account would come in a well-planned sequenced (see later). The countries, which liberalized the capital markets too quickly (e.g. the Czech Republic in 1996 or Israel and Chile in 1970s) would become hostage to the volatility of the external financial flows, often triggering financial crises and disorderly exits from pegs (Czech Republic).

- Inflation as the alternative anchor is chosen and first targets announced, often for the short-term and sometimes coexisting with the exchange rate anchor. Inflation as the alternative anchor starts appearing in this stage either out of necessity after a crisis-driven exit from the peg, or out of considering alternatives for the increasingly looser exchange rate anchor.

- A broad monetary policy independence and autonomy (including the role in the exchange rate regime) is being established. The concepts of operational, financial and personal independence of the central banks are established and legally sanctioned. The central banks sometimes get the target autonomy (or share it with the government) and authority over the exchange rate regime. ${ }^{4}$

- Analytical capacities and communication strategy develop. After inflation is chosen as the alternative anchor, the central banks work on putting in place the necessary institutional elements, including more central bank independence, transparency and accountability, and analytical forecasting capacities. The latter would often take several years to develop.

- Medium-term inflation targets are announced and ex rate anchor is finally abandoned. The exchange rate often continues to play a more important role than a mere instrument or a transmission variable, leading to the development of a specific FX intervention strategy.

However, the evidence also shows that this particular sequencing was not ideal. In particular, earlier investments in communication and analytical capacities could have contributed to a smoother transition and faster build-up of credibility. For instance, the absence of the analytical capacities led to short policy horizons, increasing macroeconomic volatility and undermining the credibility of the process. In several cases, having adequate communication tools would have helped achieve a general public consensus on the transition process earlier. In that respect it also appears that the choice of inflation as the alternative anchor could have been made faster. ${ }^{5}$ Finally, the evidence also reasons against a premature financial account liberalization, which should in general follow (rather than precipitate) greater exchange rate flexibility.

In summary, an idealized sequence could look as follows:

- Inflation is chosen as the nominal anchor and communicated (at least in the form of a medium-term inflation target).

- Some elements of interest rate targeting appear together with allowing for some exchange rate flexibility. Efforts to stimulate the development of financial markets (domestic debt market, FX spot and forward markets, sometimes FRA market) begin.

- Exchange rate flexibility is gradually increased, followed by financial account liberalization.

- The market interest rate becomes the main operational variable, the role of reserve requirements and other instruments declines. Analytical capacities and communication strategy develop, focused on the setting of the key policy rate as the main instrument. The decision making process is being adjusted accordingly.

\footnotetext{
3 Allowing foreign investors to participate in the development of the financial markets was an important positive element in these developments, as they served as conduits of good standards, added market liquidity and provided transaction counterparties in otherwise one-sided markets.

4 The central banks of Mexico and the Czech Republic (for a certain period) have enjoyed full target autonomy, otherwise the cases of central bank's full target autonomy are relatively rare.

${ }^{5}$ Colombia's experience shows in particular the importance of announcing the target as a part of the new price stability framework. The failure to do so contributed to the extremely low credibility of the new anchor and framework (Gomez et al., 2002).
} 
- Annual or continuous inflation targets are announced (and not revised) and the exchange rate anchor is being suppressed (e.g. widening bands), but the exchange rate continues to play a more important role than a mere instrument or a transmission variable, leading to the development of a specific FX intervention strategy.

- The exchange rate anchor is finally abandoned and the exchange rate continues as a supporting instrument strengthening the transmission of the interest rate as the main instrument, when needed.

The central banks played a vital role in initiating, spearheading and managing the transition. They would initiate the dialogue with the governments, take an active approach in changing the legal environment, work with opinion groups and lead interagency task forces coordinating the steps in individual areas. They would also play a very important role in the financial market development by managing liberalization, promoting good standards and codes of conduct as well as helping to establish the market technical and legal infrastructure. In later stages they would enact regulatory measures promoting the development of the local currency markets and instruments, and reducing dollarization (Serbia, Georgia, Turkey, Peru, Russia and Moldova). In several countries, the central banks were the major force behind a regular T-bill issuance at benchmark maturities and sufficient volumes to facilitate the market development (Macedonia and Thailand).

\section{What challenges did they facing and how did they manage/ overcome them?}

\section{Perceived lack of credibility}

Much of the delays experienced during the transition were linked to a perceived lack of credibility of the new policy and anchor (Turkey). The capacity to forecast and hit inflation targets was considered low, and the authorities were wary of the effects target misses may have on the nascent regimes. In several cases, the initial inflation targets were missed by a wide margin, causing sometimes a public backlash at the central bank's strategy (especially when linked to a recession, as in the Czech Republic in 1999) and vindicating a more cautious approach in other countries. In other cases, also in the advanced economies, the fiscal situation was precarious, limiting the room for the monetary policy maneuvering and often causing overly high real interest rates and macroeconomic volatility (Brazil, Turkey, Canada, United States).

As a result of the perceived lack of credibility many countries tended to "over-prepare", sometimes waiting too long before they considered themselves well prepared and at an opportune moment. Sometimes, such a moment never came (Ukraine).

The fear of undermining the nascent regimes also advocated the focus on narrower inflation indices, typically ignoring the volatile components, such as foods, and regulated prices. At the same time, the central banks would work out an elaborate list of "escape clauses" exonerating them from meeting inflation targets under specific ex ante (or ex post) circumstances. The communication challenges involved were gargantual, and both strategies eventually backfired. Ignoring volatile foods may have resulted in better forecast accuracy, but hardly endeared the regime to the population, whose consensus was important for restoring credibility. The system of escape clauses obfuscated the workings of the regime, which should have been built on clarity and transparency. As such, most countries gradually switched to targeting headline inflation and abandoned escape clauses during in 2000 s.

Also for credibility reasons, the central banks would initially refrain from using long-term inflation targets before realizing the importance this has for anchoring expectations. Most EMEs would start with short-term inflation targets, sometimes revised every year (Indonesia, Ghana, Serbia). Some relatively established ITers would even revise their targets upwards in an effort to keep credibility in the face of durable shocks (Turkey, Brazil). However, these practices are generally not considered as credibility enhancing and most countries would gradually converge to relatively constant levels of medium-term inflation targets (SchmidtHebbel and Werner, 2002).

The fear of insufficient credibility was especially acute in countries, which had suffered a currency crisis forcing them off their pegs. The sharp exchange rate depreciation, the absence of an inflation anchor, and the memories of high inflation periods fueled fears of a return to hyperinflation. Some responded by hastening the adoption of a new regime, while the others by returning (at least temporarily) under the shelter of a monetary and exchange rate target (Uruguay, Czech Republic).

\section{Fiscal dominance}

Gaining de jure and de facto the control over its own balance sheet was one of the most important preconditions for the transition process to start (Freedman and Otker-Robe, 2010). However even with a control over the balance sheet, the room for effective monetary policy in macroeconomic stabilization remained limited, as long as it remained constrained by market fears about fiscal sustainability, external balance or both (Turkey, Brazil). 
These fears gave rise to various endogenous premiums, which limited the effectiveness of monetary policy actions. For instance, an increase in interest rates in response to an inflation shock would provoke an increase in the currency premium for a fear of effects on fiscal sustainability (Ghana, Serbia). Likewise, an effort to stimulate economy by cutting rates may backfire, when the external balance is hit by a rapid capital outflow (such as in many Latin American external crises of the past). Fearing such outcomes, the monetary authority's reaction in many cases would have been muted. The "fear of float" is one of the most prominent examples of such concerns, which would slow the transition process (Schmidt-Hebbel and Werner, 2002; Ramos-Francia and Garcia, 2005). However, even the experience of industrialized countries, such as Canada in early 1990 s or US in early 1980 s shows how real interest rates were unnecessarily pushed up by a lack of support of fiscal policy to disinflation (Freedman and Otker-Robe, 2010).

Such considerations sometimes gave credence to arguments that, in addition to eliminating fiscal dominance, a country should have a sound fiscal position before the start of a process of implementing inflation targets (Carare et al., 2002; Masson et al., 1998). In fact, the evidence from industrialized as well as some EMEs shows that the adoption of more effective monetary policy preceded structural improvements in fiscal policies or went hand in hand (e.g. Columbia) (Tapsoba, 2010). Interestingly, Batini et al. (2005) examining a sample of 13 EMEs, finds the fiscal position before inflation targeting adoption or the absence of fiscal improvement after adoption does not seem to affect the regime's ability to deliver lower and stable inflation.

The experience of Israel is particularly interesting in this respect, as there seems to have been a positive feedback-loop from the benefits of a forward-looking monetary regime to fiscal discipline. The IT regime facilitated the development and lengthening of the yield curve, which in turn paved way for the development of local currency mortgage market. The mortgage market, affecting the majority of population, is particularly sensitive to fiscal policy, which thus became more disciplined for political reasons. According to some observers, it is not a mere coincidence that political cycles ceased to an issue in Israel around the time, when the IT gained credibility.

\section{Ineffective policy transmission}

An ineffective policy transmission (factual or perceived) dominated by the exchange rate channel in the environment of underdeveloped and dollarized financial markets and significant extent of price regulation would exacerbate the credibility problems, especially in the emerging market economies.

The policy transmission was often deemed dominated by the exchange rate channel (also in some AEs, such as New Zealand). Indeed, the exchange rate pass-through to inflation and sometimes to output (via exports) was very strong in the initial transition stages in most (and especially small open) economies. Further complication would often arise from a significant portion of regulated prices in the CPI basket, sometimes prompting the central banks to target narrower price indices - a strategy that would later found unproductive and abandoned.

The absence of domestic financial markets was further limiting the use of the interest rate policy. Financial stability issues of unhedged FX positions of private and public sector balance sheets advised caution vis-à-vis abrupt exchange rate changes. For instance, in Hungary in between 2008 and 2013 around two-third of household loans were denominated in the Swiss franc and FX loans were also widespread among SMEs. The central bank was afraid of the vicious circle (experienced also during the South-East Asian crisis in 1997-1998), when a sharp exchange rate weakening led to increase in default rate of $\mathrm{FX}$ borrowers turning the balance of payments crisis into a banking crisis. Therefore, in addition to inflation targeting monetary policy attached high importance to exchange rate level implicitly in its decision making and communication. This only changed after 2013 after housing FX loans were administratively converted into the local currency.

However, a gradual build-up of the pillars of modern monetary policy was found to be rapidly changing the transmission process. Indeed, according to many studies the exchange rate pass-through has declined substantially in a vast majority of IT countries over time (Baqueiro and others, 2003; Coulibaly and Kempf, 2010). This was a result of a strengthened policy framework with more systematic and predictable policies as well as a product of efforts to build stronger domestic financial markets and reduce dollarization (Chailloux et al., 2010).

The central banks played an important role in the process of creating and strengthening domestic financial markets. In the early transition stages they played a key role in setting standards of market based transactions in money and FX markets, promoting unification of trading platforms, instituting master repo agreements, promoting the establishing of the reference rates and market infrastructure in general. In later stages they would enact regulatory measures promoting the development of the local currency markets and instruments and reducing dollarization (Serbia, Georgia, Turkey, Russia, Moldova). Some of them would embark on dedicated campaigns of reducing dollarization (Hungary, Serbia, Georgia). 
In several countries, the central banks also played an important role in convincing the governments to start issuing domestic debt at benchmark maturities with adequate volumes - a key condition for the development of local currency markets.

Strengthening policy transparency through external communication has also been found instrumental in overcoming the issues with credibility and policy transmission. The efforts to increase accountability and transparency through regular communication events, such as Inflation Reports and press events, became a ubiquitous part of a monetary policy toolkit, gradually strengthening the credibility of the new regimes.

These efforts were guided by the objective of improving the predictability of the key policy rate as the benchmark rate in the local money market. The central banks working on policy transparency learned over time that admitting to own mistakes can foster the accountability and improve the credibility of its policy strategy. At the end of the day, it mattered more that the markets could well understand how the central bank will behave under particular circumstances and when it realizes its mistake.

The key elements of this communication approach involved: i) communicating that inflation forecast always goes to target eventually but with uncertainty, which does not explode over time, ii) communicating (verbally or explicitly) the expected future trajectory of the key policy rate, iii) holding regular (quarterly) meetings with financial market analysts, (iv) strengthening the role of the inflation report as the main communication vehicle and making it more forward looking, and (v) establishing a firm cycle of communication events following each policy decision making meeting according to a pre-announced calendar (such as, decision press release, press-conference, minutes, Inflation Report, events with specific audiences and journal articles).

If successful, such communication a cycles and elements would help make policy predictable by communicating policy preferences and future policy actions, and, in this manner, giving a fair idea of the policy reaction function. At the same time, the communication initiatives were instrumental in receiving a useful feedback, and also helping to improve the analytical apparatus.

While in the past the central bank's communication channels would mostly be used as a source of data, during the transition the emphasis began to be put on the text explaining the policy actions in terms of the objectives, explaining the mistakes and outlining the strategy of achieving the objectives in the future. The texts would evolve from large compendia (100+pages) of essentially statistical descriptions to relatively short, forward-looking messages, using plain language, with policy accountability and predictability as the main objectives. The Inflation Report in particular became the main vehicle in regular policy communication, emphasizing the target performance and providing a fair idea of a future policy course under particular circumstances.

Launching such a broad communication strategy would often also put extra pressure on good coordination of the many communication channels to achieve consistency and avoid over-communication. It would often require more resources in the communication departments and streamlining their organizational underpinnings. While before the transition many banks would feature just a press-service unit in the Governor's secretariat and a spokesperson, in the end the communication activities would typically concentrate in one department directly subordinated to the Governor.

\section{Multiple objectives and targets revisions}

For countries gradually abandoning the exchange rate anchor, the simultaneous pursuit of multiple objectives, especially the exchange rate and inflation, was a major challenge (Hungary). While such a situation was relatively manageable under closed capital accounts and in a slow growth environment, rapid capital flows tested the consistency of the regime soon after the local financial markets have been liberalized and/or more integrated into the world financial markets.

The experience of many countries shows that it is important to distinguish between the exchange rate as an additional intermediate target (in addition to inflation) and as an instrument of achieving an inflation target (and/or other objectives). While the former practice was not sustainable in the long-term and was difficult to manage, the latter continues to be practiced by many EM and AEs and gained special importance in the wake of the financial crisis.

During the transition process almost all EMEs experienced periods of two explicit intermediate targets: inflation and the exchange rate (Poland, Israel, Chile, Hungary). This practice would eventually lead to conflicts among these two targets. Those countries, which speedily sought to resolve these conflicts in favor of inflation (such as Israel and Poland) would see a gradual abandoning of the explicit exchange rate targets in a relatively smooth transition process. The countries, in which the priority would not be clear or fluctuate over time (such as Hungary or Chile in the early transition period), would face difficulties in establishing the regime's credibility. For instance, Chile was initially using past inflation rather than the inflation target in setting the rate exchange rate crawl, making the inflation targets almost impossible to achieve in the long-term term. In Hungary, monetary policy would occasionally loosen policy in order to defend the exchange rate band, while inflation was well above the target, eventually forcing an abandonment of the exchange rate bands. 
A related challenge was the management of implicit exchange rate targets, either factual or perceived. In many EMEs transiting to flexible exchange rate regimes, the exchange rate remained an important implicit target variable - or was perceived such by the markets and the public. This would enormously compromise the regime's credibility. The countries affected included Turkey (before the full-fledged IT was adopted in 2005), Russia, Georgia and Serbia among others. In many countries, the interventions against "excessive exchange rate volatility" would also fall under this category and would often be misused for affecting the exchange rate levels and thus further undermine the credibility of inflation as the new durable anchor.

Even when the exchange rate anchor was durably abandoned, many countries struggled in finding the right role for the exchange rate during and after the transition. The exchange rate often remained more than "a normal transmission variable", which deserves little more than casual monitoring. Many countries continued to intervene in the markets frequently, others labored over complicated intervention strategies in an effort to make their involvement in the FX market transparent.

Out of this struggle, two strategies emerged. One sought a refuge in austerity limiting its discretion to establish "credibility through principles" (Czech Republic). In others, discretion was encouraged as a way of dealing with practical short-term issues, which could have otherwise thwarted the modernization efforts (Georgia, Serbia). This eclectic approach saw the establishment of various forms of "light" IT regimes (Stone, 2003), not as a stepping stone to a full-fledged IT, but as a goal in itself (Goldstein, 2002; Freedman and Otker-Robe, 2010). Such an approach is typically characterized by having an explicit inflation target, FX interventions to smooth market movements, but not fighting fundamental shifts, and no FX targets. The interest rate policy is primarily used to target inflation, but on the margin the exchange rate consideration is also important.

On the other hand, the exchange rate remained as an instrument also in the arsenal of relatively well established full-fledged IT central banks - even if rarely used. For instance, Poland, the Czech Republic and Israel abandoned foreign exchange interventions for many years, but reactivated them again during and after the financial crisis as a supporting tool to interest rates in achieving the inflation target and restoring the economy to growth. So did Switzerland.

While for these economies, the recourse to interventions was communicated as temporary, a few other countries subscribe to these practices as a long-term strategy. For instance, Columbia works on the assumption that the interest and exchange rate instruments work through different transmission channels and thus monetary policy can be more effective when both are combined. Similarly, Israel applied two instruments with two objectives strategy for a while during 2008 and 2009.

However, these practices seem to differ from the long-standing "golden rule" of using FX interventions in IT regimes, i.e. to use the interventions in the same direction and after the interest rate moves (Holub, 2004). The main challenge in this approach is to communicate the difference between using the exchange rate as a target and an instrument, and how to execute and exit from a durable exchange rate intervention program. The Czech Republic was relatively successful by making sure the execution fulfills all the elements of Inflation Targeting, while some other central banks (Switzerland, Israel) faced considerable difficulties, perhaps owing to communication inconsistencies and unclear role of the interventions in the regime.

Another recently prominent policy issue is the coordination of monetary and financial stability policies. Various financial stability issues, including the quantity of money and asset prices, interact with monetary policy and may require a specific policy action, which may not always coincide with the desired monetary policy stance. For instance, very low inflation is likely to lead to low interest rates, which may exacerbate the financial sector imbalances and precipitate asset price bubbles.

While financial stability is a relatively new field, gaining prominence in the aftermath of the global financial crisis, the experience of many emerging market economies demonstrates that financial stability concerns should not come at the expense of undermining the primacy of the medium-term inflation objective. Any significant erosion of the central bank's credibility can unhinge inflationary expectations, with related undesirable effects on real activity and financial stability. What is crucial is to maintain a clear hierarchy of objectives with price stability being the primary objective. When price stability credibility becomes entrenched, the monetary authority gains more room to meet other objectives while not impairing price stability. Moreover, the experience shows that monetary policy is a blunt and relatively ineffective instrument for promoting financial stability. Instead, macroprudential tools should serve as the first line of defense in mitigating emerging financial imbalances, and monetary policy adjustments should only be deployed as a last resort.

Indeed, over the long-term financial stability concerns are generally complementary to the goal of price stability. For instance, a focus on inflation objectives with a credibly flexible exchange rate helps the development of financial markets by making the short term interest rate trajectory more predictable and therefore useful for pricing of longer-term financial instruments in the domestic currency. It also reduces incentives for saving and pricing in a foreign currency, thus reducing the dollarization of the economy, FX currency mismatches on private and corporate balance sheets. Especially in the EM context, the focus on price stability increases the resilience of the financial sector to swings in the exchange rate and capital flows. 
The experience of many LA countries illuminates especially well the importance of prioritizing the inflation stability objective and building capacities in being able to better manage the trade-offs among various objectives. Historically, external crises in the region were usually accompanied by muted and ambivalent monetary policy reactions and often by policy tightening for the fear of currency depreciation and the effects on dollarized balance sheets. The rigidities in the exchange rate regimes provided implicit guarantees to building up FX mismatched positions in the private sector, in turn aggravating the fear of float.

Refocusing policy on an inflation objective accompanied by intensive capacity building during 1990s and 2000s have made many of the LA economies and central banks more resilient to external shocks. During the latest financial crisis, LA central banks were able to cut interest rates to historic lows for extended periods and large exchange rate depreciation helped fight the external shock without engineering bouts of exchange rate speculation as in the past (de Gregorio, 2013). This was a product of strengthening the pillars of effective monetary policy in the recent decades, in particular the focus on price stability, flexible exchange rate and building more resilient financial markets with a capacity to hedge FX exposures. These policies, backed up by strong FX reserve buffers, became credible tools by the time the crisis struck.

\section{Looking at their performances after the transition, are there successful cases or failures that can be identified?}

The general evidence about the performance of IT-like countries across a number of criteria is very favorable, especially among the EMEs, both when examined over a longer period of time as well as during selected historical episodes (Roger, 2010; Batini et al., 2005). In AEs, on the other hand, the effects are generally small and insignificant (Roger, 2010; Ball and Sheridan, 2005; Goncalves and Salles, 2008), suggesting that establishing effective monetary policy frameworks may have greater benefits in less developed economies.

The long-term effects on reducing inflation, inflation and output volatility are significant and robust in most EMEs. Sometimes the benefits in terms of fast disinflation and reduced inflation volatility (without jeopardizing growth) appeared soon after inflation targeting was established (Turkey, Thailand, Indonesia to some extent), elsewhere it came over longer periods.

The IT regimes are especially credited for bringing about durable disinflation, sometimes on a spectacular scale (Turkey). For instance, Batini et al. (2005) surveying a sample of 13 EMEs finds the IT associate with 4.8 point reduction in average inflation, and 3.6 against the alternative regimes. While some of this may be attributable to the great moderation period in general, there seems to be evidence that the disinflation process in IT-like EMEs was independent of this. Inflation expectations declined too, and so did volatility of the exchange rate and the real interest rate (Levin, Natulucci and Piger, 2004).

At the same time, this reduction in inflation does not appear to have come at the expense of output stabilization. The IT-like countries were also found to be better able to fight both high inflation and deflation, reacting earlier and being less prone to boom-bust cycles and financial crises (probably thanks to more flexible exchange rate regime).

Some attribute the difference between the empirically observed benefits of IT in EM and AEs to the change in the credibility that accompanied the transition. While the AE central banks initially started off with a relatively high credibility stock, much of the efforts of the EME central banks during the transition focused on establishing it. This could also perhaps explain why the initial extent of satisfying various conditions mattered little for the overall success of these regimes (Batini at al., 2005).

\section{Food and Oil price shock}

As many of the EMEs countries started their transition in late 1990s, the food and oil price shock of 2007/8 was the first significant common global shock affecting most of the new regimes symmetrically at the same time. The evidence overwhelmingly shows that IT countries managed the shocks better than non-ITers (Habermeir et al., 2009). In general, they reacted faster to the shock and experienced lower inflation increase, although the targets were frequently missed.

The IT central banks understood the nature of the shocks, which allowed them to react faster and more decisively, and also enact policy easing before the shock completely subsided (Czech Republic). Also inflation expectations were found to be better anchored and resilient to the shock among ITers (Czech Republic) than non-IT countries. Among various measures used to contain the shocks, the interest rate based response of ITers was found to be more effective than administrative measures often applied by other countries.

Nevertheless, the shock posed a formidable communication challenge in many IT countries and several were not well prepared to sustain the pressures -- especially those in which the credibility of the regime had not yet been entrenched at the time. As a result, some responded with a target revision (Turkey), in others the process of establishing a full-fledged IT stalled, as the credibility was compromised (Serbia, Armenia). In Ghana the nascent IT regime fell apart during this period. 


\section{Financial Crisis}

The results from the financial crisis are also encouraging in that they show convincingly that the central banks embracing the principles of effective monetary policy gained more flexibility in responding to shocks.

The IT and flexible exchange rate regimes were able to leverage their monetary policy instruments and the flexible exchange rate to combat the crisis more effectively than others. In particular, ITers were able to reduce interest rates more than non-ITers and achieve more effective real policy easing than non-ITers, also because the inflation expectations were better anchored (de Carvalho Filho, 2010). This was especially true of the Latin American countries, where the clear and resolute response to the crisis marked a break from the muted reactions to similar events in the past, when the fear of capital outflows and other credibility concerns dominated the policy reactions. Unlike in the past, no significant adverse risk premium reactions occurred in most of the IT LA countries. The same was true of many Eastern European ITers.

The effects of monetary policy reactions to the crisis on employment and growth are less convincing, though. In part, this is perhaps because the ITers generally tended to have higher rates in the previous boom cycle than non-ITers and thus were better positioned to smooth the slump out. Nevertheless, there appears to be some evidence that the rebound from the crisis was quicker among IT countries and especially so among EM ITers, suggesting that good monetary policy can be more effective in relatively less developed economies.

Some economies were also able to use the credibility they had accumulated previously in designing unorthodox policies to fight deflation (e.g. the Czech Republic using FX commitment, UK). However, other ITers had to seek external assistance (Hungary, Romania, Serbia, Iceland) and in certain cases the regime was not resilient enough to the combined pressure of the world crisis and not yet entrenched credibility (Serbia, Iceland).

\section{The experience of Low and Low-to-Middle-Income Countries (LLMICs)}

The experience of the few LLMICs embracing IT policy principles is mixed. While Albania, Georgia and Moldova have managed to maintain their new regimes under relatively difficult circumstances of the world financial crisis and domestic political struggles, Ghana's progress stalled under fiscal dominance and too much policy discretion applied in the face of inflation shocks, which circumscribed the credibility of the nascent IT regime.

Armenia is pursuing a very eclectic regime featuring the exchange rate and money targets alongside inflation objectives, and the credibility of the regime is not yet entrenched, although it has fared well in the difficult environment of recent years. The exchange rate is an important instrument in the IT regimes of Georgia and Moldova too.

\section{Conclusion}

In the past three decades, many advanced market and emerging market economies have modernized their monetary policy frameworks. We study their motivations, experiences, challenges and factors contributing to success in order to draw common lessons useful for the monetary authorities in Ukraine, which are working to make their monetary framework more effective.

Most countries we study have adopted some form of inflation targeting, given unfavorable experiences with previous regimes based on money and exchange rate, both as intermediate targets and in an operational sense. These countries have chosen inflation as the nominal anchor with the exchange rate continuing to play an important role. Most of the pillars of effective IT monetary policy developed over time through determined efforts led by central banks, and the initial conditions did not matter for success. Countries have experienced numerous challenges with regards to communication, credibility, policy transmission, and fiscal dominance. Overcoming these challenges gave rise to new practices, which now form the state-of-the art monetary policy.

A general lesson for Ukraine (as well as other future modernizers and IT adopters) emerges in that determination and resolve in building the pillars of IT policy is paramount for success and credibility of the new framework. The experiences also show that, if the transition is managed well and proceeds speedily, larger benefits accrue more quickly to relatively less advanced economies with fewer initial conditions for success.

This article has been produced with the financial assistance of the European Neighbourhood Investment Facility.

The views expressed herein are those of the author and can therefore in no way be taken to reflect the official opinion of the European Union. 


\section{References}

- Armas A., Grippa F. (2005). Targeting Inflation in a Dollarized Economy: The Peruvian Experience. Working Paper, No. 448, IDB.

- Ball L., Sheridan N. (2005). Does Inflation Targeting Matter? In: Bernanke B., Woodford, M. (Eds), the inflation targeting debate. The University of Chicago Press: Chicago, pp. 249-276.

- Baqueiro A., de Leon A., Torres A. (2003). Fear of Floating of fear of Inflation? The Role of the Exchange Rate PassThrough in Monetary Policy in a Changing Environment. BIS Papers, No. 19, pp. 338-354.

- Barajas A., Steiner R., Villar L., Pabon C. (2014). Inflation Targeting in Latin America. Working Paper, No. 473, IDB. https://doi.org/10.2139/ssrn.2377644

- Barran F. (2005). Uruguay's Disorderly Exit from Peg to Float. IMF Mimeo.

- Batini N., Kuttner K., Laxton D. (2005). Does Inflation Targeting Work in Emerging Markets? World Economic Outlook, Chapter 4, IMF.

- Batini N., Laxton D. (2006). Under What Conditions Can Inflation Targeting Be Adopted? The Experience of Emerging Markets. Working Paper No. 406, Central Bank of Chile.

- Benes J., Berg A, Portillo R., Vavra D. (2014). Modeling Sterilized Interventions and Balance Sheet Effects of Monetary Policy in a New-Keynesian Framework. Open Economics Review, Vol. 26, No. 1, pp. 81-108.

- Blinder A. (1998). Central Banking in Theory and Practice, MIT Press, Cambridge MA.

- Blinder A., Ehrmann M., Fratzscher M., De Haan J., Jansen D-J. (2008). Central Bank Communication and Monetary Policy: A Survey of Theory and Evidence. Working Paper, No. 13932, NBER. https://doi.org/10.3386/w13932

- Capek A., Hledik T., Kotlan V., Polak S., Vavra D. (2003). Historical Perspective on the Development of the Forecasting and Policy Analysis System. Coats, Laxton and Rose (eds.): The Czech National Bank's Forecasting and Policy Analysis System, CNB, Prague.

- Carare A., Schaechter A., Stone M., Zelmer M. (2002). Establishing Initial Conditions in Support of Inflation Targeting, Working Paper, No. 02-102, IMF.

- Carare A., Stone M.R. (2003). Inflation Targeting Regimes. Working Paper, No. 03-9, IMF.

https://doi.org/10.5089/9781451842616.001

- Casta-eda J.C., Castillo C.E. (2005). Supply Shocks in the Transition Towards an Inflation Targeting Reform: An Empirical Evidence for Guatemala. Working Paper, No. 354, Central Bank of Chile.

- Central Bank of Brazil (1999). Monetary policy operating procedures in Brazil. Policy Paper, No. 5, BIS.

- Chailloux A., Ohnsorge F., Vavra D. (2010). Euroization in Serbia. Working Paper Series, No. 2010-120, EBRD.

- Corbo V., Schmidt-Hebbel K. (2001). Inflation Targeting in Latin America. Working Paper No. 105, Central Bank of Chile.

- Coulibaly D., Kempf H. (2010). Does Inflation Targeting Decrease Exchange Rate Pass-through in Emerging Countries? Working papers, No. 303, Banque de France.

- de Carvalho Filho I.E. (2010). Inflation Targeting and the Crisis: An Empirical Assessment. Working Paper, No. 45, IMF. https://doi.org/10.5089/9781451963045.001

- de Gregorio, J. (2013). Resilience in Latin America: Lessons from Macroeconomic Management and Financial Policies. Working Paper, No. 13-259, IMF. https://doi.org/10.5089/9781475550214.001

- Debelle G., Lim G.C. (1998). Preliminary Considerations of an Inflation Targeting Framework for the Philippines. Working Paper, No. 98-39, IMF.

- Duttagupta R., Fernandez G., Karacadag C. (2004). From Fixed to Float: Operational Aspects of Moving Toward Exchange Rate Flexibility. Working Paper, No. 04-126, IMF.

- Eichengreen B., Hausmann R. (1999). Exchange Rates and Financial Fragility. Working Paper Series, No. 7418, NBER. https://doi.org/10.3386/w7418

- Elberg A., Corbo V., Tessada J. (1999). Monetary Policy in Latin America: Underpinnings and Procedures. Cuadernos de Economia, Vol. 109, pp. 897-927.

- Fane G. (2005). Post-crisis Monetary and Exchange Rate Policies in Indonesia, Malaysia and Thailand. Bulletin of Indonesian Economic Studies, Vol. 41, Issue 2, pp. 175-195. https://doi.org/10.1080/00074910500117024

- Freedman C., Lexton D. (2009). Why Inflation Targeting? Working Paper, No. 09-86, IMF. 
- Freedman C., Ötker-Robe I. (2009). Country Experiences with the Introduction and Implementation of Inflation Targeting. Working Paper, No. 09-161, IMF.

- Freedman C., Ötker-Robe I. (2010). Important Elements for Inflation Targeting for Emerging Economies. Working Paper, No. 10-113, IMF.

- Galindo L.M., Ros J. (2006). Alternatives to inflation targeting in Mexico. Available at:

http://www.networkideas.org/feathm/oct2007/pdf/Galindo_Ros.pdf

- Gemayel E.R., Jahan S., Peter A. (2011). What Can Low-Income Countries Expect from Adopting Inflation Targeting? Working Paper, No. 11-276, IMF.

- Goldstein M. (2002). Managed Floating Plus. Institute for International Economics, Policy Analyses in International Economics, No. 66. Washington, D.C.

- Gómez, J., Uribe J.D., Vargas H. (2002). The Implementation of Inflation Targeting in Colombia. Available at: http://banrep.gov.co/docum/ftp/borra202.pdf

- Gonçalves C.E.S., Salles J.M. (2008). Inflation targeting in emerging economies: What do the data say? Journal of Development Economics, Vol. 85, pp. 312-318.

- Gurkaynak R.S., Sack B.P., Swanson E.T. (2004). Do Actions Speak Louder Than Words? The Response of Asset Prices to Monetary Policy Actions and Statements. Working Paper, No. 2004-66, FEDS. https://doi.org/10.2139/ssrn.633281

- Habermeier K., Ötker-Robe I., Jacome L., Giustiniani A., Ishi K., Vavra D., Kışınbay T., Vazquez F. (2009). Inflation Pressures and Monetary Policy Options in Emerging and Developing Countries: A Cross Regional Perspective. Working Paper, No. 1, IMF.

- Hamann F., Hofstetter M., Urrutia M. (2014). Inflation Targeting in Colombia, 2002-2012. Working Paper Series, No. 487 , IDB.

- Hammond G. (2012). State of the Art of Inflation Targeting - 2012. Centre for Central Banking Studies, Bank of England, Handbook No. 29.

- Holub T. (2004). Foreign Exchange Interventions under Inflation Targeting: The Czech Experience. Research and Policy Notes, No. 2004-01, Czech National Bank, Research Department.

- Hurnik J., Tuma Z., Vavra D. (2010). The Czech Republic on Its Way to the Euro: A Stabilization Role of Monetary Policy Revisited. Available at: https://www.elgaronline.com/view/9781849804363.00013.xml

- Hurnik J., Tuma Z., Vavra D. (2010). The Euro Adoption Debate Revisited: The Czech Case. Czech Journal of Economics and Finance, Vol. 60, No 3, pp. 194-212.

- International Monetary Fund (2005). World economic Outlook (Washington, September).

- Josifidis K., Pucar E.B., Srdic S., Ivan G. (2014). Inflation Targeting in Advanced vs. Emerging Economies before and after the Crisis. Panoeconomicus, Vol. 1, Special Issue, pp. 79-106.

- Kubo, A. (2009). Monetary targeting and inflation: Evidence from Indonesia's post-crisis experience. Economics Bulletin, Vol. 29, No.3, pp. 1805-1813.

- Lamberte M.B. (2002). Central Banking in the Philippines: Then, Now and the Future. Discussion Paper Series, No. 2002-10, PIDS.

- Levin A.T., Natalucci F.M., Piger J. (2004). Explicit inflation objectives and macroeconomic outcomes. Working Paper Series, No. 0383, European Central Bank.

- Lim J. (2006). Philippine Monetary Policy: A Critical Assessment and Search for Alternatives. Available at: http://www.peri.umass.edu/fileadmin/pdf/inflation/lim_paper10.pdf

- Martínez G.O. (2008). Inflation Targeting. Available at:

http://www.imf.org/external/np/seminars/eng/2011/res/pdf/go2.pdf

- Masson P.R., Savastano M.A., Sharma S. (1998). Can Inflation Targeting Be a Framework for Monetary Policy in Developing Countries? Finance and Development, Vol. 35, pp. 34-37.

- McLeod R. (2002). Toward Improved Monetary Policy in Indonesia. Australian National University, Arndt-Corden Department of Economics, Departmental Working Paper, No. 10.

- Medina Cas S., Carrión-Menéndez A., Frantischek F. (2011). Improving the Monetary Policy Frameworks in Central America. Working Paper, No. 11-245, IMF.

- Minelli A. (2005). Transition to a Floating Exchange Rate Regime: The Brazilian Experience. IMF Mimeo.

- Mishkin F.S. (2004). Can Inflation Targeting Work in Emerging Market Countries? Working Paper, No. 10646, NBER.

https://doi.org/10.3386/w10646 
- Mishkin F.S., Schmidt-Hebbel K. (2006). Monetary Policy under Inflation Targeting: An Introduction. Working Paper, No. 396, Central Bank of Chile.

- Mishkin F.S., Schmidt-Hebbel K. (2007). Does Inflation Targeting Make a Difference? Monetary Policy under Inflation Targeting, Vol. XI, edited by F. Mishkin and K. Schmidt-Hebbel, Banco Central de Chile, pp. 291-372.

- Nowotny E., Mooslechner P., Ritzberger-Grunwald D. (2010). The Euro and Economic Stability: Focus on Central, Eastern and South-Eastern Europe, Edward Elgar, Cheltenham UK. https://doi.org/10.4337/9781849805698

- Ostry J.D., Ghosh A.R., Chamon M. (2012). Two Targets, Two Instruments: Monetary and Exchange Rate Policies in Emerging Market Economies. Staff Discussion Note, No. 12-01, IMF. https://doi.org/10.5089/9781475503623.006

- Ötker-Robe I., Polanski, Z., Topf, B., Vavra, D. (2007). Dealing with Capital Inflows: Experiences of Selected European Countries. Working Paper, No. 07-190, IMF.

- Ötker-Robe I., Vavra D. (2005). Country Experiences with Moving To Greater Exchange Rate Flexibility: Operational Aspects. Occasional Papers, No. 256, IMF.

- Parkin M. (2014). The Effects of Central Bank Independence and Inflation Targeting on Macroeconomic Performance: Evidence from Natural Experiments. Review of Economic Analysis, Vol. 6, pp. 1-35.

- Polański Z. (2005). Poland's Experience in Dealing with Capital Inflows: Policies, Challenges and Effectiveness of Measures. IMF Mimeo.

- Polański Z., Szpunar P. (2005). Poland's Gradual and Orderly Exit to Exchange Rate Flexibility: Pace, Sequencing and Challenges. IMF Mimeo.

- Poon W.C., Lee Y.S. (2014). Inflation Targeting In Asean-10. South African Journal of Economics, Vol. 82, Issue 1, pp. 141-157.

- Psalida L.E., Elsenburg W., Jobst A., Masaki K., Nowak S. (2009). Market Interventions During the Financial Crisis: How Effective and How to Disengage? Global Financial Stability Report, Chapter 3.

- Ramos-Francia M., García A.T. (2005). Reducing Inflation through Inflation Targeting: The Mexican Experience. Working Paper, No. 2005-01, Banco de México. https://doi.org/10.1007/3-540-28201-7_1

- Reichlin L., Baldwin R. (2013). Is Inflation Targeting Dead? Central Banking after the Crisis. Vox eBook. Available at: http://www.voxeu.org/sites/default/files/file/P248\%20inflation\%20targeting\%282\%29.pdf

- Roger S. (2010). Inflation Targeting Turns 20. Finance \& Development, Vol. 47, No. 1, pp. 46-49.

- Roger, S., Restrepo J.E., Garcia C. (2009). Hybrid Inflation Targeting Regimes. Working Paper, No. 234, IMF.

- Schmidt-Hebbel K., Werner A. (2002). Inflation Targeting in Brazil, Chile, and Mexico: Performance, Credibility, and the Exchange Rate. Working Paper, No. 171, Central Bank Of Chile. https://doi.org/10.1353/eco.2002.0007

- Siregar R.Y., Goo S. (2009). Effectiveness and Commitment to Inflation Targeting Policy: Evidences from Indonesia and Thailand. Staff Paper No. 73, The South East Asian Central Banks, Research and Training Centre.

- Sotocinal N.R. (2010). Inflation targeting and interest rate rules: A characterization of the Philippine case. Discussion Paper, No. 1001, UP College of Business Administration.

- Stone M. (2003). Inflation Targeting Lite.Working Paper, No. 03-12, IMF. https://doi.org/10.5089/9781451842920.001

- Taguchi H., Kato C. (2010). Assessing the Performance of Inflation Targeting in East Asian economies. Macroeconomics Working Papers, No. 23078, East Asian Bureau of Economic Research.

- Tapsoba R. (2010). Does Inflation Targeting Improve Fiscal Discipline? An Empirical Investigation. Working Paper, No. 201020, CERDI.

- Topf B. (2005a). Dealing with Capital Inflows: The Israeli Experience. IMF Mimeo.

- Topf B. (2005b). Transition to Greater Exchange Rate Flexibility: The Israeli Experience. IMF Mimeo.

- Valdés J.A.B. (2007). The Conduct of Monetary Policy in Central America and Dominican Republic, in an Increasingly Globalised Environment. Available at:

http://www.secmca.org/INVESTIGACIONES_ECONOMICAS/InvestigacionesSECMCA/barbados.pdf.

- van der Merwe E.J. (2004). Inflation targeting in South Africa. Occasional Paper No. 19, South African Reserve Bank.

- Vavra D. (2005a). Czech experience with exit to float. IMF Mimeo.

- Vavra D. (2005b). The Czech Republic: Dealing with Capital Inflows. IMF Mimeo. 


\title{
USING MACROECONOMIC MODELS FOR MONETARY POLICY IN UKRAINE
}

\author{
Sergiy Nikolaychuk \\ National Bank of Ukraine
}

Yurii Sholomytskyi

National Bank of Ukraine

\begin{abstract}
An important precondition for successful implementation of inflation targeting is the ability of the central bank to forecast inflation given the fact that the inflation forecast has become an intermediate target. Certainly, this means there should be clear understanding of the monetary policy transmission mechanism functioning within the bank, because it is precisely through transmission channels that a central bank has to ensure convergence of its inflation forecast to the target. And it is almost impossible to pursue inflation targeting without a set of macroeconomic models that describes the monetary policy transmission mechanism and helps to analyse the current state of the economy as well as forecast (simulate) short- and medium-term macroeconomic scenarios. This article provides a review of the current state of macroeconomic modelling at central banks and describes the history of development and actual stance of the National Bank of Ukraine's system of macroeconomic models. The existing system provides quite reliable support for the current monetary policy decision-making process, but it has to be improved by implementing a more sophisticated model (such as a dynamic stochastic general equilibrium model) and enhancing the set of econometric models for short-term forecast purposes in the future.
\end{abstract}

JEL Codes: E37, E52

Keywords: macroeconomic models, monetary policy, transmission mechanism, forecasting and policy analysis systems

\section{Introduction}

Monetary policy decisions are based on solutions to multi-criteria problems with numerous constraints, dealing with large flows of information that come from current data analysis, expert opinions and forecast scenarios. Therefore, it has become necessary for a modern central bank to formalize and structure the decision-making process, which is usually accomplished by setting up an economic model system. Of course, models simplify reality and cannot fully reproduce all economic processes. At the same time, models provide a systematic approach to economic analysis that ensures consistency in monetary policy decisions.

Models have become especially important for the central banks that follow an inflation targeting regime and thus pursue quantitative goals because of the need to know the exact size and lags for final combination of economic shocks influence on inflation as well as on other indicators. Therefore the monetary policy decision-making process at central banks following inflation targeting (IT) is based on a forecasting and policy analysis system (FPAS) that usually has a set of models as its core, where each model has its own purpose. Such systems may become the basis for decision-making or at least be used for the verification of analysis and forecasting results, which are obtained by using of other tools, also by central banks that pursue other monetary policy types (e.g. when it is impossible to provide an independent monetary policy, e.g. under a currency board or because of monetary union membership). 
The key advantages of a model approach are as follows: 1) the understanding of economic processes under the admissible level of their simplification; 2) bringing discussions about economy to a common basis; 3 ) the high speed and flexibility of policy scenario generation.

The latest achievements in economic theory and computational methods encourage the inclusion of numerous economic phenomena in the models. However, trying to put too many of them into one large-scale model in an attempt to reflect as many of the economy's features as possible may substantially complicate the use of the model for regular forecasts. That's why, on the one hand, the core FPAS model must be quite complicated in order to reproduce the specifics of the monetary transmission mechanism, but on the other hand, it should be simple enough to be used for everyday tasks as well as to understand and discuss the model output. The lacunas that are generated by simplification of the core model can be filled with satellite and auxiliary models.

This paper is organized as follows. Section 2 describes the current central banks' organization approach to an analysis and forecast system that is based on a set of models, where the core model has a solid theoretical foundation, is a medium-term type and is used as the main tool for forecasting and simulation. Section 3 focuses on satellite and auxiliary models, which are used by central banks in order to ensure the plenitude of economic analysis, e.g. to assess the current state of auxiliary indicators, produce short-term forecasts and analyse non-standard problems. Section 4 describes the set of models used at the National Bank of Ukraine (NBU) for monetary analysis purposes. The last section offers concluding remarks and considers possible directions for enhancing the NBU's modelling tools system, especially within the context of transition to an inflation targeting regime.

\section{Systemic approach to analysis and forecasting at central banks based on core structural model}

Economic analysis and forecasting are inherent components of an IT central banks' activity, where forecast and simulation results stand as the basis of the monetary policy decision-making process. Significant progress in economic theory, mathematical and computational methods for economics as well as in information technologies is recognized by central banks as a great chance to improve their analysis and forecasting process. Needs in a fast and comprehensive policy reaction to external and internal shocks under significantly increased volatility of economic indicators encourage the organization and formalization of economic analysis and forecasting at central banks in the form of an FPAS.

A modern central bank FPAS may be characterized as a (1) formalized (via directives, resolutions that represent the forecast process), (2) organized (hierarchically), and (3) interdependent (e.g. connected into iterations and dependence on other stages) set of instruments and procedures intended to process and analyse historical economic data, to forecast the development of the economy, to determine the role of monetary policy and to find its optimal trajectory in order to achieve the target (e.g. inflation). Such systems represent the technical element of the political decision-making process. These systems allow raw data to be processed (seasonal adjustment etc.), to provide different measures of economic indicators (ratios, gaps, trends etc.) that help analyse the current economic stance, to create forecast scenarios and to assess policy scenarios.

A notable example of such an FPAS is the Bank of England's Forecasting Platform, which includes short- and medium-term forecasting models, enables aggregation of the models' forecasts through an automatic procedure, and provides a clear and coherent organizational process for developing regular forecasts and simulating various scenarios (Burgess et al., 2013). However, because of the substantial complexity of developing and maintaining such systems, only a limited number of central banks (European Central Bank, Federal Reserve Board of Governors, and the central banks of Canada, Norway, Sweden, the Czech Republic, New Zealand, etc.) currently explore this feature. At the same time, many other central banks actually follow the same approach, albeit at a more simple level.

\section{The key elements of a prototype FPAS were structured as follows in the work by Laxton et al. (2009):}

1) A database and reporting system based on a set of key macroeconomic indicators and providing the same information to every person involved in the forecasting and development of monetary policy-related decisions;

2) Regular updates of databases and short-term forecasts accompanied by reports on the effect of updated information on short-term forecasts (and its consequences for long-term forecasts, if applicable). Usually, short-term forecasts (2-3 quarters) are based primarily on the combination of econometric model results and expert judgments that allow the factors that are not covered by the core model to be taken into account;

3) A relatively simple model for medium-term forecasting reflecting the vision of monetary policy's transmission mechanism and the standard set of shocks affecting the economy. The most important requirement of this model is that it should be usable to quickly generate forecast scenarios, and understand and discuss results. In other words, the base model should not become a black box; 
4) Regular harmonized macroeconomic forecasts for every quarter, including evaluation of changes vis-à-vis the previous base forecast;

5) Measures of forecast uncertainty, such as model-based confidence intervals. These measures may also be used to show the size of uncertainty both inside a central bank and for the society;

6) Identifying the specific risks of the baseline forecast scenario and developing a policy plan if risks become reality between publications of official forecasts.

The key elements of an FPAS within one forecasting cycle are shown schematically in Figure 1.

\section{Figure 1. Interrelations between FPAS elements within one forecasting cycle}

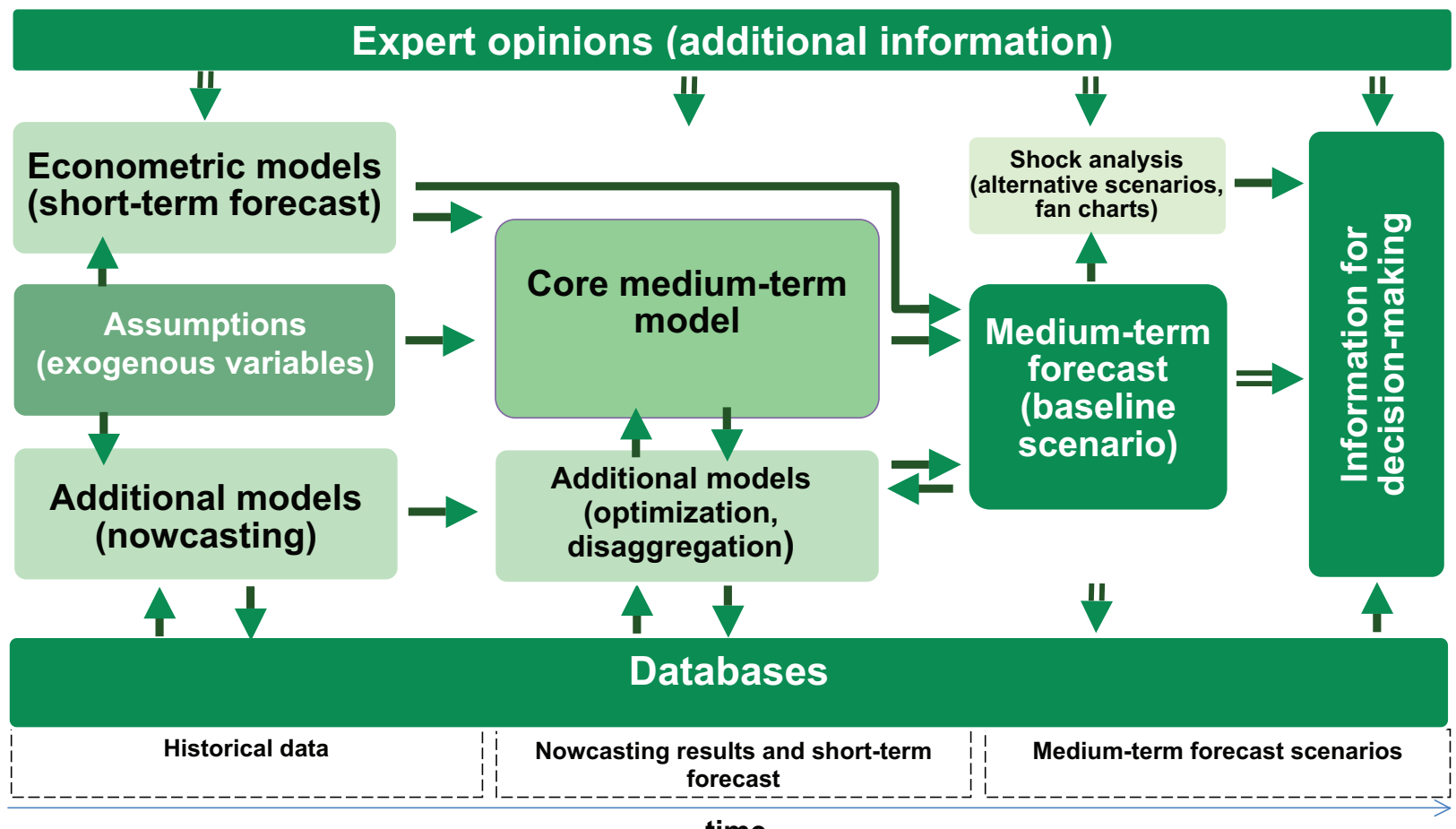

time

Usually, the core element of an FPAS is a relatively small (medium)-scale middle-term macroeconomic model with a solid theoretical basis. The choice of a middle-term horizon is determined by lagged effects of monetary policy shocks on the economy, for instance, an interest rate shock effect lasts for one or two years. The theoretical principles of the model have to ensure the existence of a framework that allows the effects of monetary policy decisions on the economy to be explained, reflecting the monetary transmission mechanism vision of decision-makers and taking into account the influence of the policy on expectations (thereby eliminating, or at least minimizing, the "Lucas critique" problem (Lucas, 1976)).

The FPAS core model size must be chosen in a way that ensures high-quality results; the model has to contain at least the most important economic indicators, albeit it must be simple enough to generate comprehensible results, as one has to avoid turning it into a "black box". The main targets of the monetary policy and, therefore, model variables are inflation and the

\footnotetext{
${ }^{1}$ The Lucas critique says that changes in macroeconomic policy based on an economic model should take into account the fact that economic agents' behaviour will change in response to policy measures. The appearance of the Lucas critique led to the loss of popularity of large econometric models based on historical relationships between common economic indicators and the transition to models that are built on "deep parameters" that express preferences, technology etc., i.e. factors determining the individual behaviour of economic agents driven by the principle of rationality.
} 
aggregate output; however, information regarding the structure of consumption, labour market indicators (unemployment rate, level of income), productivity etc. is often needed as well. Adding these indicators to the model may lead to improvement of the model's statistical accuracy and improve the explanation of the model output. At the same time, the larger number of variables may lead to difficulties in forecasting some disaggregated variables and greater forecast errors compared to errors for aggregated variables, at least as a result of the larger inertia of the latter. In addition, excessive attention to the use of smaller variables may substantially complicate the explanation of the model's logic.

Therefore the core model usually has a medium size, whereas modelling other indicators (not included in the core model list) becomes a task for additional models. Altogether these models form the modelling component of an FPAS. This approach allows for a larger number of explained indicators and does not violate the principles of interpreting core model output results. The use of several models is also justified by their different capabilities in using data of different frequencies: a shortterm forecast based on monthly data is traditionally more accurate than one that is based on quarterly data. At the same time, models on a quarterly basis better reflect the steady state of the economy, and therefore their results (forecasts or scenario simulations) are coherent with long-term trends.

We can highlight several different classes of macroeconomic models in the history of central banks that were used as core models for monetary policy purposes:

1) Large-scale models using empirical interrelations on the basis of econometric evaluations (however, the interest in these works has significantly diminished as a result of the criticism in the works of Lucas (1976) and Sims (1980);

2) Structural VAR models, which became very popular after an article by Sims (1980) due to their simplicity of use and the possibility of combining information coming from statistical data and theoretical constraints;

3) Hybrid models that combine long-term relationships, based on economic theory and confirmed by data, with short-term statistical relationships; such models were mostly performed in the form of vector error correction models);

4) Incomplete dynamic stochastic general equilibrium models such as gap models that combine long-term relationships that come from theoretical models with a microeconomic basis with equations that reflect short-term dynamics, thereby allowing for quite good statistical properties and keeping the desired steadystate properties of the economy;

5) Dynamic stochastic general equilibrium (DSGE) models where "dynamic" means that the model's solution sets the dynamics of all endogenous variables; "stochastic" means that the dynamics of variables are influenced by stochastic shocks; and "general equilibrium" means that supply equals demand in all markets in all periods.

In academic literature and the practice of central banks, DSGE models are now considered a benchmark. The appearance and rapid development of these models resulted from the consolidation of two competing modern economic schools. Socalled "new Keynesian economics" (or "new neoclassical synthesis") combines the neoclassical theory of real business cycles with rational agents who optimize their behaviour and elements of the neo-Keynesian theory of market imperfections (Roger and Vlček, 2012). The key advantage of such models for monetary policy was the possibility of combining nominal rigidities (which make monetary policy non-neutral) with the completely specified dynamic structure of economy that tends toward general equilibrium.

Typical examples of DSGE models suitable for practical implementation in monetary policy are presented in the works by Smets and Wouters (2003), Woodford (2003), Gali (2008), Christiano et al. (2010) and lots of others. These are the models based completely on a microeconomic foundation and with implemented mechanisms that reflect nominal (for prices and wages) and real rigidities (e.g. investment adjustment costs).

These models have the following types of main economic agents that optimize their activity: households, firms, monetary and fiscal authorities. In some cases, such models include financial intermediaries (e.g. commercial banks) and regulatory as well as macroprudential policy instruments.

The principle of optimization modelling may be described by considering households as an example. A typical simplified model usually assumes the existence of a large number of identical (typical) households with an infinite lifespan, who split their time between work and leisure. Households are monopolistic suppliers of labour force, which allows them to influence wage rates. Households optimize their behaviour by differentiating their income (from work and capital) into consumption and savings and maximizing their function of usefulness (from consumption and leisure). They also meet limits on the maximum long-term level of borrowing to prevent a household from getting into a situation of the Ponzi scheme type, i.e. unlimited accumulation of debts. 
In their turn, firms hire a labour force and combine it with capital to make specific products. That allows them to have monopolistic power, and therefore set the prices for their products (services). A typical firm uses the labour resources of households to produce different goods, thereby maximizing their profit.

An important feature (which has been standard for quite some time) of models is the use of mechanisms reflecting the existence of nominal and real rigidities. Nominal rigidities are modelled through special price- or wage-setting principles that reflect the limited contemporary reaction of firms to shocks; this results in only a partial revision of prices and wages. Real rigidities are the consequences of investment adjustment costs, costs of changing capital utilization, etc.

In the simplest models, fiscal policy is neutral toward demand, i.e. economic agents behave according to the Ricardian principles. $^{2}$ But now, lots of models use more complex mechanisms of the fiscal sector's effect, which are often implemented by dividing households into several types. In particular, some households are modelled as having limited rationality, i.e. households that have no savings (Coenen and Straub, 2004; Céspedes et al., 2012).

Monetary policy in a model is most often based on the Taylor rule: a central bank's target short-term interest rate is set as a neutral (average) nominal rate plus the sum of deviations of the inflation rate from the target inflation rate and of actual output from potential output.

Among the important recent trends are the growing role of the financial sector represented mainly by the financial accelerator model (Bernanke et al., 1999), models with an explicit banking sector (Goodfriend and McCallum, 2007), etc.

While, in the beginning, DSGE models were used mostly for theoretical analysis, afterwards they were found to be capable of explaining the actual dynamics of macroeconomic indicators and making relatively good forecasts. Therefore, more and more central banks are now implementing models of this class as the base models for their AFSs.

Such models have substantially improved the ability to analyse the economic trends, exploring the underlying motives of economic agents' behaviour, as well as simulating forecast scenarios.

At the same time, the main drawback of DSGE-class models is the overly hard constraints that theory places on ratios, which therefore cause problems with the reproduction of actual data dynamics (Sims, 2008). The practical use of these models in developing countries has become especially difficult due to problems with data as well as fast and significant structural changes, particularly in macroeconomic policy (Ukraine is a very typical example of such a country). It often requires substantial adjustment of equations obtained by optimizing the behaviour of particular economic agents (e.g. households) according to empirical data. In addition, the complexity of models requires substantial resources (both human and financial) and makes it harder to understand how models work and to explain results produced by these models to monetary policy decision-makers.

Many central banks have chosen simplified or incomplete dynamic stochastic models as the core models for their FPASs, often in the form of "gap models". Reflecting business cycles, gaps (deviations of variables from their long-term equilibrium trends) draw the biggest interest when designing the model's behaviour equations. Overall, these models are usually small in size, which, nevertheless, is sufficient to describe the monetary policy's transmission mechanism and, therefore, the role of the central bank in the dynamics of the key macroeconomic variables, output and inflation.

In fact, these models follow log-linearized versions of DSGE models based on optimizing microeconomic dependences, although they are not the result of explicit derivations. Nevertheless, they account for rational expectations (combining them with adaptive expectations), inertia in the economy (as a result of nominal and real rigidities) and the long-term neutrality of monetary policy, and all equations have an economic interpretation. Another key difference between these models and their fully fledged dynamic stochastic general equilibrium counterparts is the specific reproduction of long-term equilibrium levels (natural levels of variables), where supply effects are still rarely taken into account and the consistency of levels of variables is also often lacking. This, in particular, leads to difficulties in measuring the impact of financial sector turmoil on the economy in the case of substantial balance sheet effects (capital flight, revaluation of assets/liabilities caused by currency devaluation, etc.).

A typical example of this model is the Quarterly Projection Model of the Czech National Bank (Coats, Laxton, and Rose, 2003), which became a prototype for similar models employed by the central banks of many countries, in particular Ukraine, the Russian Federation, Turkey, Serbia, Armenia, Georgia, Romania, Chile and others. ${ }^{2}$ According to the Ricardian neutrality principle, current tax decreases have to be compensated by tax increases in the future and the presented value of taxes doesn't
change. Similarly, the presented value of the future disposable income of households doesn't change either, which forms the composition of consumption and investment, therefore the consumption expenditure trajectory once again doesn't change. 


\section{Auxiliary models at central banks}

As mentioned earlier, no model can fit all needs appearing every time in the course of monetary policy decision-making. And the desire to devise a model to answer all questions results in this model being turned into a "black box", which becomes harder and harder to maintain and its results impossible to communicate. Therefore, central banks employ a multi-model approach whereby the core model is supplemented by a suite of auxiliary models, each of which has its own purpose and appropriate specification. Overall, these models can be divided into four classes:

\section{Models for current economic stance analysis}

A forecasting cycle usually begins with the analysis of "current conditions", i.e. the stage of the business cycle the economy is presently at. The task is often complicated by significant lags in the publication of national account data, which serve as the basis for this analysis, although at the same time, substantial data arrays are available to economists at a higher frequency. Therefore, models for nowcasting, i.e. assessment of data for the current period, which would be published later, have gained wide popularity (after publication of the paper by Stock and Watson (1989)). Dynamic factor models are used for that purpose most often; vector autoregression models with mixed periodicity of data and also "bridge" equations or their modification called MIDAS (mixed data sampling) (see examples in the works by Lieberman (2011), Banbura et al. (2013), Schumacher (2014), etc.) are used more rarely. Dynamic factor models use a large number of variables, putting them together into several aggregated indicators (factors), which become the key elements. At the next stage, these factors (key elements) are aggregated, using factor loadings, to forecast the resulting variable. Vector autoregression models are based, with mixed periodicity, on the principle of using variables with higher frequency to forecast variables with lower frequency. For example, monthly data regarding manufacturing and agricultural production outputs, retail sales turnover, monetary and financial data, etc. are used to forecast quarterly GDP. Approaches based on simple equations also use mixed-frequency data, and equations themselves may come in various forms, for example, a composition of autoregressive distributed lags.

An important element of the assessment of the economy's current stance is the decomposition of macroeconomic indicators into trends and deviations or gaps that reflect a cyclic component of variables and, consequently, the position of the economy in the business cycle. In technical terms, signal extraction models or models clearing signals from "noise" are used for that purpose. In the simplest case, these are single-dimensional filters, for example, the Hodrick-Prescott filter, Beveridge-Nelson decomposition or frequency filters. But most often, these are multivariable state space models evaluated using the Kalman filter and whose structure fully reproduces the structure of the FPAS's core model.

\section{Econometric models for short-term forecasting}

The use of econometric (time series) models for short-term forecasting is based on the evidence that statistical relations between data in the past would, with a sufficiently high degree of probability, be the same over a short period of time (usually up to two quarters). The main selection criterion for models of this type is their ability to reproduce empirical data in both in-sample and out-of-sample fit.

Despite the significant diversity of models that can be used for short-term forecasting, models that could be classified into the following groups have become the most commonly used at central banks across the world:

- simple univariate autoregression models (unconditional mean, random walk, ARMA and other autoregression models);

- simple multivariate autoregression models (simple vector autoregression models, structured vector autoregression models, error correction models, vector error correction models, etc.);

- models for use in environments with a substantial number of variables and requiring complex evaluation procedures (dynamic factor models, "bridge" equations, factor-augmented vector autoregression models, Bayesian autoregression models, mixed-frequency state space models, MIDAS models, etc.);

- models with changing regime (Markov chain models, regime-switching models).

In particular, the Bank of England uses results produced by these models (systems of models) to make inflation and GDP statistical forecasts and as one of the sources of information for the Bank of England's Monetary Policy Committee (Burgess et al., 2013). A similar suite of models is used for forecasting purposes by other central banks; for instance, Norges Bank uses monthly and quarterly vector autoregression models, dynamic factor models, etc. (Gerdrup et al., 2011). The Central Bank of 
the Republic of Turkey develops short-term inflation forecasts using a large set of models as well, for example, vector autoregression models and Bayesian autoregression models, dynamic factor models, models with multi-frequency data and models with timevariable parameters, which helped improve the accuracy of forecasts for the following two quarters by 30\% (Öğünc et al., 2013).

\section{Additional optimization models for analysis of specific problems}

Besides the base structural model per se, which usually reproduces only the key features of the monetary policy's transmission mechanism, central banks develop additional structural models to analyse particular specific matters. Usually, these models resemble DSGE models, but integration of additional blocks into the base model is not recommended because it has to remain sufficiently simple. However, results produced by these satellite models may be included in forecasts on the basis of the core model via appropriate shocks and transformations.

Among the most important issues that have recently been analysed using additional models are accounting for financial rigidities (i.e. financial accelerator channel), financial intermediation (i.e. banking funding channel), unconventional fiscal and monetary policies, in particular analysis of the government's and central bank's balance sheets, etc. All these issues have stirred up huge interest in the academic world and in the studies of central banks since the beginning of the global economic and financial crisis. Certainly, these issues could be of no less importance for many central banks, and therefore the inclusion of the financial sector (with its various rigidities) in the core DSGE models of leading central banks has recently become commonplace. MAPMOD, a model developed by the IMF to support analysis of macrofinancial and macroprudential policy, may serve as the prototype for these models, enabling explicit assessment of the effect of excessive credit expansion and formation of price bubbles on assets (Benes et al., 2014).

\section{Additional models for disaggregation}

The behaviour of components of aggregated indicators, e.g. GDP components by expenditures (private consumption, investments, etc.) or added value (by sectors), is quite possible to reproduce using a set of auxiliary models. Usually, these models use the core structural model's results regarding aggregated indicator dynamics and decompose this indicator using simpler behaviour models (regression, vector autoregression and other models). These models may provide additional explanations as regards the dynamics of aggregated indicators taking into account their factors. On the other hand, if they do not use aggregated variable forecasts as an instrumental variable but are based on forecasts of own exogenous variables, these models allow the quality of an aggregated variable forecast as the sum of separate components to be checked. A good example of that is the forecasted production output of particular sectors of the economy aggregated into the total GDP and comparison of the results with the core structural model's forecast.

\section{NBU's forecast and policy analysis system}

Before 2005, the forecasting process at the NBU (as well as at many other central banks of countries with emerging markets) was based on numerous small-scale models, usually with one or several equations. These econometric models were used as short-term forecasting tools mainly to corroborate expert forecasts. The NBU also used a large-scale semi-structural model developed under a joint project by the International Centre for Prospective Studies, the Ministry of the Economy of Ukraine and the National Bank of Ukraine. However, its regular use for analysis and forecasting purposes was complicated by the annual periodicity of data, large-scale and, consequently, large-maintenance efforts, and an obsolete theoretical foundation.

In response to these problems, in 2005-2006 the National Bank of Ukraine developed the Quarterly Projection Model (QPM), which is still used today, albeit with certain modifications, as the FPAS's core model for monetary policy purposes. First of all, the QPM provides an organizational framework for the forecasting process and coordinates the process of combining nowcasting, short- and medium-term forecasts and expert opinions. Secondly, being an analysis tool, this model enables the functioning of the monetary transmission mechanism to be studied and analysis of the impact of exogenous shocks and political decisions on the basis of simulation experiments. And thirdly, this model plays a key role in assessing the uncertainty, and in particular, in building consistent alternative scenarios.

The QPM's class places it among gap models, close to dynamic stochastic general equilibrium models. This model takes into account rational expectations but has a lower degree of structuring; it also has a clear and easy-to-understand theoretical basis and is simple and convenient to use.

The QPM is built at a very aggregated level, describes only the most important macroeconomic interrelations in the Ukrainian economy and is focused on the features of the monetary policy transmission mechanism. This model converges to a well-defined steady state, although this steady state is exogenously obtained, quite simplified and not based on a microeconomic foundation. The modelling of macroeconomic variables' divergences from their equilibria (gaps) constitutes the model's basis. To evaluate gaps, it uses the multivariate filter with the structure based on the QPM structure. 
The key difference between the QPM and similar versions of new Keynesian monetary transmission mechanism models used by other central banks is that it enables modelling of various interim regimes of monetary policy, from exchange rate pegging to inflation targeting. In fact, it enables the simultaneous use by a central bank of two policy instruments: interest rate and exchange rate. An especially useful feature in the modelling of Ukrainian realities is the implementation of a mechanism for partial breach of arbitration condition envisaging uncovered interest parity using, for example, sterilized interventions or administrative restrictions.

In addition, in order to improve the model's forecasting properties and the ability to reproduce particular specific features of the Ukrainian economy, a number of modifications have been implemented in recent years, including:

- expenditure-based decomposition of GDP gap: gaps in private consumption, public consumption, investments, exports and imports;

- fiscal block: identifying cyclical and structural components of a consolidated (state) budget's revenues and expenditures and evaluating fiscal impulse added to IS curve;

- equation for loans and deposits enabling clarification of the assessment of the state of an monetary area (besides the previously existing monetary conditions based on the weighted sum of the gaps in real interest rate and real exchange rate);

- equation for principal items of the balance of payments enabling implementation of a mechanism of dependence of risk premiums on the balance of payments position and exogenous shocks;

- equation for equilibrium real exchange rate depending on export and import trends (i.e. of the BoP's current account position) for accommodation of the key elements of a fundamental equilibrium exchange rate approach;

- improving the long-term loan interest rate formation principles by also accommodating the costs of banking (in particular, deposit) funding when modelling this interest rate's dynamics;

- block of agricultural supply shocks (when evaluating the gap as the difference between the aggregate demand and the trend level influenced by the supply).

Work on improving the QPM still continues; in particular, transition to a model with a more detailed and in-depth theoretical basis and full balance of stock and flow variables is currently underway. In fact, we are talking about the inclusion in this model of the financial sector in an explicit form (to show the effect of the credit crunch on the aggregate demand due to balance sheet problems in the banking system) and external imbalances (to improve the reflection of the effect that the external sustainability stance has on risk premium). These innovations are intended to improve understanding of the economy's behaviour during periods of instability and assess the reasons for, and probability of, their occurrence.

As at other central banks, macroeconomic analysis and forecasting at the NBU (which constructs a ground for monetary policy decision-making) is based not only on the core structural model (QPM) but also a set of auxiliary models is used, first of all, in short-term forecasting.

At the beginning, this set consisted of a number of simple econometric models and approaches, including simple mean, random walk, autoregressions, moving average and reduced-form vector autoregression models. These models were used to forecast inflation and gross domestic product (by forecasting their particular components and subsequently aggregating them). The forecast that this package of models produced was the simple average of forecasts by individual small models. This system was convenient to use thanks to automation of the process, but on the other hand, such a "machine" approach caused uncertainty as regards the accuracy of these models and, consequently, the forecasts they produced and also the low quality of explanations of the reasons behind the dynamics of this or that variable.

The desire to achieve extremely accurate forecasts, especially inflation forecasts, drove the development and maintenance of a small semi-structural econometric model for inflation that uses demand pressure, exchange rate, imported inflation, prices for raw materials and other indicators as explanatory variables, combining them into a system of equations. These equations have different forms depending on the inflation component - simple regression equations, error correction models or equations with autoregressive distributed lags.

The NBU's evaluation of GDP changes in a current quarter (official data are published only 45 days after the end of a quarter) and the two subsequent quarters is based on the bridge model approach, which allows the use of monthly indicators 
to evaluate quarterly data. In particular, the use of a set of Bayesian vector autoregression models with mixed-frequency data (monthly and quarterly) and constraints placed upon monthly indicators (they are not affected by quarterly data) helps substantially diminish the problem of a short length of time series with a large number of variables in models.

Currently, the model forecasting GDP components, both expenditures (private and public consumption, investments, export and import of goods and services) and production-related, is also an important FPAS component. The equation for most GDP components is set in the form of an error correction mechanism, and cross-relations are used as well (import is based on consumption and investments in past periods, etc.). These equations allow the overall GDP forecast and forecasts of its components to be harmonized and the forecasts produced by the core model to be verified.

The model for foreign trade in goods has a similar purpose. It consists of equations (or a system of equations) for export and import of particular product groups (value-based turnovers). Aggregated results produced by this model (together with expert opinions regarding particular components) concerning the dynamics of value-based export and import turnovers are also used as additional information for QPM-based forecasting.

The expansion of FPASs not only entailed the increased complexity of forecasting indicators that are of key importance for the NBU (inflation and GDP) but necessitated the creation of satellite models reflecting other sectors of the economy or other indicators. The most important of these satellite models were the following:

(1) Models for assessment of cyclical and structural components of the state budget's balance. This model consists of simple regressions for particular components of budget revenues and expenditures and then decomposing them into parts brought by the economic cycle and, as a result, balance, which, in our opinion, reflects the stance of fiscal policy. Subsequently, this model's results are used as additional information for QPM-based forecasting (where the fiscal block is more simplified).

(2) Equilibrium real effective exchange rate evaluation model based on the behavioural approach to the determination of equilibrium REER and using the BoP's current account, net external assets and interest rates as explanatory variables. The results of this evaluation are also used to adjust equilibrium REER dynamics in QPM-based forecasting.

(3) Augmented monetary conditions indicator. The QPM incorporates the effect of the monetary sector on the aggregate demand and price dynamics via money price indi cators (interest rates and exchange rate). Thus, the real monetary conditions index ( $\mathrm{RMCl}$ ) representing a weighted sum of deviations of the real loan interest rate for non-financial corporations and the real effective exchange rate from their equilibrium levels is an explanatory valuable for the output gap. In other words, changes in monetary conditions result in changes in aggregate demand, which, in turn, represents a source of pressure on prices. However, $\mathrm{RMCl}$ in the form of price-based indicators alone does not always correctly reflect the actual situation. In particular, with the interest rate being the same, the accessibility of financing may differ substantially due to, for example, strict requirements for borrowers. In that case, the amount of loans in the economy would decline, thereby reflecting more stringent conditions in the monetary sector. And vice versa, monetary conditions may soften without changing interest rates (which may already be quite low). An example of this situation is "quantitative easing". Therefore, the monetary conditions index requires certain supplementation, in particular by using loan volume indicators, monetary aggregates, etc. based on alternative models and approaches. An appropriate augmented monetary conditions indicator was developed on the basis of a principal components approach and is also used in the QPM as additional information to reflect the impact of monetary conditions on economic activity (for details, see Sholomytskyi (2012)).

\section{Concluding remarks}

Macroeconomic modelling at central banks is a live process, and the development of modelling tools for the purposes of monetary policy is only accelerating as we face new challenges. At the same time, one should remember that every model has drawbacks and only partially shows the reality. Nevertheless, macroeconomic models enable formalization of the vision of the economy's functioning and monetary transmission mechanism in mathematical formulae. The process of developing, testing and revising these models deepens the understanding of economic phenomena, intensifies debates on economic policy issues, and stimulates the research process.

In the last few years, the National Bank of Ukraine has achieved substantial progress in improving its FPAS as part of the preparation for transition to an inflation targeting regime. Currently, the NBU's forecasting process is based on the Quarterly Projection Model, which forms the core of its FPAS and enables consistent combining of the assessment of the current stance of the economy, based on the multivariate filter, expert judgments, and the results of time series models and satellite modules. 
However, despite the progress that has been achieved, further improvement of the National Bank's modelling tools in order to enhance analytical and forecasting capabilities necessary to support the process of monetary policy decisionmaking is undoubtedly needed. The above regards both the improvement of the suite of short-term forecasting models and the core structural model.

Although the QPM has a solid theoretical foundation and good forecasting capabilities and may be used to forecast macroeconomic variables and in policy analysis, a DSGE model still needs to be developed and implemented. Today, models of this type are becoming more and more popular among central banks as the core models of their FPASs. The DSGE model-based approach allows, on the one hand, the latest achievements in macroeconomic and monetary theory to be employed, and on the other hand, it has proved its ability to produce forecasts with a sufficient level of accuracy.

The key advantage of DSGE models over the present version of the QPM lies in the microeconomic basis that enables the equilibrium of stock and flow variables to be ensured, the impact of structural economic shocks arising from changes in preferences of economic agents or technological changes to be simulated, and thus the overall impact of various shocks constantly occurring in the Ukrainian economy to be studied. The most important feature of DSGE models is the opportunity to deal with forward-looking variables, which are crucial for modelling the behaviour of inflation, exchange rates, interest rates, consumption and investment etc. This is especially relevant under the NBU's declaration on transition to inflation targeting - a monetary policy regime based on the control of inflation expectations. DSGE models enable the fullest reflection of the expectation channel of the monetary policy transmission mechanism, in contrast to reduced-form models that cannot use such a feature.

Undoubtedly, the DSGE model development project must provide a substantial impetus aimed at enhancing the FPAS and further research processes at the NBU.

\section{References}

- Adolfson M., Laséen S., Christiano L., Trabandt M., Walentin K. (2013). Ramses II - Model Description.

Occasional Paper Series, No. 12, Sveriges Riksbank.

- Andrle M., Hlédik T., Kamenik O., Vlček J. (2009). Implementing the new structural model of the Czech

National Bank. Working Paper Series, No. 2-2009, Czech National Bank.

- Bańbura M., Giannone D., Modugno M., Reichlin L. (2013). Now-casting and the real-time data flow. Working

Papers, No. 1564, ECB. https://doi.org/10.1016/B978-0-444-53683-9.00004-9

- Benes J., Kumhof M., Laxton, D. (2014). Financial Crises in DSGE Models: A Prototype Model. Working Paper, No. 14-57, IMF. https://doi.org/10.5089/9781475540895.001

- Bernanke B., Gertler M., Gilchrist S. (1999). The financial accelerator in a quantitative business cycle

framework, in: J.B. Taylor, M. Woodford (red.), Handbook of macroeconomics, North-Holland, Amsterdam.

- Brubakk L., Husebø T.A., Maih J., Olsen K., Østnor M. (2006). Finding NEMO: Documentation of the Norwegian economy model, Norges Bank, Staff Memo, 6.

- Brubakk L., Sveen T. (2009). NEMO - A New Macro Model for Forecasting and Monetary Policy Analysis.

Norges Bank Economic Bulletin, Vol. 80, No. 1, pp. 39-47.

- Burgess S., Fernandez-Corugedo E., Groth C., Harrison R., Monti F., Theodoridis K., Waldron M. (2013). The Bank of England ss forecasting platform: COMPASS, MAPS, EASE and the suite of models. Working Paper, No. 471, Bank of England. https://doi.org/10.2139/ssrn.2266506

- Céspedes L.F., Fornero J., Galí J. (2012). Non-Ricardian aspects of fiscal policy in Chile, Working Paper, No. 663, Central Bank of Chile.

- Christiano L.J., Trabandt M., Walentin K. (2010). DSGE models for monetary policy analysis. Working Papers Series, No. 16074, NBER. https://doi.org/10.3386/w16074

- Christoffel K., Coenen G., Warne A. (2008). The new area-wide model of the Euro area. A micro-founded openeconomy model for forecasting and policy analysis. Working Paper Series, No. 944, ECB.

- Coats W., Laxton D., Rose D. (2003). The Czech National Bankıs Forecasting and Policy Analysis System, Prague: Czech National Bank. 
- Coenen G., Straub R. (2004). Non-Ricardian households and fiscal policy in an estimated DSGE model of the euro area, manuscript prepared for the International Finance conference on New Policy Thinking in Macroeconomics, New York.

- Dorich J., Johnston M., Mendes R., Murchison S., Zhang Y. (2013). ToTEM II: An Updated Version of the Bank of Canadass Quarterly Projection Model. Technical Report, No. 100, Bank of Canada.

- Gerdrup K.R., Nicolaisen J. (2011). On the purpose of models - The Norges Bank experience. Staff Memo, No. 06, Norges Bank.

- Goodfriend M., McCallum, B.T. (2007). Banking and interest rates in monetary policy analysis: A quantitative exploration. Journal of Monetary Economics, Vol. 54, No. 5, pp. 1480-1507.

https://doi.org/10.1016/j.jmoneco.2007.06.009

- Harrison R., Nikolov K., Quinn M., Ramsay G., Scott A., Thomas R. (2005). The Bank of England Quarterly Model, London, Bank of England.

- Kilponen J., Ripatti A. (2006). Learning to Forecast with a DGE Model, Unpublished manuscript. Available at: http://www.bde.es/f/webpi/SES/seminars/2006/files/sie0619.pdf

- Laxton D., Rose D., Scott A. (2009). Developing a structured forecasting and policy analysis system to support inflation-forecast targeting (IFT). Working Paper, No. 65, IMF. https://doi.org/10.5089/9781451872125.001

- Liebermann J. (2012). Short-term forecasting of quarterly gross domestic product growth. Quarterly Bulletin Articles, Central Bank of Ireland, pp. 74-84.

- Lucas R.J. (1976). Econometric policy evaluation: A critique. Carnegie-Rochester Conference Series on Public Policy, Vol. 1, No. 1, pp. 19-46. https://doi.org/10.1016/S0167-2231(76)80003-6

- Nikolaychuk S., Mariyko E. (2007). Estimation of Equilibrium and Cyclical Components of Macroeconomic Indicators Using Kalman Filter. Visnyk of the National Bank of Ukraine, No. 5, pp. 58-64.

- Öğünç F., Akdoğan K., Başer S., Chadwick M.G., Ertuğ D., Hülagü T., Kösem S., Özmen M.U., Tekatlı N. (2013). Short-term inflation forecasting models for Turkey and a forecast combination analysis. Economic Modelling, Vol. 33, pp. 312-325. https://doi.org/10.1016/j.econmod.2013.04.001

- Petryk O., Nikolaychuk S. (2006). The Structural Model of Transmission Mechanism in Ukraine. Visnyk of the National Bank of Ukraine, No. 3, pp. 12-20.

- Polovnev Y., Nikolaychuk S. (2006). Modelling of Transition from Exchange Rate Peg to Inflation Targeting: Case of Ukraine, Paper presented at the workshop Applied economic research at central banks in Deutsche Bundesbank, Frankfurt am Main (13-17 November 2006).

- Roger S., Vlček J. (2012). Macrofinancial Modeling at Central Banks: Recent Developments and Future Directions. Working Paper, No. 12-21, IMF.

- Schumacher C. (2014). MIDAS and bridge equations. Discussion Paper, No. 26. Deutsche Bundesbank.

- Sholomytskyi Y. (2012). Using the indicators of monetary sector volumes for determining the contribution of monetary conditions to consumer inflation. Visnyk of the National Bank of Ukraine, No. 7, pp. 52-56.

- Sims C.A. (1980). Macroeconomics and Reality. Econometrica, Vol. 48, No.1, pp. 1-48.

https://doi.org/10.2307/1912017

- Smets F., Wouters R. (2003). An estimated dynamic stochastic general equilibrium model of the euro area. Journal of the European economic association, Vol.1, No.5, pp. 1123-1175.

https://doi.org/10.1162/154247603770383415

- Stock J.H., Watson M.W. (1989). New Indexes of Coincident and Leading Economic Indicators, NBER Macroeconomics Annual 1989, pp. 351-393.

- Weber A. (2009). The role of forecasting for central banks, Keynote address given at the conference on Forecasting and monetary policy, organized by the Deutsche Bundesbank, Freie Universität Berlin and the Viessmann European Research Centre, Berlin, 23 March 2009.

- Woodford M. (2003). Interest \& Prices, Princeton, New Jersey: Princeton University Press. 